CENTRO UNIVERSITÁRIO FEI

ALEXANDRE VICENTIN

IMPLEMENTAÇÃO DE RETROFIT EM MÁQUINAS INDUSTRIAIS LEGADAS PARA A INSERÇÃO NO CONTEXTO DA INDÚSTRIA 4.0

São Bernardo do Campo 
ALEXANDRE VICENTIN

\title{
IMPLEMENTAÇÃO DE RETROFIT EM MÁQUINAS INDUSTRIAIS LEGADAS PARA A INSERÇÃO NO CONTEXTO DA INDÚSTRIA 4.0
}

\begin{abstract}
Dissertação apresentada ao Centro Universitário FEI, como parte dos requisitos necessários para obtenção do título de Mestre em Engenharia Mecânica. Orientada pelo Prof. Dr. Fábio Lima.
\end{abstract}

São Bernardo do Campo

2021

ALEXANDRE VICENTIN 
Vicentin, Alexandre.

Implementação de retrofit em máquinas industriais legadas para a inserção no contexto da indústria 4.0 / Alexandre Vicentin. São Bernardo do Campo, 2021.

100 p. : il.

Dissertação - Centro Universitário FEI.

Orientador: Prof. Dr. Fábio Lima.

1. Indústria 4.0. 2. Retrofit. 3. Consumo de Energia. 4. Conectividade. 5. Internet das Coisas.

I. Lima, Fábio, orient. II. Título.

Elaborada pelo sistema de geração automática de ficha catalográfica da FEI com os dados fornecidos pelo(a) autor(a). 
Título do Trabalho: Implementação de retrofit em máquinas industriais legadas para a inserção no contexto da indústria 4.0.

Área de Concentração: Produção

Orientador: Prof. Dr. Fábio Lima

Data da realização da defesa: 23/02/2021

\section{ORIGINAL ASSINADA}

\section{Avaliação da Banca Examinadora:}

O cadidato demonstrou domínio na apresentação e na arguição. Foi unanimidade na arguição da banca que o trabalho traz uma contribuição prática e teórica importante dentro do contexto da indústia 4.0.

Ainda, deve se tornar uma plataforma de base para novas dissertações nesse assunto.

São Bernardo do Campo, 23 / 02 / 2021.

\section{MEMBROS DA BANCA EXAMINADORA}

Prof. Dr. Fábio Lima

Prof. Dr. Fabrizio Leonardi

Prof. Dr. Fabiano Camargo Rosa
Ass.:

Ass. :

Ass. :

A Banca Julgadora acima-assinada atribuiu ao aluno o seguinte resultado:

APROVADO $\square \quad$ REPROVADO

\section{VERSÃO FINAL DA DISSERTAČ̃̃O}

APROVO A VERSÃO FINAL DA DISSERTAÇÃO EM QUE FORAM INCLUÍDAS AS RECOMENDAÇÕES DA BANCA EXAMINADORA
Aprovação do Coordenador do Programa de Pós-graduação

Prof. Dr. Rodrigo Magnabosco 


\section{IMPLEMENTAÇÃO DE RETROFIT EM MÁQUINAS INDUSTRIAIS LEGADAS PARA A INSERÇÃO NO CONTEXTO DA INDÚSTRIA 4.0}

Dissertação, apresentada ao Centro

Universitário FEI, como parte dos requisitos necessários para obtenção do título de Mestre em Engenharia Mecânica.

Comissão julgadora

Orientador e presidente

Examinador (1)

Examinador (2)

São Bernardo do Campo 
Este trabalho é dedicado à minha Querida Mãe (in memoriam), por sempre me incentivar à busca pelos meus objetivos. 


\section{AGRADECIMENTOS}

Antes de tudo, agradeço à Deus, por sempre ter escutado meu coração em fé e ter permitido a minha busca por evolução no campo intelectual.

À minha querida e amada esposa Ivana, pois sempre me incentivou e apoiou o meu desbravamento intelectivo, mesmo que fora necessário o distanciamento familiar para a conclusão desse trabalho.

Aos meus familiares, que entenderam a necessidade do distanciamento para a minha evolução.

Aos Professores Doutores Wilson de Castro Hilsdorf, Claudia Aparecida de Mattos, Ana Paula Vilas Boas Viveiros Lopes, Alexandre Augusto Massote, que me ajudaram a construir um trabalho com bases sólidas, mas também em momentos que não acertava na direção a seguir.

Ao Professor Doutor Fábio Lima, por orientar e acreditar nesse trabalho, e principalmente pela amizade e paciência com as minhas dificuldades.

Ao amigo Rafael Gomes Alves, por me auxiliar em questões técnicas, principalmente em uma área de seu domínio e conhecimento.

Aos colegas de jornada, que em muitos momentos me ajudaram seja diretamente ou indiretamente.

Por fim, ao Centro Universitário FEI, que acreditou no meu potencial e abriu as portas para que eu pudesse completar mais essa etapa da minha vida. 
“Aprender é a única coisa de que a mente nunca se cansa, nunca tem medo e nunca se arrepende"

Leonardo Da Vinci 


\section{RESUMO}

Nos dias atuais, a conectividade no escopo fabril é de suma importância para fornecer informações detalhadas da real situação do funcionamento dos diversos equipamentos e dispositivos, como também, o aprimoramento na obtenção de dados para uma manutenção preditiva, aperfeiçoamento na eficiência energética, redução das paradas não planejadas para, por fim, elevar a confiabilidade e a vida útil do maquinário. Neste trabalho, é discutido o retrofit de máquinas legadas a partir do contexto da Industria 4.0, propondo uma transição com baixo custo, e focada no consumo de energia e na conectividade. A implementação de dispositivos Gateways, como também os sensores e concentradores de energia, viabilizam o acesso de máquinas de comando numérico computadorizado (CNC) legadas a Internet das Coisas, Big Data e a computação em nuvem, gerando dados focados no consumo de energia dessas máquinas. Com esta solução, é possível também desenvolver e melhorar a automação da máquina $\mathrm{CNC}$ e encorajar as indústrias a seguirem este modelo para que possam inserir-se no contexto da Indústria 4.0.

Palavras-chave: Indústria 4.0, Retrofit, Consumo de Energia, Conectividade, Internet das Coisas. 


\begin{abstract}
Nowadays, connectivity in the manufacturing scope is of paramount importance to provide detailed information on the real situation of the operation of the various equipment and devices, as well as, the improvement in obtaining data for predictive maintenance, improvement in energy efficiency, reducing downtime not planned to ultimately increase the reliability and useful life of the machinery. In this work, the retrofit of legacy machines from the context of Industry 4.0 will be discussed, proposing a low-cost transition, focused on energy consumption and connectivity. The implementation of Gateways devices, as well as energy sensors and concentrators, will enable the access of CNC machines to the Internet of Things, Big Data and cloud computing, generating data focused on energy consumption of these machines. Regarding this solution, it is also possible to develop and improve the automation of the CNC machine and encourage industries to follow this model so that they can fit into the context of Industry 4.0 .
\end{abstract}

Keywords: Industry 4.0, Retrofit, Energy Consumption, Connectivity, Internet of Things. 


\section{LISTA DE ILUSTRAÇÕES}

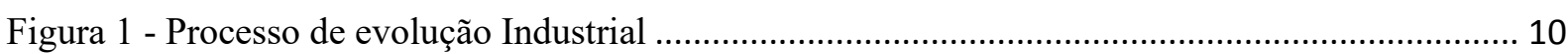

Figura 2 - Integração a partir da cadeia de suprimentos............................................................... 13

Figura 3 - Arquitetura de comunicação Industrial em confluência com o OPC UA............................. 16

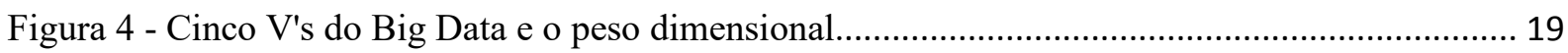

Figura 5 - Transposição dos dados coletados para gerar o Gêmeo Digital .......................................... 21

Figura 6 - Composição para a formação de um CPS ...................................................................... 25

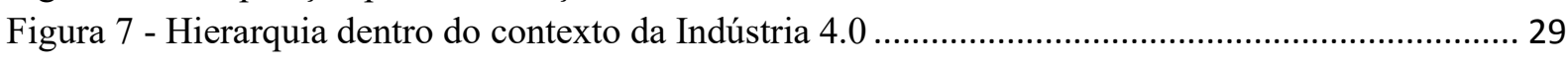

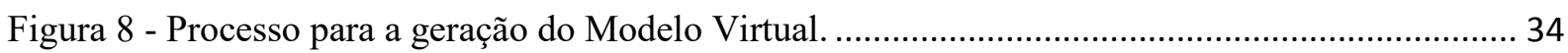

Figura 9 - Questões levantadas a partir da análise do contexto da Indústria 4.0 para com as PME's. .. 36

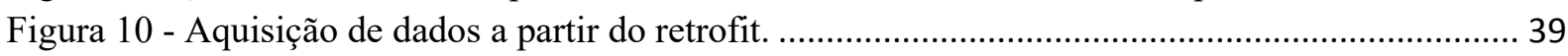

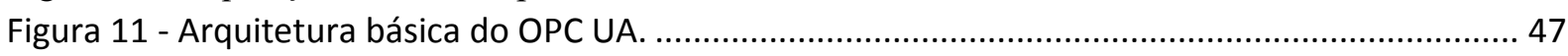

Figura 12 - Mapeamento detalhado da máquina para análise do retrofit. ........................................... 50

Figura 13 - Sistema de mensagens cliente/servidor pelo serviço Modbus............................................ 54

Figura 14 - Mapeamento e implementação das conexões entre os dispositivos. ................................... 56

Figura 15 - Programa para comissionar o Acti 9 Smartlink .............................................................. 58

Figura 16 - Comissionamento do Acti 9 Smartlink e PowerTag...................................................... 59

Figura 17 - Programa Putty como configuração de acionamento do Nod-red...................................... 65

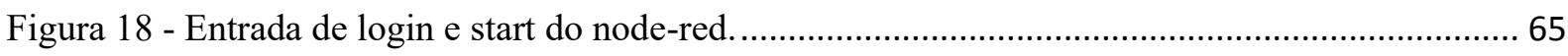

Figura 19 - Fluxo do programa que adquire os dados e envia para o MindSphere............................... 66

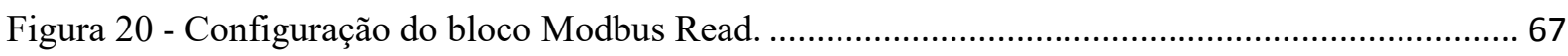

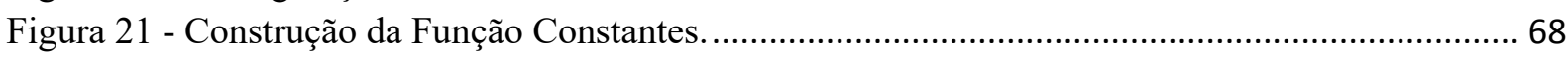

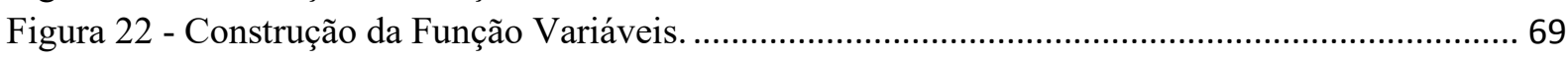

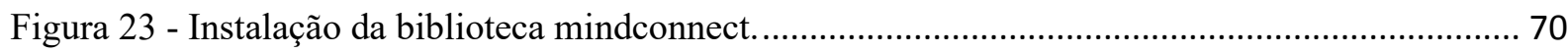

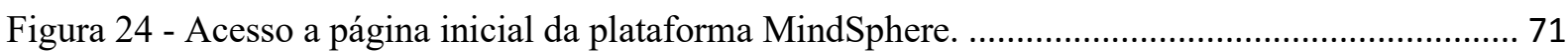

Figura 25 - Criando Types e Incluindo Aspects.......................................................................... 72

Figura 26 - Processo para acessar a biblioteca MindConnect Lib .................................................... 73

Figura 27 - Processo para gerar a Chave de Segurança. .................................................................. 73

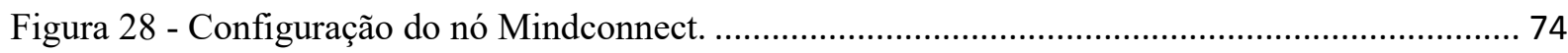

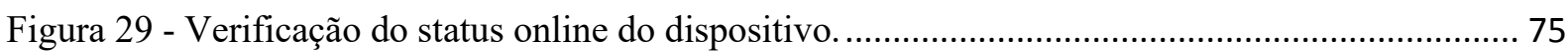

Figura 30 - Visualização de dados através de gráficos. .................................................................. 76

Figura 31 - Gráfico com as grandezas elétricas gerado a partir do CNC legado. ................................ 77 


\section{LISTA DE TABELAS}

Tabela 1 - Descrição da organização dos dados na tabela Modbus. 60

Tabela 2 - Descrição dos valores possíveis que podem ser movimentados pelo Modbus. ….................. 61

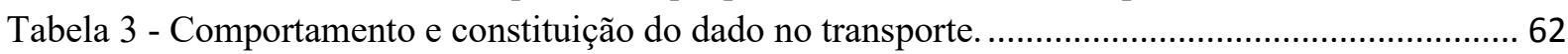

Tabela 4 - Endereçamento dos dados de medição da corrente, tensão e potência. ................................. 63

Tabela 5 - Leitura das Medições elétricas a partir do gráfico no MindSphere no dia 11/01/2021 ........ 78

Tabela 6 - Leitura das Medições elétricas a partir do gráfico no MindSphere no dia 18/01/2021........ 79

Tabela 7 - Leitura das Medições elétricas a partir do gráfico no MindSphere no dia 25/01/2021........ 80

Tabela 8 - Leitura das Medições elétricas a partir do gráfico no MindSphere no dia 01/02/2021........ 81 


\section{LISTA DE ABREVIATURAS}

CNC Comando Numérico Computadorizado

CPS Ciber-Physical Systems

FDL Field Date Ink Layer

IoS Internet on Service

IoT Internet on Things

IIoT Industrial Internet on Things

M2M Machine-to-Machine

OPC UA Plataforma de Comunicação Aberta e Arquitetura Unificada

PME's Pequenas e Médias Empresas

RFID Radio Frequence Identificator

TI Tecnologia da Informação

TIC Tecnologia da Informação e Computação

ERP Enterprise Resource Planning

MES Manufacturing Execution System

SCADA Supervisory Control And Data Acquisition

PaaS Platform as a Service

SSL Secure Sockets Layer

TLS Transport Layer Security 


\section{SUMÁRIO}

1 INTRODUÇÃ

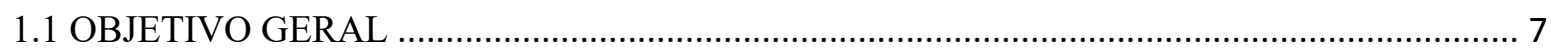

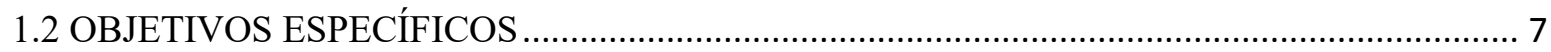

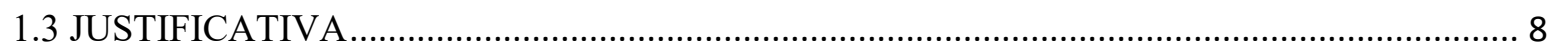

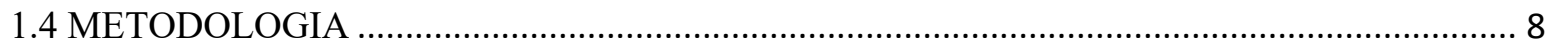

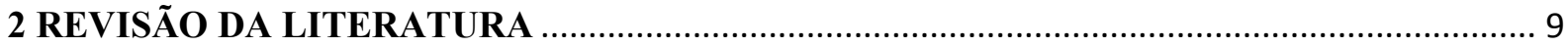

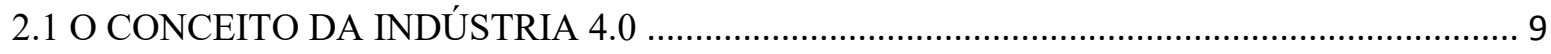

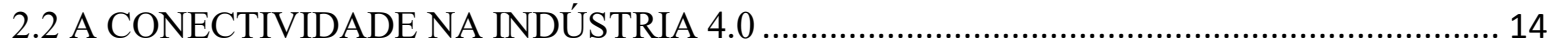

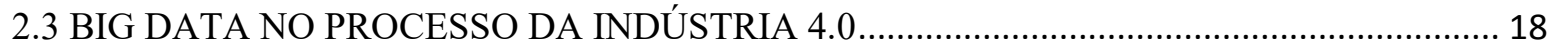

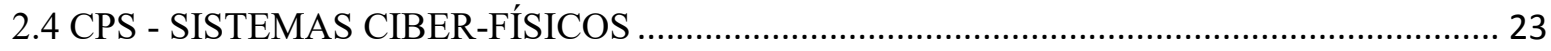

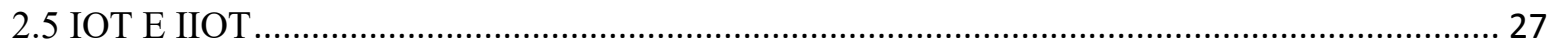

2.6 A DIGITALIZAÇÃO PARA COSOLIDAR O MODELO FÍSICO............................................ 31

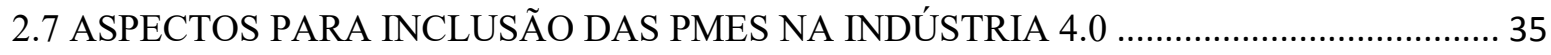

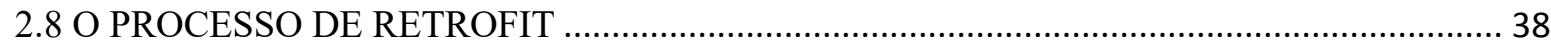

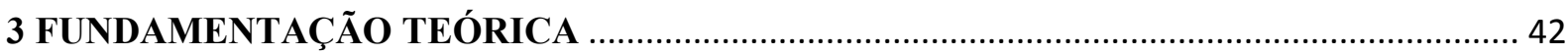

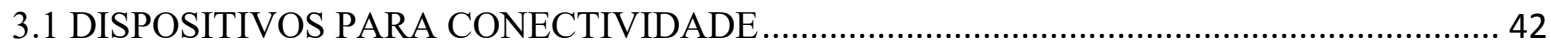

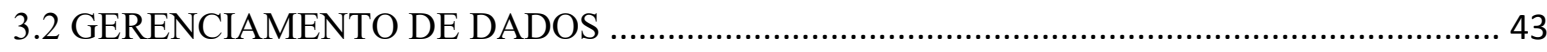

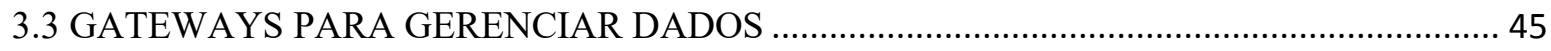

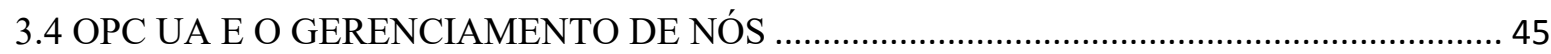

3.5 O RETROFIT COMO ADAPTABILIDADE DE DISPOSITIVOS........................................... 48

3.6 A CONECTIVIDADE COMO BASE PARA O RETROFIT .................................................. 49

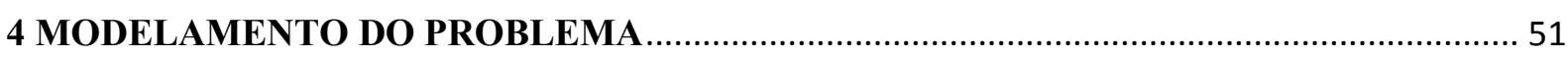

4.1 IMPLEMENTAÇÂO DE DISPOSITIVOS E LEVANTAMENTO DE DADOS....................... 52

4.2 DISPOSITIVO DE MEDIÇÃO DE PARÂMETROS DE ENERGIA …..................................... 53

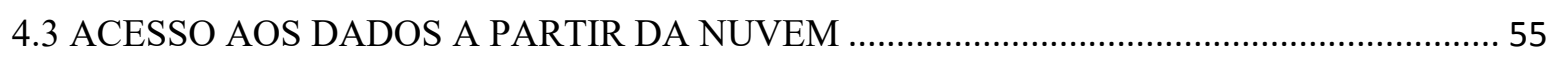

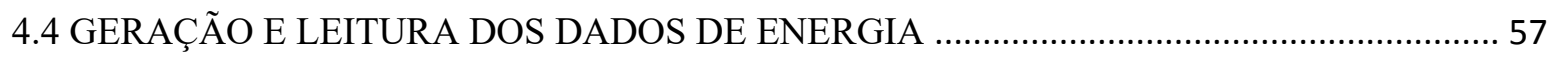

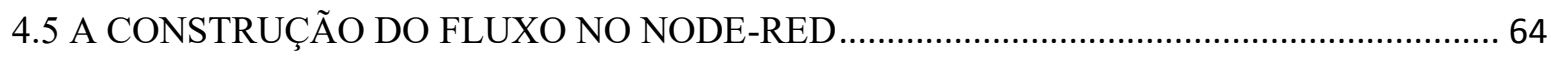

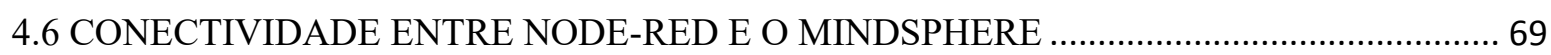

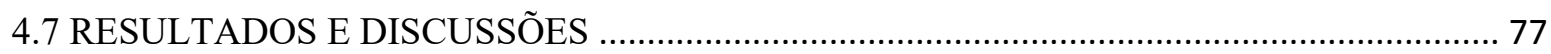

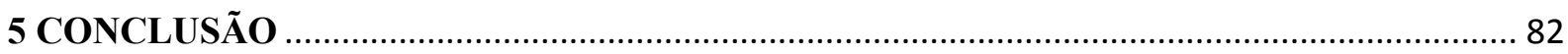

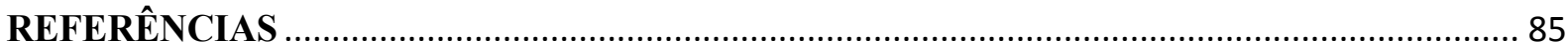




\section{INTRODUÇÃO}

O contexto da Industria 4.0 vem sendo aplicado de modo intensivo em toda a cadeia de suprimentos e valores, melhorando a eficiência de modo geral. Isso se deve principalmente ao forte desenvolvimento das fábricas inteligentes que, em linhas gerais, são fábricas baseadas no IIoT (Industrial Internet of Things) que conectam máquinas inteligentes, pessoas, produtos e sistemas. Zhong et al. (2017) mencionam que máquinas inteligentes trabalham com a extração de informações relativas ao seu próprio funcionamento e produtividade, onde posteriormente enviam as informações coletadas a um banco de dados fundamentado em nuvem.

Outra propriedade importante é a possibilidade de comunicação entre máquinas, denominadas "M2M" ou "Machine-to-Machine". Segundo Hill et al. (2018), essa comunicação tornou mais apropriada a inclusão de dispositivos de controle, com ou sem cabo, ou ainda uma terceira via, que venha ser híbrida (parte com cabo e parte via wi-fi), entre outras formas de melhoria para as máquinas.

A indústria 4.0 baseia-se em alguns conceitos como pilares para sua implementação e sustentação. Segundo Rüßmann et al. (2015) são nove os pilares que formam o conceito de indústria 4.0: Big Data, Robôs autônomos, Simulação, Realidade aumentada, Integração de sistemas, Manufatura aditiva, Ciber segurança, Nuvem e IIoT.

Os modelos de máquinas presentes na maioria das indústrias, muitas vezes não possuem qualquer tipo de preparo para serem inseridos no conceito da Indústria 4.0. Bakir, Bakir, e Engels (2018) alegam que o melhor caminho para as indústrias com máquinas legadas é realizar uma atualização agressiva, sem interferir em qualquer processo que está sendo executado.

O processo de modernização das máquinas pode ser realizado em diversos níveis, desde o básico, como por exemplo a substituição de motores, parte eletrônica ou qualquer tipo de acionamento existente, até partes mais complexas, como sensores conectados, ou em uma proposta abrangente, incorporando dispositivos que melhorem ou envolvam a IoT (Internet of Things), Big Data, Cloud, Digitalização, Realidade Aumentada, entre outros.

Uma alternativa é a implementação do Retrofit, onde este método funciona como forma de substituir ou adaptar novos dispositivos aos equipamentos legados levando em conta a vida útil da máquina e o valor agregado. Com o foco nessa perspectiva econômica, segundo Gao e Wang (2017), o Retrofit pode custar menos da metade de uma máquina 
nova. Para equipamentos ou máquinas onde o hardware são dedicados e proprietários, este trabalho sinaliza como alternativa e para muitos casos como solução, pois os dispositivos inseridos a partir deste tipo de retrofit em nada interfere no funcionamento da máquina legada, já que realizam medições sem intervir no processo em andamento.

Este trabalho de pesquisa tem como abordagem o retrofit de máquinas legadas, com foco no monitoramento do seu consumo de energia, a partir da instalação de dispositivos dedicados para tal função. De acordo com Thoben, Wiesner, e Wuest (2017), novas análises devem ser efetivadas em relação ao consumo de energia para poder consolidar a manufatura inteligente em relação à indústria 4.0.

Como protótipo, foi implementado em uma máquina $\mathrm{CNC}$ legada um sensor para monitoramento do consumo de energia, no qual, com os dados adquiridos será possível conectar essa máquina à uma plataforma em nuvem, e realizar uma análise a respeito do consumo de energia.

Neste trabalho, serão discutidos o Retrofit de máquinas a partir do contexto da Industria 4.0, propondo uma implementação baseada em conectividade, e focada no consumo de energia.

\subsection{OBJETIVO GERAL}

Implementar o Retrofit de máquinas legadas em conformidade com os conceitos da indústria 4.0, com foco na monitoração do consumo de energia elétrica.

\subsection{OBJETIVOS ESPECÍFICOS}

- Instalar o hardware para o sensoriamento e envio de dados em uma máquina $\mathrm{CNC}$ legada;

- Garantir a interoperabilidade entre os dispositivos;

- Descrever todo o processo de conectividade e envio de dados, considerando aspectos de hardware e software; 


\subsection{JUSTIFICATIVA}

Máquinas conectadas podem fornecer informações detalhadas de sua real situação de funcionamento, como por exemplo a obtenção de dados para uma manutenção preditiva e consumo de energia elétrica.

De acordo com Yang et al. (2018), a conectividade requerida pelo conceito da Indústria 4.0 entre os diversos elementos da cadeia de suprimentos, proporciona certa conveniência para um novo padrão de serviços agregados ao produto. Entretanto, muito do maquinário existente em algumas fábricas (principalmente em pequenas e médias empresas), não possui qualquer tipo de conectividade.

Uma opção à aquisição de novo maquinário é realizar o retrofit naqueles equipamentos que se encontram na própria fábrica, pois já estão consolidados na sua operabilidade no processo produtivo. Portanto, a compreensão do retrofit constitui em recuperar ou modernizar uma máquina com foco em normalizar o desempenho, ou até mesmo, melhorar o estado de operação que a constitui, como descreve Gao e Wang (2017).

Outro fator preponderante é a questão do custo agregado, pois uma máquina nova não traz apenas o valor dela em si, mas também outros gastos, como por exemplo, novo treinamento para o pessoal que irá atuar sobre ela, novos protocolos de comunicação, que demandam novas instalações, entre outros aspectos.

Com a implementação de tecnologias que possam melhorar as máquinas legadas, pode-se, por exemplo, controlar o consumo de energia elétrica, ou ainda, como sugere Gao e Wang (2017), monitorar as máquinas em uma planta produtiva, delineando uma manufatura sustentável do ponto de vista de eficiência energética.

\subsection{METODOLOGIA}

Em um primeiro momento, foi realizado um levantamento bibliográfico. $\mathrm{O}$ processo de pesquisa utilizou diversas bases de dados, como por exemplo Scopus e Web of Science, a partir de palavras-chaves dentro do contexto da pesquisa.

A aquisição de dados de funcionamento provenientes de uma máquina $\mathrm{CNC}$ foi a próxima etapa, esses dados puderam ser adquiridos e enviados à nuvem a partir do uso de dispositivos chamados de Gateways, bem como os denominados Smart links. 
O panorama ideal é o fechamento de todo um ciclo, que pela sequência se verificará por: Retrofit com a implementação de dispositivos adequados, aquisição de dados e fornecendo-os a nuvem, análise dos dados recebidos, e por fim, tomada de decisão baseada nesta última análise.

Quanto à metodologia de pesquisa, este trabalho é classificado como quantitativo e exploratório.

\section{REVISÃO DA LITERATURA}

Como referido anteriormente, a indústria 4.0 baseia-se em alguns conceitos para sua implementação e sustentação. Entretanto, como foco deste estudo, serão discutidos aspectos ligados diretamente ao processo de implementação do projeto, a saber: Retrofit, IIoT, Big Data, CPS (Cyber Physical Systems), Digitalização (Simulação e Realidade aumentada), Segurança de rede, Manutenção, Conectividade, PME’s (Pequenas e Médias Empresas) e Indústria 4.0 como ponto de partida.

\subsection{O CONCEITO DA INDÚSTRIA 4.0}

Em 2011, o Governo alemão apresentou um projeto intitulado "Indústria 4.0", que previa uma quarta revolução industrial com base em inteligência artificial e Big Data. A partir desse ponto, e de acordo com Rüßmann et al. (2015), o conceito de Indústria 4.0 desenvolveu-se e passou a integrar outras tecnologias, promovendo um sistema mais digital, com mais informações descentralizadas, com recursos para personalização e com maiores possibilidades de ser sustentável. Ainda, de acordo com Rüßmann et al. (2015), o conceito de Indústria 4.0 é um marco posicional em relação a abrangência de tecnologias disponibilizadas e integradas para tal cometimento. As conexões entre tais tecnologias, como Big Data, Cyber Physical Systems, Internet of Things (IoT), Realidade Aumentada, Serviços em Nuvem, entre outras, tornam possível a atribuição do termo Industria 4.0.

Estudos indicam que o conceito da Indústria 4.0 pode impactar de maneira positiva em toda a cadeia produtiva, desde processos de manufatura até a customização de produtos, como apresenta Pereira e Romero (2017). 
A transformação que se desenha no setor 4.0 vai além de meras expectativas, pois como menciona Rüßmann et al. (2015), os dispositivos conectados formam um novo espaço virtual em que todos esses sensores, atuadores e maquinas podem interagir e criar uma inteligência artificial para gerenciarem a si mesmos no caso de possíveis falhas, diagnósticos de paradas, mudanças necessárias, entre outras.

Delineando o contexto de Indústria 4.0, aparecem três tecnologias de importância essencial: Internet of Things (IoT), Cyber Physical Systems (CPS) e Big Data. O sistema IoT trabalha na conexão digital de dispositivos em tempo real, onde muitas vezes utilizase do CPS para a conexão física. Portanto, segundo Pereira e Romero (2017), o CPS é um meio de conexão entre mundo físico e o mundo digital. Já a Big Data depende das duas tecnologias anteriores para processar, analisar, disponibilizar e armazenar os dados que chegam das fontes primárias. Essa integração das três principais tecnologias mencionadas traz enorme poder de transformação na cadeia de valor, principalmente no sistema de produção, nas tomadas de decisão, no melhoramento do design, entre outras. A figura 1 mostra como se desenvolveram as revoluções industriais até chegar a quarta Revolução Industrial.

Figura 1 - Processo de evolução Industrial

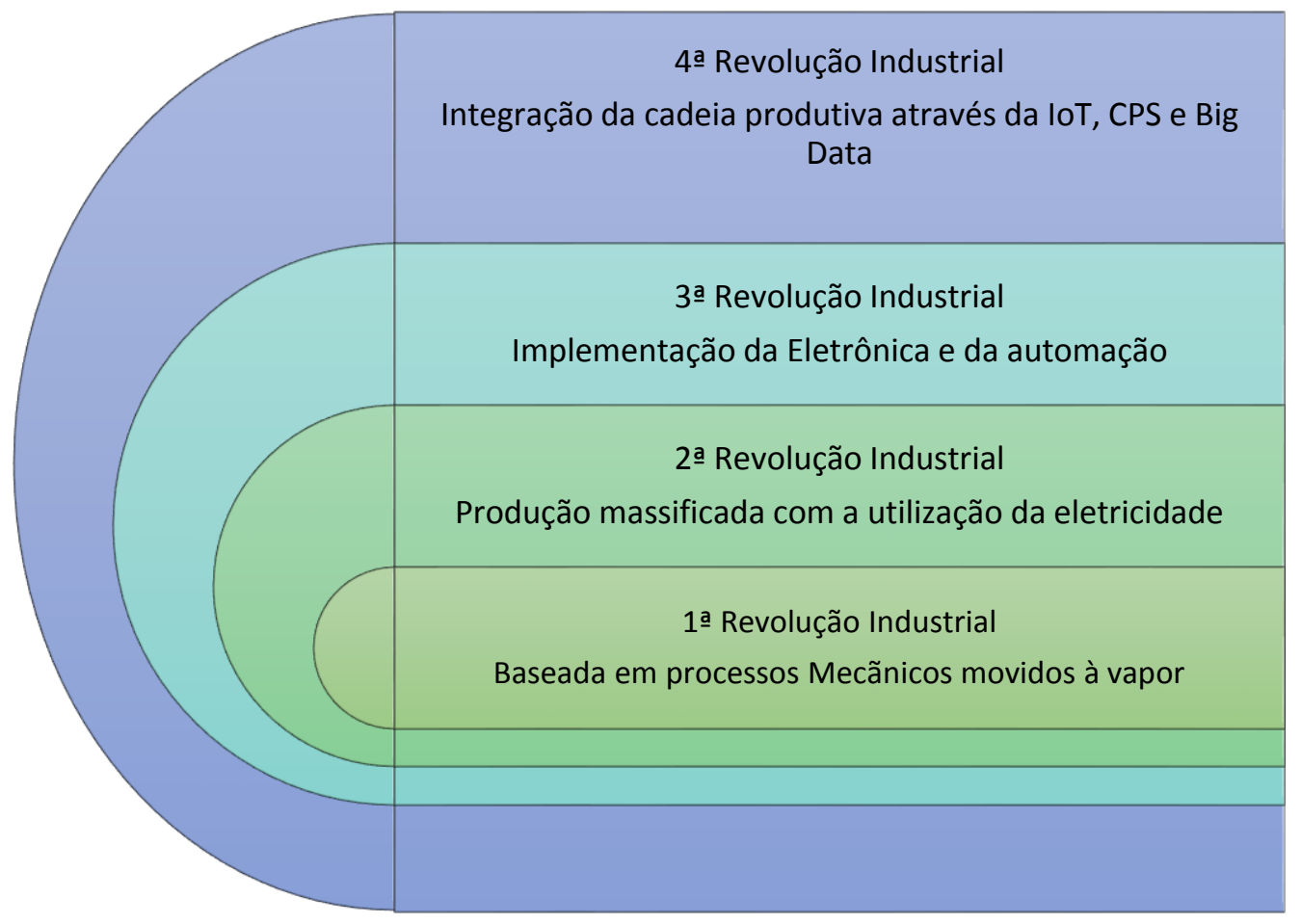

Fonte: Autor 
Como mencionado anteriormente, também participa da elaboração da indústria 4.0 a tecnologia da Big data, que trabalha efetivamente com a aquisição de dados, onde posteriormente, segundo Hill et al. (2018), com os dados analisados através de informações mais precisas, pode-se interferir diretamente na tomada de decisão.

Com o rápido crescimento do volume de dados, a Big Data tornou-se peça chave como facilitador de tecnologias de computação, desenvolvimento de melhores softwares de análise, digitalização com recursos de dados e implementação de tecnologias que utilizam dados para fabricação aditiva e prototipagem de produtos, como descreve Yang et al. (2018). De qualquer forma, com um bom desenvolvimento da Big Data e com dados validados, como define Strange e Zucchella (2017), isso traz valor às indústrias e recursos técnicos para poder melhorar a agilidade nos mecanismos de decisão corporativa.

Também é de vital importância para o setor 4.0 um CPS totalmente integrado aos dispositivos, até por que muitas funções como, computação de rede, protocolos, gerenciamento da rede, segurança cibernética, passam por este sistema, onde, como menciona Zhou, Liu, e Zhou (2016), interage com todos os elementos da cadeia de valor determinando a conexão de ponta a ponta. O CPS é a tecnologia que permite a interoperabilidade entre maquinas e realidade virtual, possibilitando o incremento de tecnologia de inteligência artificial, desenvolvimento da computação de conectividade e manufatura inteligente, como define Hill et al. (2018).

Não menos importante para a indústria 4.0 é o IoT, que oferece soluções para sistemas industrias em termos de interatividade entre máquinas, processos e gerenciamento, pois segundo a definição de Xu, Xu, e Li (2018), a camada de aplicação analisa em que condições a máquina está operando para conectar a IoT que por sua vez, interage com dispositivos que transmitem e recebem dados. De acordo com FULANO, esta camada de aplicação é abstrata e trabalha com protocolos de comunicação End-toEnd, sendo a "interface" analítica e interação com o usuário. Os riscos que podemos indicar na implementação da IoT é o aumento de dados coletados a partir de sensores, atuadores e outros dispositivos que colocam em situação de alerta devido a questões de segurança e armazenamento dos dados.

Assim como a IoT, a virtualização e o desenvolvimento dos Sistemas CiberFísicos (CPS) também participam do conceito de Indústria 4.0. De acordo com Xu, Xu, e Li (2018), a virtualização participa efetivamente do setor 4.0 pois traz a vantagem de 
minorar problemas encontrados na camada física, principalmente a participação em nuvem de informações.

Entretanto, o CPS permite a integração entre mundo físico e digital e proporciona um valor agregado à cadeia produtiva. Esse processo de conectividade entre as máquinas em um chão de fábrica aliado, a sistemas de comunicações centrais, não é novidade nos escopos fabris, contudo como indica Hill et al. (2018), esse paradigma é isolado e centralizado, o que limita a integração com dispositivos embarcados e processos de implementação de inteligências artificias.

As tecnologias de segurança desenvolvidas para rede de comunicação comum, também podem servir de parâmetro para as redes baseadas em IoT, pois como menciona Rüßmann et al. (2015), os protocolos de comunicação existentes vêm aumentando devido a inclusão de sistemas abalizados em IoT, e esses protocolos são a base para proteger sistemas fabris consolidados.

Há um enorme potencial econômico em relação a todos modelos organizacionais de uma empresa, porém, como menciona Pereira e Romero (2017), o conceito propriamente dito ainda necessita de novos estudos e pesquisas abalizadas para fornecerem uma maior compreensão e capacitação dos envolvidos.

Segundo Dalenogare et al. (2018), as principais características em termos organizacionais do conceito de Industria 4.0 é a integração tanto vertical como horizontal, além da ação do processo end-to-end em toda a cadeia de suprimentos. A integração vertical traz a governança de sistemas TIC no gerenciamento de dados, enquanto a integração horizontal leva a um direcionamento no processo produtivo em cooperação com outras empresas na questão da troca de dados. A figura 2 indica a interconexão entre os diferentes processos. 
Figura 2 - Integração a partir da cadeia de suprimentos

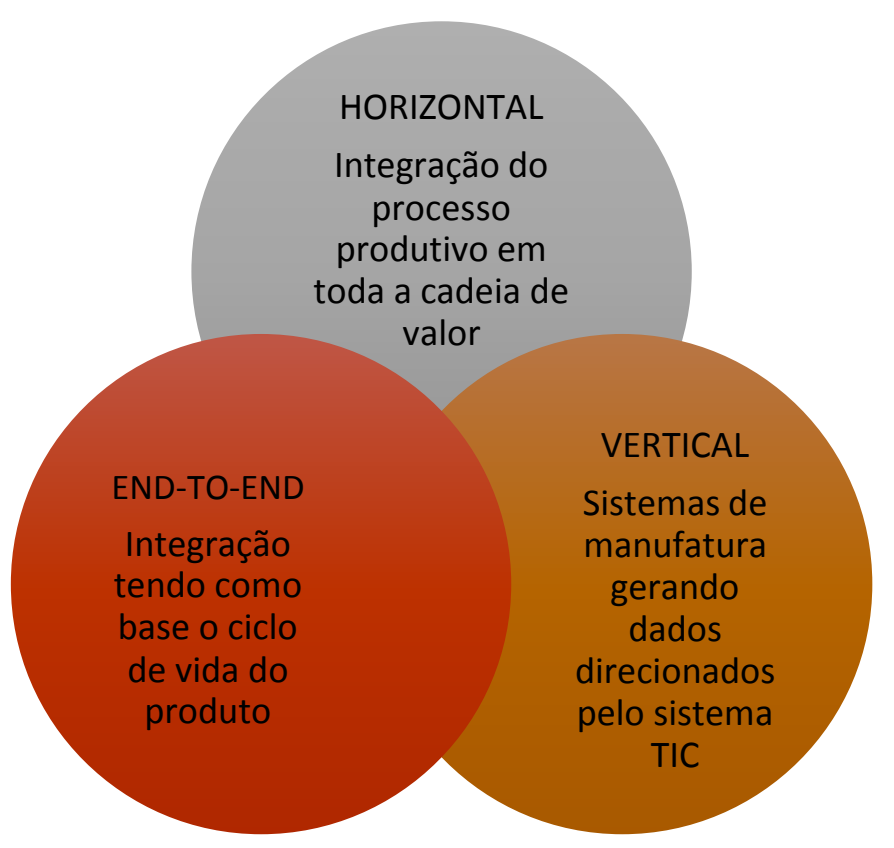

Fonte: Autor

Um dos benefícios que a Industria 4.0 pode trazer é o desenvolvimento da manufatura sustentável, pois como define Sousa Jabbour et al. (2018), o desimpedimento de tecnologias sustentáveis está inserido no âmbito do conceito, que minimiza desperdícios, melhora processos onerosos e descentraliza o gerenciamento. De acordo com Xu, Xu, e Li (2018), logo após apresentar o conceito de indústria 4.0, o governo alemão designou uma alta cifra econômica para desenvolver as PME's em tecnologias ligadas à indústria 4.0 .

A indústria 4.0 massificou a utilização de dispositivos, como por exemplo, RFID (Identificador de Rádio Frequência), ZigBee, entre outros. O RFID tem papel fundamental no rastreamento de produtos e/ou identificação de produtos, e é uma tecnologia que permite a criação de novos sensores. Entretanto, o ZigBee trabalha com baixo consumo de energia e baixo custo de implementação, porém com um alcance reduzido, e de acordo com Xu, Xu, e Li (2018), os dispositivos ZigBee introduzidos em um chão de fábrica minimiza custos e elimina em muitas instancias a interferência humana em certos processos. O ZigBee é o apelo desse trabalho na questão de automatizar a verificação do consumo de energia da máquina $\mathrm{CNC}$. 
Por fim, o foco deste trabalho está na ideia do desenvolvimento de um retrofit direcionado a máquinas legadas e baseado na conectividade, como também abalizado no contexto da Indústria 4.0, que para isso, adaptar-se-á sensores, Gateways, Smartlinks, entre outros, pois seguindo a indicação de Yang et al. (2018), com os dados coletados a partir dos sensores, pode-se melhor diagnosticar o equipamento no que diz respeito ao consumo de energia, como também trazer uma sobrevida ao equipamento e eliminar a possibilidade de aquisição de novas máquinas. Com a implementação de um sensor no sistema elétrico, será possível analisar a saúde da máquina em termos energéticos, falhas decorrentes de sobrecarga e realocar a usinagem de peças de acordo com o consumo.

\subsection{A CONECTIVIDADE NA INDÚSTRIA 4.0}

De acordo com Mitchell e Chen (2014), os sistemas de comunicação atuam em conjunto com diversos circuitos de controle, e com os rastreadores de trafego da rede, que requerem condições rígidas de tempo e sistemas de escalabilidade.

Os sistemas constituídos por Automação Industrial, geralmente possuem redes heterogêneas que atendem as necessidades de comunicação em tempo real devido ao entroncamento de padrões de Ethernet Industriais, que sejam, Ethernet/IP, Profinet, Ethercat, entre outros, e movendo as informações em tecnologias de Internet para o destino desejado, como informa Zezulka et al. (2018).

A automação também trouxe um desenvolvimento maior na comunicação entre dispositivos instalados em máquinas ou em processos, principalmente com a introdução da Industrial Ethernet (IE), onde segundo Drahoš et al. (2018), possibilitou a unificação da estrutura de comunicação no chão de fábrica.

Geralmente, várias estruturas de rede são integradas com a finalidade de transmitir dados e informações para a nuvem, onde segundo Drahoš et al. (2018), o modelo mais adequado para suprir a necessidade é classificado em primeira ordem, que neste caso é a ferramenta OPC UA.

A partir do molde de conectividade conhecido, o OPC UA (Open Platform Communications Unified Architecture) vem se tornando padrão dentro do conceito de Industria 4.0 e consequentemente como um dos pilares da IIoT, o que promove uma corrida em direção a essa tecnologia por partes das nações desenvolvidas, como destaca Zezulka et al. (2018). 
A interoperabilidade é um assunto recorrente dentro do conceito de Indústria 4.0, e para tanto, o OPC UA é uma das ferramentas centrais para esse novo paradigma, pois segundo Drahoš et al. (2018), provê um padrão industrial em termos de comunicação onde atua tanto horizontalmente como também verticalmente, possibilitando a troca de dados entre sensores, atuadores, entre outros dispositivos com a nuvem, que está baseado em um servidor.

O OPC UA encontra uma gama de diferentes aplicações em plantas fabris, não somente em sistemas operacionais, mas também segundo Drahoš et al. (2018), em processos de transporte de dados por um caminho que o modelo de comunicação esteja alinhado à infraestrutura, integrando informações entre fornecedores, organizações e clientes.

A definição para o OPC UA no contexto de sistema de comunicação, é uma plataforma que auxilia na interoperabilidade entre servidores e clientes em diferentes tipos de redes, em vários níveis hierárquicos, conectando os diversos protocolos de várias formas possíveis e com diversas topologias. Para tanto, segundo Imtiaz e Jasperneite (2013) o OPC UA fornece um modelamento entre os clientes e servidores que permite uma grandeza de serviços, multiplicidade de protocolos de Comunicação, além dos dados poderem serem compilados de formas variadas, garantindo uma maior eficácia de conectividade.

Com o aumento do compartilhamento de dados e informações entre os processos automatizados, máquinas e equipamentos, trouxe a necessidade de uma IoT industrial (IIoT), onde de acordo com Drahoš et al. (2018), o OPC UA é componente fundamental no desenvolvimento da automação industrial para a conectividade entre sensores, atuadores, entre outros, controlando a comunicação desde os dispositivos até os servidores centrais. Ainda segundo Drahoš et al. (2018), o OPC UA é a ferramenta mais apropriada para manter a fábrica interconectada, promovendo em escala, a arquitetura e a estrutura o acesso à IIoT. A figura 3 explica como os diversos protocolos de comunicação interagem. 
Figura 3 - Arquitetura de comunicação Industrial em confluência com o OPC UA

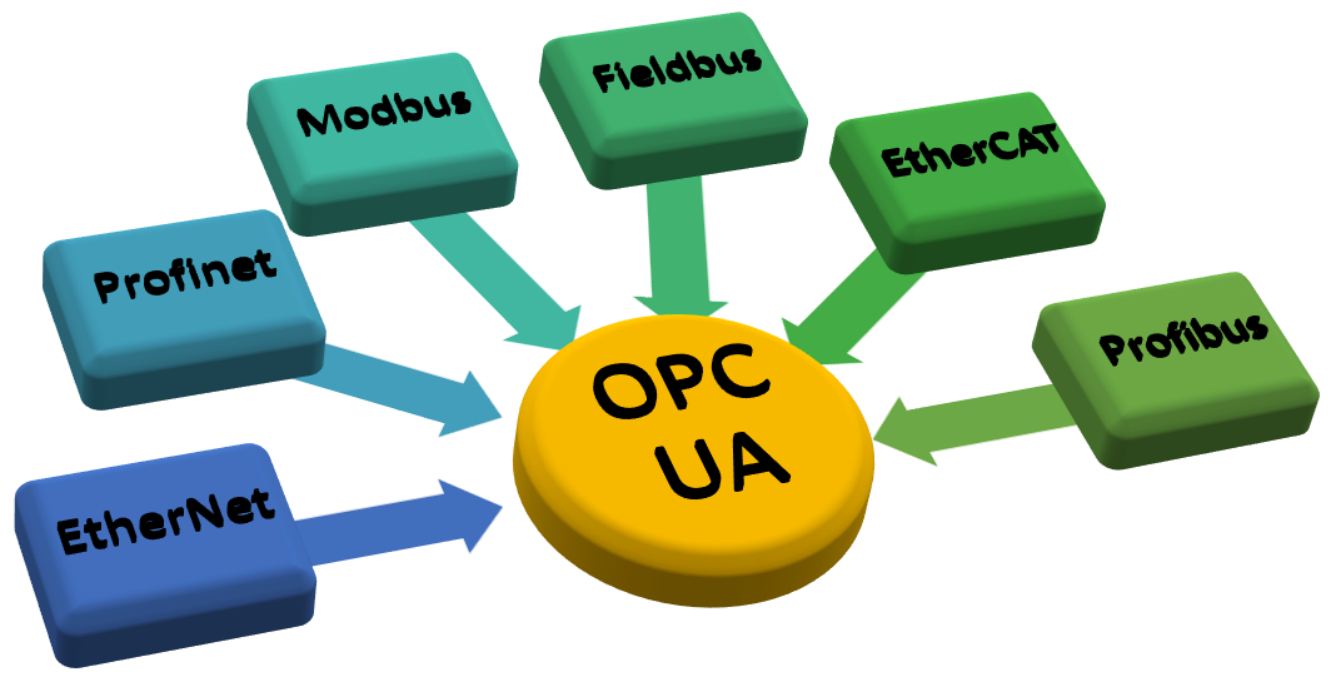

Fonte: Autor

Segundo Liu et al. (2017), os processos de integrações industriais estão baseados em três componentes vitais para a circulação da informação, a saber: Computação, comunicação e controle. Para tanto, esses três componentes realizam em ressonância a ordem de sensoriamento, disponibilização de informações em tempo real e um controle efetivo e dinâmico nos processos industriais.

A utilização de padrões conhecidos para a comunicação ou transporte de dados, com ou sem fio, permite uma integração horizontal e vertical na rede muito mais consistente e confiável, então por isso, de acordo com Imtiaz e Jasperneite (2013), o OPC UA comporta os mecanismos desejáveis com recursos escalonáveis para tal cometimento, a partir das demandas de aplicação.

As implementações das pilhas de comunicação do sistema OPC UA acontece a partir de uma série de linguagens estruturadas que constroem os protocolos de comunicação necessários para navegar nos ambientes de redes com padrões TCP/IP, como indica Zezulka et al. (2018).

Existem métodos e protocolos que operam e validam a camada de transporte para a transmissão de dados pela rede, onde esses elementos mantém informações necessárias 
a um servidor, pois como afirma Zezulka et al. (2018), o modelo OPC UA atua baseado em nós de rede de malha completa e com meta informação.

Os metadados e os dados do processo são mantidos pelos nós, que dirigidos por Serviços Base do OPC, garantem a sua funcionalidade e, ao mesmo tempo, podem verificar os perfis dos usuários que possuem uma viabilidade para o suporte do servidor.

A plataforma OPC UA detecta a presença de um novo dispositivo e força a conexão imediata ao servidor; utilizando as credenciais necessárias. Também verifica e testa a interoperabilidade entre servidor, cliente e dispositivo, como descreve esse processo Imtiaz e Jasperneite (2013).

Segundo Liu et al. (2017), a partir dos nós, há um direcionamento no controle em lançar um comando para as unidades assistidas dentro do espaço físico, e que acomodam e controlam o processo físico. Os vários nós que entrelaçam os sensores, detectam as informações provindas do mundo físico, que sejam, temperatura, umidade, pressão, entre outras, e são aproveitadas para as tomadas de decisões.

Em termos de conectividade industrial, os protocolos legados ainda operam robustamente mesmo com a introdução de novos padrões de comunicação em plantas industriais, e nesse caso, segundo Mamo, Sikora, e Rathfelder (2017), o Profibus faz parte desse crescimento em termos de plataformas de comunicação.

O Profibus está relacionado aos padrões IEC, com possibilidade de operarem diferentes tipos de arquivos dentro das necessidades dos estados industriais, que vai desde um simples diagnóstico até dados do processo, a partir da transmissão dos dados em uma camada de enlace denominada FDL (Field Date Ink Layer), segundo a descrição de Mamo, Sikora, e Rathfelder (2017).

Na questão de segurança, as redes inteligentes trabalham com auditorias norteadas em host, onde esse critério especifica e detecta invasores potenciais, além de gerenciar a portabilidade dos nós, no qual segundo Mitchell e Chen (2014), fornece a liberdade de análise e sustentação dos logs.

Com um desempenho eficiente de uma rede, mesmo diante de diversos padrões de protocolos, e a partir da ferramenta correta para gerenciar toda essa rede, pode-se tomar as decisões apropriadas com um sistema de monitoramento hábil, sendo assim, como deduz Lee, Bagheri, e Kao (2015), tudo pode ser resumido em um gêmeo digital, por 
exemplo uma máquina, e transacionar as informações de forma objetiva e segura, aprimorando no futuro uma autoconsciência cibernética.

\subsection{BIG DATA NO PROCESSO DA INDÚSTRIA 4.0}

No ano de 1997, em uma conferência do Institute of Electrical and Electronics Engineers (IEEE), foi apresentado um artigo onde estava impresso o termo "Big Data", onde Cox e Ellsworth (1997) exemplificaram a dimensão dos dados juntamente com o desafio que os sistemas computacionais iriam enfrentar a partir daquele momento. Podemos sintetizar que Big Data é definida como um grande fluxo de dados que contém muitas informações, ou seja, uma ferramenta gerenciadora capaz de administrar, capturar, armazenar e analisar dados, como indica Yin e Kaynak (2015).

A partir da criação do termo Big Data, começaram os estudos e compreensões em direção dos recursos: Volume, Velocidade, Variedade, Valor e Veracidade. Dentro da matriz da Big Data nota-se a importância do volume de dados, pois a partir do mesmo estão inseridos os aspectos como escala, dimensão, quantidade e tamanho de dados. Entretanto, Segundo Demchenko et al. (2013) o volume alcança uma importância e qualificação em direção de certa especificidade tecnológica, orientado para todas as ferramentas que utilizam a Big Data.

Outro aspecto importante é a questão da veracidade dos dados, pois é de vital importância a confiabilidade dos dados, confiabilidade estatística e consistência dos dados que remontam desde a origem, coleta e processamento. Para que a questão da veracidade se conclua por completo, a parte de segurança deve ser muito bem estruturada e de máxima responsabilidade e reputação, como indica Demchenko et al. (2013). São consideradas três V's em questão dimensional em relação a Big Data: volume com geração enorme de dados; veracidade com dados gerados dentro de confiabilidade e consistência; e validação com dados gerados a partir de uma claridade e valor.

Distintos autores indicam estudos em diferentes aspectos da análise da Big Data, que são: geração de dados, aquisição de dados, armazenamento de dados e análise de dados. Segundo Demchenko et al. (2013), os dados são instâncias multi-complexas com base própria e devem suportar bases físicas (ou lógicas), trazendo a missão de gerenciar, acessar e armazenar os dados. 
Os dados são gerados com muita rapidez, mesmo aqueles que se iniciam em sensores ou atuadores, acarretando um processamento em tempo real ou como fluxos de dados. A valorização dos dados depende muito dos processos que eles representam, podendo ser de matriz probabilística, estocástica, aleatória ou regular.

Geralmente os dados encontrados em uma Big Data são de eventos físicos (como por exemplo, a leitura de um sensor) ou de eventos digitais (exemplo, redes sociais), como menciona Jin et al. (2015). Com a utilização de várias fontes de dados, a saber, computação em nuvem, Internet das coisas e outras tecnologias de evidência computacional, os dados encontrados estão cada vez mais complexos e aumentando a um percentual massivo.

Portanto, segundo Demchenko et al. (2013), um dos grandes desafios dentro da Big Data é o desenvolvimento de soluções de infraestrutura ou processos correlatos para minimizar o aumento exponencial em relação ao volume de dados, consolidação de estruturas eletrônicas e fornecer serviços constantes de aprimoramento estrutural. A figura 4 mostra a classificação dos 5 V's.

Figura 4 - Cinco V's do Big Data e o peso dimensional
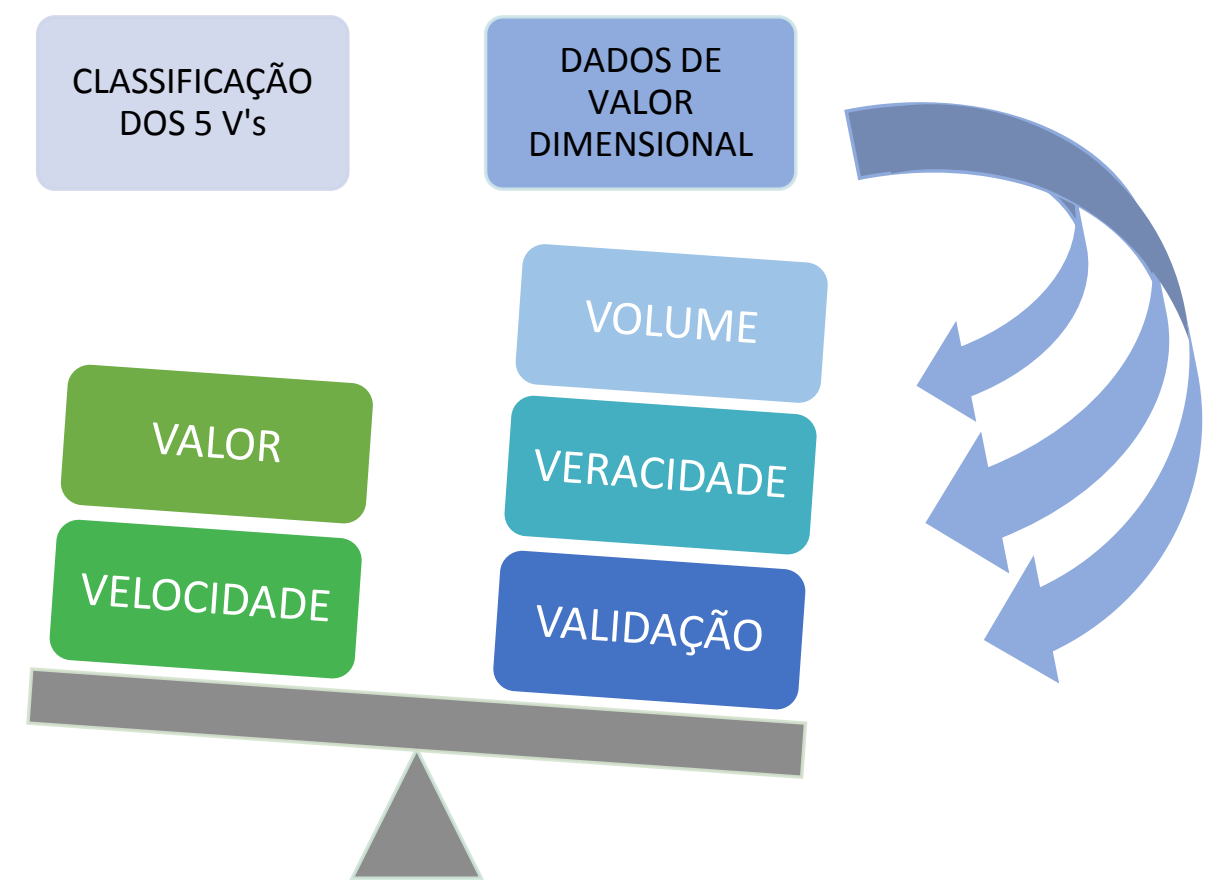

Fonte: Autor 
A origem do Big Data em conjunto com tecnologias baseadas em dados, propicia a melhoria de outras tecnologias correspondentes (por exemplo, IoT), caracterizando a justaposição tecnológica a diferentes aparências das atividades humanas. Ainda sobre a Big Data, segundo Gandomi e Haider (2015), algumas questões pertinentes rodam alguns tópicos, como por exemplo, quais as métricas que determinam a dimensão da Big Data? Quais ferramentas e tecnologias despendem o total aproveitamento da Big Data? A partir destas questões chegamos em outra, talvez com maior relevância, que pode ser: qual a frequência que os dados são gerados a partir de sensores ou atuadores?

Em uma análise sucinta, através da ótica de Gandomi e Haider (2015), a geração de dados imprecisos e hipotéticos criam a necessidade de ferramentas analíticas com maior poder de gerenciamento e correção diante da mineração desses dados. Portanto, todo o ciclo de consolidação da Big Data está estruturado a partir da sequência: aquisição dos dados, processamento, validação e visualização em um terminal.

Também é de grande interesse que os dados captados gerem conteúdos úteis, pois como indica Gandomi e Haider (2015), avaliza o valor agregado a partir do elemento abordado (por exemplo a leitura de um sensor), levando a utilização da informação de forma ampliada.

Dentro da tecnologia da Big Data, as capacidades de processo, armazenamento, memória e rede, solicita técnicas e ferramentas que aplicam essas combinações, como por exemplo o MindSphere.

A partir de pesquisas relacionadas ao assunto Big Data, segundo Yin e Kaynak (2015), podemos mapear algumas tendências dentro do contexto da indústria 4.0, que são: análise estatística mais proeminente, combinação de cenários através da mineração de dados para gerenciamento de risco, direcionamento de dados em nuvem para armazenamento e sistemas inteligentes baseados em Big Data para gerenciamento de sistemas energéticos limpos.

De forma geral, as empresas inseridas no modelo da indústria 4.0 necessitam estar dispostas em ir ao encontro de tecnologias de processamento altamente confiáveis de banco de dados, pois segundo Khan, Uddin, e Gupta (2014), a velocidade que chegam os dados é cada vez maior. Por isso, a Big Data tem se mostrada complexa a partir de modelos representativos, inclusivos e inteligentes com desafios relevantes na computação tradicional, que estão centrados em padrões totais de dados. 
Os dados coletados e organizadas a partir da Big Data podem ser utilizadas para a criação de aplicativos, manutenções preventivas, acompanhamento de processos produtivos e otimização do consumo de energia. A figura 5 mostra um cenário fabril de como os dados podem se comportar a partir do momento da aquisição dos dados, até a geração de um Gêmeo Digital como exemplo de utilização dos dados.

Figura 5 - Transposição dos dados coletados para gerar o Gêmeo Digital

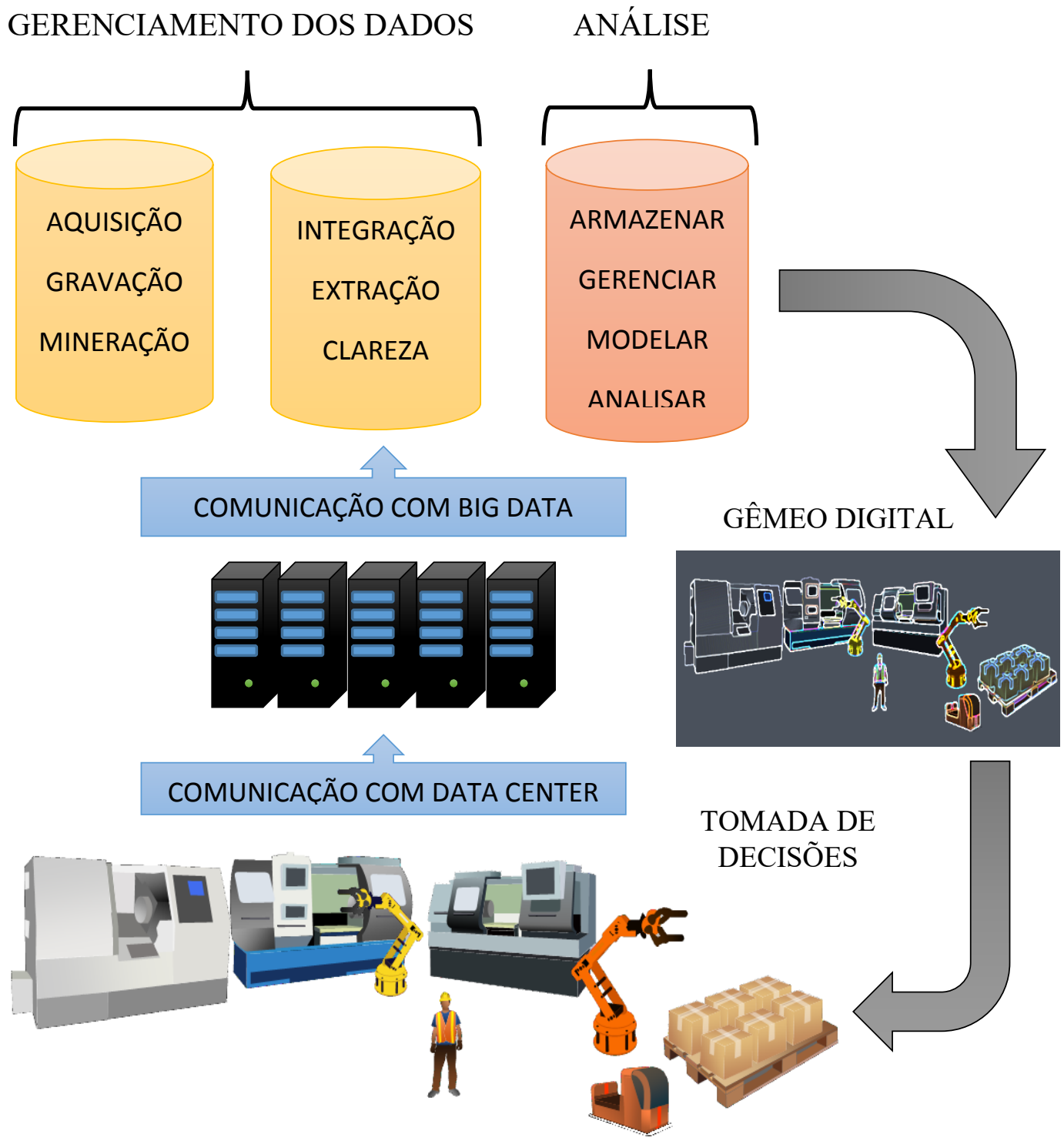

Fonte: Autor

Segundo Wan et al. (2017), para estabelecer uma manutenção preventiva a partir de uma Big Data, é preciso incluir os dados referentes a logs, alarmes e status do dispositivo, além da leitura que o mesmo está direcionado. Ainda na questão da 
manutenção centrada em Big Data, enquanto da mineração de dados a partir de dispositivos localizados em máquinas, os dados coletados podem ser enviados a uma plataforma em nuvem através de redes sem fio, não onerando assim o meio físico da fábrica. Da mineração dos dados brutos, e com o processamento complexo até a modificação em informação, a publicação dos dados relevantes torna-se uma importante marca para o modelo gerenciado. De encontro com esse ponto, haverá uma disposição em digitalizar os elementos físicos em uma fábrica, como por exemplo máquinas ou processos, onde, de acordo com Demchenko et al. (2013), aumentará consideravelmente a quantidade de dados, requerendo, portanto, que a acessibilidade seja ampla e rápida.

É fato que ao adquirir os dados, ele pode não ter a mesma propriedade ou valor que na origem, pois ao atravessarem as camadas inferiores podem sofrer algum colapso ou interferência externa. Por isso, de acordo com Demchenko et al. (2013), a caracterização entre cliente e provedor passa por serviços de segurança de dados, onde requer confiabilidade no sistema do provedor por parte do cliente, pois o cliente precisa da certeza que os dados adquiridos da sua planta industrial estão armazenados e seguros.

De encontro as necessidades das Pequenas e Médias Empresas (PME’s), em uma análise pontual através da Big Data, segundo Gandomi e Haider (2015), a extração de volumes de dados enormes auxilia na implementação de nova ordem de gerenciamento produtivo. Em direção a essa força motriz, está o desenvolvimento tecnológico da computação em nuvem e com resultados em alguns setores como internet das coisas, há que se melhorar na implementação de aplicativos que trabalhem com os dados em tempo real para suportar dados de sistemas de energia e fabricação inteligente. Para isso entrar em uma operação dinâmica, implementa-se algoritmos adaptativos de aprendizagem e mineração de dados, mesmo suportando dados onde o relacionamento não parece ser definido com facilidade, ou como indica Khan, Uddin, e Gupta (2014), em autenticando o dado e levando ao dispêndio almejado.

Na realidade a principal proposta de implementação de Big Data em plantas industriais é a utilização para detecção de problemas em eventos, através da análise dos dados, diminuir os custos e assim poderem melhorar a qualidade do processo. Entretanto, em termos de aplicabilidade da Big Data, a indústria pode ser afortunada dentro desse propósito, pois a necessidade de possuir dados em tempo real, a utilização desses dados em tempo real, e diante da indicação de Lee, Kao, e Yang (2014), o processamento real da Big Data é a forma inovadora e sustentável para o acesso no contexto da indústria 4.0. 
Não é de hoje que a diversidade de equipamentos, protocolos de comunicação e diferentes dispositivos embarcados acabam dificultando o fluxo de dados para uma análise aperfeiçoada e rápida, como indica Wan et al. (2017). Na aquisição de dados, como também em um processamento inicial, o dispositivo conectado ao CNC trabalha com a transmissão de dados baseados no Gateway Siemens IoT 2040. Com isso, os dados alocados em uma Big Data, o gerenciamento do consumo de energia pode ser mais completo, além de adotar deliberações mais objetivas na referida questão. A partir do mecanismo mencionado acima, diferentes procedimentos na questão do desempenho da máquina $\mathrm{CNC}$ podem ser discutidos e utilizados em manobras futuras para a saúde dela. Com o crescimento dos dados a partir da mineração dos mesmos, segundo Lee, Kao, e Yang (2014), faz-se necessário aperfeiçoar a habilidade de ligar as condições complexas da máquina real com o funcionamento da máquina em um processo virtual.

O investimento em armazenamento de dados pode ser econômico do ponto de vista do tamanho ou no momento da aquisição do pacote inicial, porém isso pode vir a anular o investimento, pois os dados relevantes podem se perder devido à complexidade dele. Para resolver essa questão, investe-se em ampliação do armazenamento de dados, ou como indica Jin et al. (2015), expande-se o a capacidade de processamento para poder mitigar o problema de armazenamento.

\subsection{CPS - SISTEMAS CIBER-FÍSICOS}

Com avanços recentes nos dispositivos de comunicação e nas tecnologias dos sensores, foram desenvolvidas as técnicas ideais para a interoperabilidade entre o mundo físico e os aplicativos de internet, caracterizando assim os Sistemas Ciber-físico (CPS). De acordo com Wang, Kung, e Byrd (2018), o CPS controla a operação no mundo físico enquanto gerencia ao mesmo tempo o mundo cibernético a partir dos chamados gêmeos digitais. Portanto com um acesso a sensores melhores, infraestrutura de rede e sistemas de aquisição de dados, leva a indústria na direção de implementar sistemas CPS para inserir as mesmas no contexto da indústria 4.0.

A princípio, segundo Shi et al. (2011), uma das funções principais dos sistemas CPS é a integração de processos físicos com o chamado mundo virtual, através de softwares e protocolos de comunicação. Também conduzem a transferência dos dados 
coletados dos sensores entre as camadas inferiores até o software de gerenciamento da Big Data.

O CPS traz diferentes questões a serem discutidas, principalmente nas estruturas da camada física, onde o acionamento precisa de mais integração entre o mundo físico e virtual. Isso se deve, segundo Shi et al. (2011), a sistemas embarcados e computacionais separados da mesma engrenagem, pois os mesmos precisam avalizar o gerenciamento de falhas, manutenções, diagnósticos, entre outras. Alguns modelos de CPS já foram desenvolvidos e pesquisados, como por exemplo, modelo espaço-temporal, físico, de evento, entre outros.

Segundo Leitão et al. (2016), o CPS interconectou diversas tecnologias existentes, estabelecendo o uso de forma a maximizar a produção, a manutenção, a operação, além de poder reconfigurar os atores envolvidos. De certa forma o CPS se destaca em duas funções principais, que são conectividade para aquisição de dados e gerenciamento inteligente dos dados. Frequentemente são sistemas computacionais que interconecta o espaço físico com o meio virtual e gerando serviços de acesso aos dados através da internet.

A associação entre CPS, Internet das coisas (IoT) e Internet de Serviços (IoS), estabelece novos modelos de negócios, onde propicia melhores produtos aos consumidores e novas técnicas de gerenciamento de empresas, como indica Leitão et al. (2016). Geralmente, são sistemas conectados à rede que abrangem sensores, atuadores, dispositivos de comunicação, entre outros, onde todos interagem em tempo real.

De acordo com Jazdi (2014), o CPS tem a operabilidade de um controlador, com a função de gerenciar os sensores e atuadores que atuam no chão de fábrica, interagindo através do processamento de dados. A partir desse processamento de dados, os mesmos podem ser utilizados para a determinação de manutenção ou detecção de diagnósticos. Portanto o CPS é um sistema associado a uma rede por onde se recebe e envia os dados para determinar ações ou receber feedback. A figura 6 demonstra o mapeamento do Sistema CPS. 
Figura 6 - Composição para a formação de um CPS

REDE DE COMUNIÇÃO

Transferência de dados e informações

por meio eletrônico e intermediada por

computadores ou dispositivos.
COMPUTAÇÃO

Trabalha a partir de entradas e saidas (inputs e outputs) com soluções através de algorítimos.
SISTEMAS CIBER

FÍSICOS
CONTROLE

Sistema construído com equipamentos e/ou dispositivos que tem a função de controlar máquinas ou outros sistemas similares.
TECNOLOGIA DA INFORMAÇÃO e COMUNICAÇÃO

Baseia-se em informações técnicas para auxiliar a comunicação em um sistema.

Fonte: Autor

Diversos autores concentram suas pesquisas a respeito do CPS em assuntos que abrangem gerenciamento de energia, segurança na rede e transmissão e gerenciamento de dados. Dentro dessas pesquisas recentes, de acordo com Shi et al. (2011), o foco principal é a eficiência energética, mesmo que ainda o consumo de energia é menor que outros atores, mas no entendimento da engenharia sustentável é um grande inconveniente.

O CPS é utilizado em todas as áreas comerciais e industriais, que vão desde edifícios inteligentes até a automação de uma fábrica. Segundo Rajkumar et al. (2010), com a introdução do CPS em muitas áreas, vários paradigmas foram fragmentados, como por exemplo, a redução no custo do sensor, dispositivos de computação com melhor performance, redução no consumo de energia de alguns dispositivos, comunicabilidade com dispositivos sem fio melhorada, entre outras. Portanto, o CPS apresenta uma confluência de tecnologias disruptivas, tornando-os mais confiáveis e com acesso a custo reduzidos para uma implementação sólida e rápida.

Em níveis cibernéticos, de acordo com Lee, Bagheri, e Kao (2015), as informações estão disponíveis a partir da máquina física, e com a implementação de algoritmos computacionais, a possibilidade de detectar falhas em um tempo menor se torna mais eficaz. A partir do processo mencionado anteriormente, sugere a sintetização de um gêmeo digital para controlar de forma paralela à máquina digitalizada. 
$\mathrm{Na}$ primeira camada do CPS estão os equipamentos industriais, onde com a aplicação de sensores, realizam as leituras relacionadas ao estado atual do processo produtivo, consumo de energia, desgaste da ferramenta, entre outras. Toda essa gama de informações, segundo O’Donovan et al. (2018), é intermediada com gateways e softwares, que facilitam a chegada dessas leituras ao ambiente da segunda camada. A segunda camada é reconhecida como nuvem, onde encontra-se os dispositivos que recebem os dados para análise e dispor as ferramentas de execução no espaço ciber-físico.

De acordo com Monostori et al. (2016), com a implementação do CPS a abordagem em campo fornece um melhor desempenho para a malha de controle, enquanto que em níveis mais altos a característica é um controle descentralizado. Uma estrutura de dados pode ser desenvolvida misturando leitura do sensor com algoritmo de busca para dinamizar as mudanças no espaço físico.

Os sistemas embarcados de alguma forma apresentavam problemas de conectividade em plantas industrias, pois o desempenho ficava abaixo dos processos industriais como indica E. A. Lee (2008). Esses sistemas embarcados funcionam com uma unidade de controle que estão acoplados por um barramento central em campo. Unir o barramento ao CPS poderia maximizar a atuação dos sensores já instalados, além de poder enviar os dados coletados para a nuvem via barramento. Os sistemas embarcados também possuem abstrações que trabalham em tempo real com protocolos de largura de banda, roteamentos, entre outros, dinamizando as comunicações em diferentes níveis modulares.

Em questão de segurança o principal objetivo do CPS é conservar o modo operacional dos equipamentos fornecendo bloqueios aos ataques cibernéticos, pois como menciona Cárdenas, Amin, e Sastry (2008), a importância de proteger atuadores, sensores e controladores, afora os dados coletados, fornece a estabilidade necessária para retomar as atividades.

Apesar de toda ciência empregada para suprir a segurança nos mecanismos que trabalham em CPS, segundo Cárdenas, Amin, e Sastry (2008), algumas situações estão sujeitas ao rompimento dessa garantia, como por exemplo, falhas humanas, configuração errada do sistema, problemas em softwares e vulnerabilidade do projeto de engenharia. A partir disso, algoritmos de mineração devem ser incorporados com a intenção de cooperar 
no aprendizado da inteligência artificial, possibilitando e agilizando as análises de Big Data para o melhoramento na segurança cibernética.

De acordo com O’Donovan et al. (2018), o CPS é o eixo central na engrenagem da indústria 4.0, pois esse processo é o elo entre outras tecnologias, como por exemplo Big Data, IoT, digitalização, etc.

Modelando esse processo pode-se prever o comportamento do sistema, e ainda controlar e monitorar o consumo de energia, por exemplo de uma máquina $\mathrm{CNC}$, além de produzir dados para pesquisas futuras ou manutenções preditivas.

No entanto, um dos problemas da modelagem do sistema é o tempo de construção do mesmo, pois como menciona Monostori et al. (2016), desde a concepção do projeto, passando por distribuição de dispositivos até consolidação do modelo, o tempo é muito alto e os processos envolvidos são dinâmicos, podendo sofrer alterações.

Um dos objetivos em termos de utilização do CPS em nosso estudo é a aquisição de dados a partir do sensor, e reunindo as informações produtivas da máquina, cruza-se as informações para gerar o monitoramento e um gêmeo digital dela.

Na pesquisa desenvolvida a partir deste trabalho, o primeiro passo é a aquisição de dados confiáveis a partir do sensor instalado na máquina, onde a leitura dos dados é depurada com a utilização de um gateway, que posteriormente são enviados à um aplicativo conectado ao sistema Ciber - Físico. Um feedback pode ser fornecido através do espaço cibernético, atuando como um supervisor autônomo, podendo reconfigurar o status da máquina e priorizando decisões para otimizar o processo. Particularmente em nosso sistema os sensores estão coordenados a realizar leituras do consumo de energia do CNC, e através da rede de comunicação enviar dados a plataforma em nuvem.

\subsection{IOT E IIOT}

De acordo com Ray (2018), equipamentos que dispõe de tecnologia que conectam a IoT podem processar dados, coletar dados e trocar dados a partir de um aplicativo fundamentado em nuvem e, por conseguinte, realizar trabalhos locais em um chão de fábrica. Um dispositivo que detém as propriedades do sistema IoT pode abrigar diversas 
funções, como por exemplo, adaptabilidade a novos equipamentos, autoconfiguração, modelagem de sistemas, controle, como define Ray (2018).

Uma boa vantagem do recurso IoT é a adaptabilidade a diversos padrões, a saber: LoRaWAN, IEEE 802.15.4, LR-WPAN, entre outras. Além desses padrões, também estão inseridos os protocolos tradicionais como, Fieldbus, Common Industrial Protocol, Profibus e Profinet, P-Net, Interbus, HART, Modbus, entre outros. De acordo com Ray (2018), os protocolos e os padrões são necessários para a intercomunicação entre os diversos dispositivos e equipamentos que dispõe de rede. Para normatizar e padronizar esses protocolos, é necessário a chancela de órgãos internacionais, como por exemplo a IEC e a ISO.

A IEC (International Electrotechnical Commission) é uma organização fundada em 1906, com a missão de normatizar e padronizar as questões técnicas relacionadas a parte elétrica. Por outro lado, a ISO (International Organization for Standardization) foi fundada em 1947, com a união de grêmios na intenção de criar normas técnicas e/ou padronizações técnicas para diversas áreas. Tanto a IEC quanto a ISO uniram-se para comparar normas técnicas internacionais, onde, os padrões são analisados e adotados em conjunto, e posteriormente serem enviados aos órgãos nacionais para a aprovação mediante a $75 \%$ ou mais dos integrantes, e assim ser considerado uma norma internacional.

As redes sem fio estão cada vez mais atuantes em um sistema fabril, pois de acordo com Junyang Shi, Sha, e Yang (2018), esse modus operandi não precisa de uma estrutura física baseada em cabeamento, o que permite a redução de custos de implementação. Outro fator importante é que os sensores e atuadores que trabalham no padrão IEEE 802.15.4, geralmente atuam com baixo consumo de energia, facilitando a retirada do uso de baterias. Há outros sistemas padronizados dentro dos protocolos de comunicações, como por exemplo Wireless HART, que utiliza um dispositivo gateway com o controle de diversos sensores, formando uma malha de rede local, como define Junyang Shi, Sha, e Yang (2018). Essa pesquisa utilizará exatamente desse recurso, pois entendemos que para o controle dos sensores instalados indica um baixo custo de implementação e manutenção.

Há uma nova categoria de IoT disseminada no meio industrial conhecida como IIoT (Internet das Coisas Industriais), onde conforme Urquhart e McAuley (2018), esse 
novo modelo de Internet trabalha com infraestrutura de aspectos industriais, como por exemplo, nuvem, banco de dados, CPS, servidores, sensores e atuadores, maquinas e equipamentos.

A IIoT possui conexão à rede mundial de computadores, mas também tem a funcionalidade de transformar dispositivos comuns em elementos conectados. Portanto, de acordo com Sisinni et al. (2018), os benefícios são enormes e amplamente defendidos para a implantação no sistema industrial.

O modelo IIoT foi utilizado industrialmente pela GE (General Eletric) em 2012, com tecnologias conectivas de baixo custo e baixo consumo de energia, e em redes sem fio, onde segundo Aazam, Zeadally, e Harras (2018), os dados recolhidos dos diversos dispositivos na planta industrial e aliados a isso um controle de dados e análise de dados concisos, formam a base da IIoT. A figura 7 indica a hierarquia entre CPS, IIoT e IoT dentro do contexto da Indústria 4.0.

Figura 7 - Hierarquia dentro do contexto da Indústria 4.0

\section{INDÚSTRIA 4.0}

\section{IoT}

\section{IIoT}

\section{CPS}

Fonte: Autor

A principal diferença entre IoT e IIoT está nos elementos ou dispositivos que cada conceito atua, pois segundo Sisinni et al. (2018), a IoT traz soluções para consumidores diretos enquanto que a IIoT trabalha a partir do chão de fábrica, utilizando os dispositivos (sensores atuadores, etc.) para gerir, analisar ou até mesmo controlar as maquinas. A 
semelhança entre IoT e IIoT está na forma de acesso e controle dos dispositivos, porém a IIoT é mais aprofundada em questões de conectividade, utilizando protocolos mais elaborados e padronizados, segurança e confiabilidade mais robustos, tratamento de dados em plataformas eficientes, assim como destaca Sisinni et al. (2018).

O IIoT tem a capacidade de suportar diversas tecnologias, facilitando a obtenção de informações oriundas dos sensores possibilitando a realização do translado dos dados a Big Data e retornado à informação ao sensor após uma análise, configurando assim uma malha fechada como indica Witkowski (2017).

Segundo Aazam, Zeadally, e Harras (2018), devido à produção de dados em quantidades maiores, maior poder de comunicação e armazenamento, mais a interoperabilidade do maquinário, tornam deficitários e vulneráveis o sistema, onde as invasões e as pilhagens de dados ficam frequentes em um espaço IIoT. A IIoT participa com alguns modelos para a sua conformação, que são: a interconexão entre os dispositivos e sua contribuição em todos os níveis, a extensão em termos de atuação (não havendo limite para tal) e todo objeto para se tornar "coisa" deve ter um sensor acoplado (ou atuador) com acesso à rede. Portanto, deve-se desenvolver um sistema que engloba as questões ciberfísicas, Big Data e dispositivos com inteligência como propõe Boyes et al. (2018).

É importante destacar que o IIoT precisa de um bom dispositivo integrador para um melhor desempenho, em termos de conectividade e processamento de dados locais, fazendo uso de algoritmos sincronizadores e com baixo consumo energético, como define Aazam, Zeadally, e Harras (2018).

Também verifica-se que a parte conectiva de uma IIoT abrange uma grande concordância de arquiteturas tanto digitais como físicas, com ou sem fio, mas como indica Sisinni et al. (2018), os protocolos hierarquizam as camadas de comunicação disponibilizando as informações de forma mais rápida. Ainda no contexto da IIoT, os gateways têm papel fundamental no poder de conectividade de diversos equipamentos e vinculação com provedores para tratamento dos dados coletados. No entanto alguns recursos precisam de melhor desenvolvimento para alavancar a independência dos aplicativos, como propõe Verba et al. (2017).

O gateway tem a funcionalidade de enviar as informações sobre os dispositivos que estão configurados na rede que ele atua, e também as informações sobre os aplicativos 
utilizados, pois toda configuração elementar de aplicativos e dispositivos precisam estar em sintonia com o gateway como recomenda Verba et al. (2017).

Há muitos problemas cibernéticos em relação a vulnerabilidade dos sistemas que participam de uma rede IoT, principalmente com dispositivos que trabalham diversas horas online e sem práticas adequadas de segurança, o que traz uma preocupação considerável de todo o sistema implementado, como menciona Urquhart e McAuley (2018). Para que isso não ocorra a empresa deve criar tarefas de atualização de software e firmware tanto do sistema como dos dispositivos instalados, além de associar tudo isso a um bom software antivírus.

Muitos dos equipamentos legados tiveram um incremento em sua funcionalidade devido à instalação de sensores e atuadores, resultam em diversas possibilidades de otimização na produção, melhora do gerenciamento de uma máquina ou linha de máquinas e promove um efetivo controle da eficiência energética como sugere Aazam, Zeadally, e Harras (2018). A partir dessa dinâmica descrita anteriormente, a pesquisa propõe investir em três frentes: a instalação de sensor em uma máquina legada $\mathrm{CNC}$, o monitoramento do consumo de energia e a digitalização do processo sendo tudo isso disponibilizado através de uma rede IIoT.

Segundo Ray (2018), os dados gerados a partir de dispositivos conectados à IoT devem fornecer parametrização para direcionar o posicionamento ideal em decisões gerenciais, como também aprimorar os recursos de análise do equipamento disposto remotamente. Um exemplo dessa formulação é a forma como dispor o sensoriamento, a coleta de dados, a análise e, posteriormente, com todas essas informações, traçar diretrizes de acompanhamento do consumo energético da máquina legada. Portanto, para a pesquisa, a grande vantagem é poder verificar em diversos momentos e através de diversos dispositivos cibernéticos (entre eles a IIoT), o consumo de energia real, podendo equacionar os horários de funcionamento, como também a precificação e também a demanda necessária da rede, conforme indicação de Aazam, Zeadally, e Harras (2018).

\subsection{A DIGITALIZAÇÃO PARA COSOLIDAR O MODELO FÍSICO}

Podemos definir o gêmeo digital como sendo portador de três frentes, a saber: dispositivos ou equipamentos físicos, modelos dos dispositivos digitalizados e os dados provenientes dos dispositivos físicos. Segundo a descrição de Qi e Tao (2018), o gêmeo 
digital é um espelho da planta física (ou equipamento), simulando integralmente todos os movimentos do modelo real.

A importância que se entende em implementar o gêmeo digital está em sua funcionalidade em todos os níveis do processo, desde as informações do produto, até o funcionamento complexo de um sensor. Porém, como menciona Halenar et al. (2019), o gêmeo digital não pode ser percebido como ferramenta única na solução de problemas encontrados no chão de fábrica, mas sim como um modelo de colaboração para tomadas de decisão.

Construindo o modelo digital pode-se encontrar defeitos no design que não são percebidos no modelo físico, impedindo horas de testes ou substituições desnecessárias. Outra vantagem verificada, segundo Qi e Tao (2018), são as mudanças rápidas e precisas, pois dispondo de dados estatísticos e comportamentos já padronizados facilitam essas modificações.

A integração cibernética está relacionada com a aquisição de gêmeo digital, pois como descrevem Qi e Tao (2018), é a forma mais viável de conexão entre o mundo físico e o virtual, provendo as indústrias de uma ferramenta habilitadora de otimização de processos.

Os gêmeos digitas operam com dados do mundo físico como também do próprio modelo virtual, o que para a Big Data não há necessidade. Para que haja um funcionamento correto do gêmeo digital a fonte fornecedora de dados deve ser segura, provendo uma interpretação conveniente com o modelo físico. Segundo Qi e Tao (2018), o funcionamento do gêmeo digital também depende de dados que são coletados a partir dos sensores para posteriormente, através de softwares de transferência atracarem na nuvem, onde finalmente armazenados possam ser utilizados no modelo proposto. A partir do processo descrito, monitora-se o modelo digital inserindo os dados em tempo real e cooperando nos processos de diagnósticos de falhas, otimização de processos, previsões de manutenções, entre outras.

O gêmeo digital e a Big Data por vezes se confundem na maneira que o processo de aquisição de dados e transferência acontecem, como também as decisões a partir dos mesmos. Porém, segundo a descrição de Qi e Tao (2018), eles diferem em muitos detalhes, a começar que o gêmeo digital recebe os dados para criar um paralelo virtual de 
funcionamento do mundo físico, enquanto que a Big Data trabalha essencialmente com decisões estatísticas.

A Big Data é focada em ferramentas de processamento de dados avançadas, softwares de algoritmos sólidos, plataformas em nuvem, alocação de dados, enquanto o gêmeo digital se consolida em consistência de dados. Outra diferença marcante é que o gêmeo digital tem características menos eficientes na questão velocidade/volume de dados, até porque a Big Data trabalha com ferramentas altamente eficiente nesses atributos, segundo Qi e Tao (2018).

É possível, por exemplo, disponibilizar o modelo digital como uma ferramenta de interação entre usuário final e fornecedor do produto, por isso a necessidade da criação de modelos minimalistas.

Um dos proveitos da digitalização é o tempo de redução nas alterações do modelo físico, pois como indica Martins, Costelha, e Neves (2019), os testes e as configurações podem ser ajustadas sem que interfira no modelo real, ou ainda, construir modelos diferentes para possíveis implementações. O gêmeo digital deve incluir os aspectos dimensionais da fábrica (espaço físico), a circulação de operadores com regras comportamentais, circulação de materiais, entre outros.

Em Resumo, segundo Qi e Tao (2018), o gêmeo digital trabalha com as tecnologias de realidade virtual, realidade aumentada, simulação, entre outras, enquanto que a Big Data se baseia nas tecnologias de mineração de dados, verificação de dados, validação de dados, volume, velocidade, variedade e valor. Portanto, em muitos casos o dado proveniente de algum equipamento necessariamente passa pela Big Data para posteriormente ser usado em um gêmeo digital.

A implementação de sensores e atuadores, e associada com a coleta de dados estruturada, possibilitou a interconexão do mundo físico com o mundo virtual através de simuladores completos, permitindo nova vida aos dispositivos industriais mais legados, segundo Martins, Costelha, e Neves (2019).

Para uma virtualização adequada, onde simulação e software devem ser de alto nível, em nossa pesquisa utilizaremos o software da Siemens, Process Simulate, pois garante um esforço menor em termos de programação.

Os dados coletados que alimentam o modelo digital seguem a seguinte dinâmica: 
1) dados de fabricação;

2) dados de materiais ou produtos;

3) dados de funcionamento, como por exemplo, temperatura, pressão, consumo de energia, etc. A figura 8 mostra a organização para a construção de um modelo virtual.

Figura 8 - Processo para a geração do Modelo Virtual

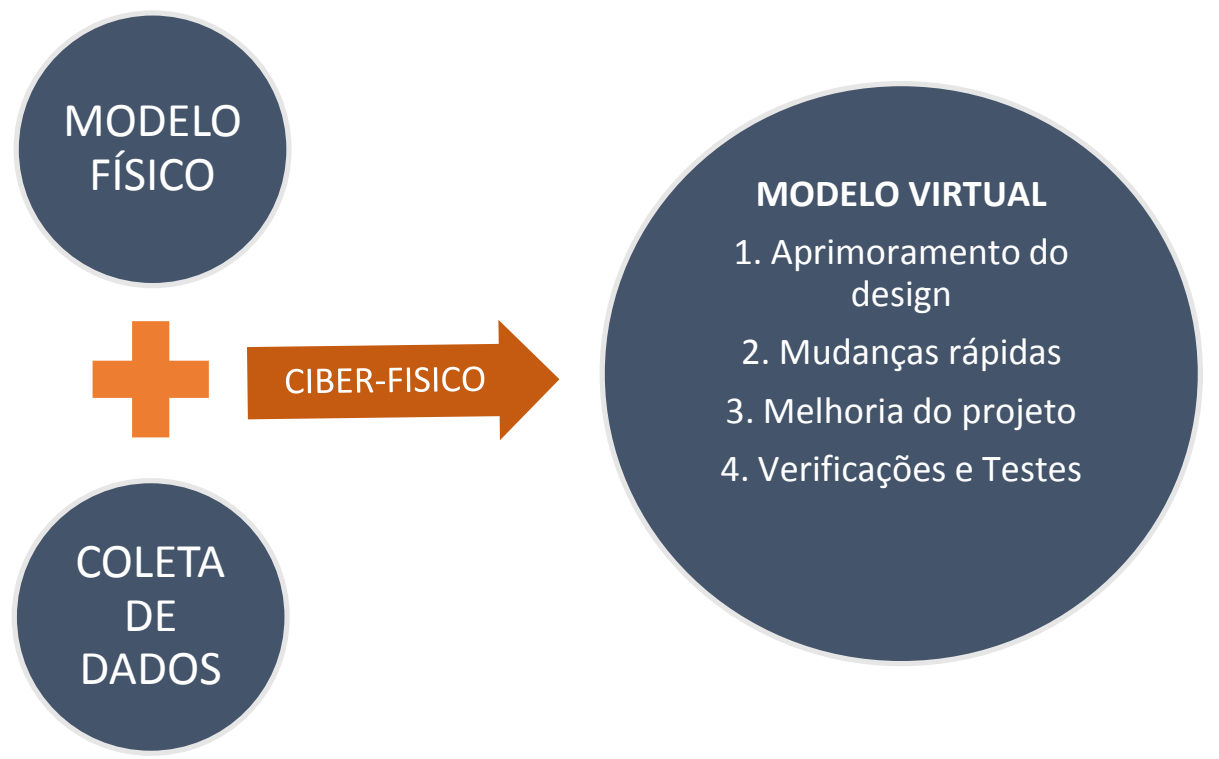

Fonte: Autor

Ao determinar uma falha através do modelo virtual, a análise do problema tornase imediata, transferindo a determinação para o modelo físico. Isso propicia uma previsibilidade de manutenção ou como indica Qi e Tao (2018), até mesmo uma diminuição na provável parada inesperada, que é um grande causador de altos custos de produção.

Alguns processos podem ser criados a partir de dados coletados do sensor e relacionadas com dados históricos do mesmo dispositivo, testando em cenários do modelo digital as prováveis anomalias e direcionando as decisões a partir de informações expressivas, como sugere Jantunen et al. (2018).

Os maiores problemas analisados a partir de pesquisas relacionadas são:

a) sincronização em tempo real; 
b) modelos virtuais imprecisos;

c) não conformidade na avaliação do ambiente real;

d) previsões não condizentes com o modelo real (capacidade de processamento do modelo físico);

e) processamento de dados insuficientes.

Segundo Jantunen et al. (2018), por meio de um gêmeo digital pode-se concluir que os princípios da indústria 4.0 se consolida nas seguintes tecnologias: interoperabilidade entre mundo físico e virtual, informações em tempo real e mudanças rápidas a partir do modelo digital.

Em relação à pesquisa, a parte operacional baseia-se na fundamentação de análise, previsibilidade e otimização dentro de dados minerados a partir do sensoriamento da máquina legada. De posse dos dados do consumo energético, pode-se simular novos cenários para encontrar a melhor forma de consumo de energia, a partir da construção de um gêmeo digital.

\subsection{ASPECTOS PARA INCLUSÃO DAS PMES NA INDÚSTRIA 4.0}

De acordo com Rauch et al. (2018), o ingresso das PME's no processo da Industria 4.0 passa por uma abordagem mais acentuada, a partir das necessidades previstas para estas empresas, pois muitas tecnologias associadas ao setor 4.0 não terão as implicações anunciadas para as mesmas. Segundo Davies (2015), o Parlamento Europeu concedeu bilhões de euros em empréstimos com o intuito de capitalizar esses recursos para as PME's européias, principalmente em projetos de alta eficiência tecnológica, como por exemplo, energia, digitalização, robótica, entre outros.

O termômetro abalizador na questão da implementação das tecnologias encontradas no contexto da Indústria 4.0 são os processos primários, como por exemplo, IoT, CPS e digitalização. No entanto, segundo Sommer (2015), essas tecnologias estão muito longe de serem introduzidas nas PME's por diversos fatores: baixo investimento em equipamentos com tecnologia associada a Industria 4.0; incertezas na aquisição de modalidades que proporcionam acesso a dados (Big Data); projetos voltados a 
implementação do conceito de indústria 4.0; capacitação do agregado humano em relação a novas tecnologias.

As PME's enfrentam o desafio de entenderem qual o real sentido em trazer tecnologias associadas ao setor 4.0, pois conforme Schröder (2016), as grandes empresas já se posicionaram em favor de angariar processos relacionados a essa nova frente, distanciando ainda mais as PME's do cenário industrial competitivo. Logicamente as tecnologias associadas a Industria 4.0 podem melhorar o gerenciamento industrial nas PME's, devido ao barateamento de muitos sistemas e por possuíram uma maior flexibilização de acordo com o escopo, como indica Moeuf et al. (2018).

Como propõe Ganzarain e Errasti (2016), pode-se escalonar um projeto de implementação de alguns conceitos da indústria 4.0 em nível gerencial, desde situações onde: dentro da empresa não existe discussões sobre o assunto apesar de algum conhecimento; há abordagens especificas como um projeto em análise para um setor da empresa; e pôr fim a concepção de um plano a partir de uma necessidade verificada. A figura 9 traz questões levantadas no que diz respeito a inclusão das PME's no contexto da indústria 4.0.

Figura 9 - Questões levantadas a partir da análise do contexto da Indústria 4.0 para com as PME's
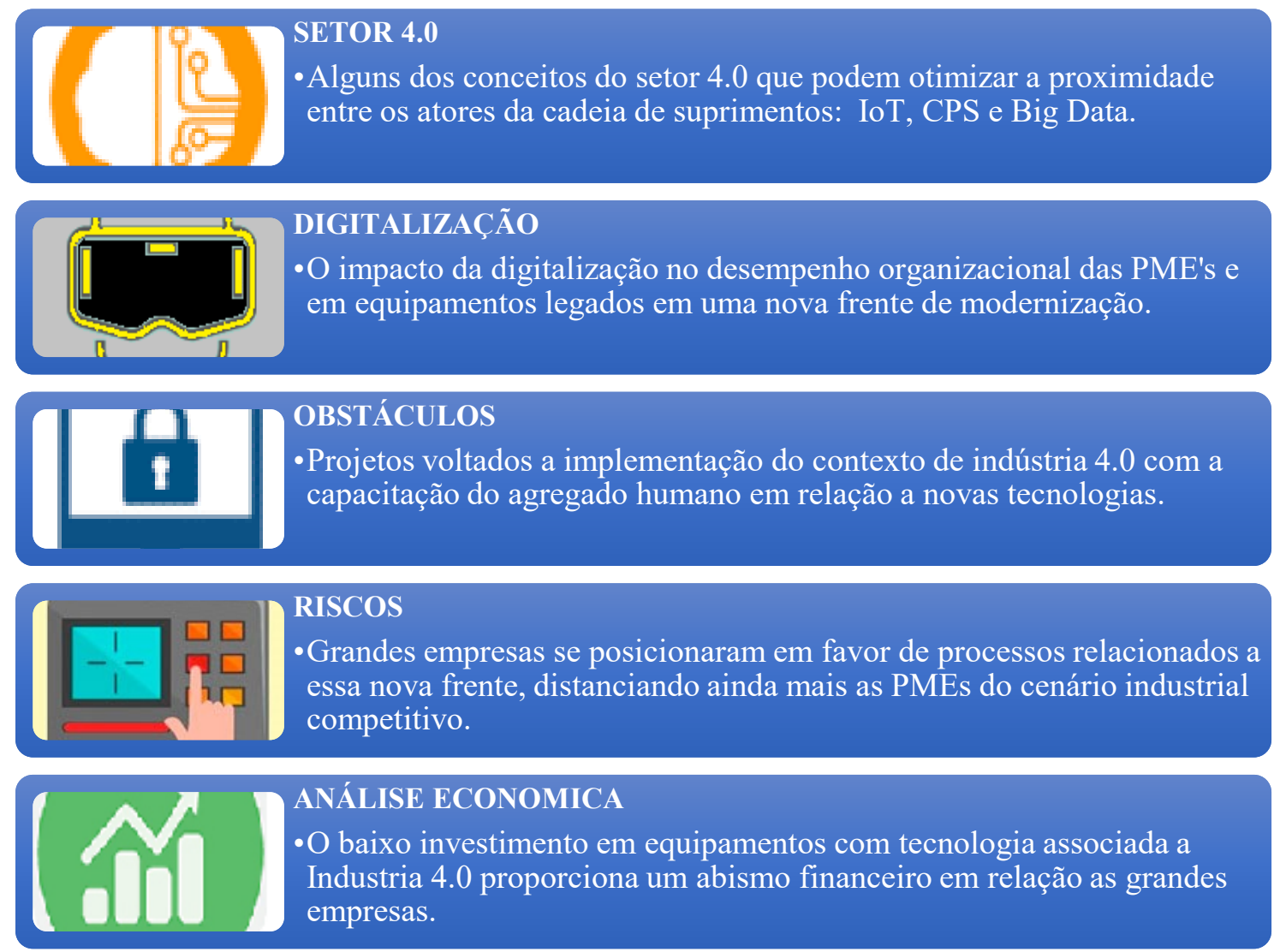

Fonte: Autor 
Outro problema detectado a partir das PME's, é o fato de que muitas não possuem departamentos de TI ou computação, o que segundo Schröder (2016), diminui a integração com outras empresas da cadeia de suprimentos, mas principalmente no quesito relacionamento com o cliente. Também é possível notar que a maior parte do equipamento em pequenas e médias empresas são legadas, dificultando ainda mais a integração horizontal na aquisição de dados.

As PME's também utilizam métodos mais adaptativos em relação a modelo de negócios, como por exemplo flexibilização produtiva, reatividade tecnológica, e principalmente otimizações em processos, como indica Moeuf et al. (2018).

A condição de trabalhar com padrões e protocolos na questão da conectividade de rede para as grandes empresas é questão primordial para interagir com CPS. Entretanto, para as PME's, o modelo de rede é mais adaptativo, o que torna a vulnerabilidade cibernética muito alta, como adverte Schröder (2016).

A tecnologia mais usada atualmente pelas PME's é a computação em nuvem, pois como indica o estudo do Moeuf et al. (2018), 65\% trabalham com essa ferramenta, Fonte: Autor.

entretanto, a extensão do uso dos dados encontrados na nuvem para fornecer um meio analítico com uso da Big Data, praticamente não existe. É notório que o aspecto da digitalização de processos, de maquinas ou até mesmo de todo chão de fábrica, faz parte do modelo de negócios das grandes empresas, por outro lado, de acordo com Schröder (2016), as PME's não participam desse modelo por diversos problemas, porém o maior destacadamente é o financeiro. Para as PME's, a simulação de cenários indica a otimização de processos, melhora da capacitação na análise de dados, indica consideravelmente a tomada de decisões e pode-se praticar intervenções em tempo real, como sugere Moeuf et al. (2018).

Evidentemente, pesquisas relacionadas a utilização da Big Data pelas PME's devem ser aprofundadas, embora, conforme estudo de Moeuf et al. (2018), tem que se pensar em formas adequadas para a implementação da Big Data em PME's, pois este paradigma engloba questões como segurança de dados, armazenamento de dados, analise com técnicas adequadas, entre outras.

O contexto da indústria 4.0 não encontra uma uniformidade na questão de aplicabilidade de tecnologias, porém em uma breve indicação por Schröder (2016), isso 
se deve ao fato de uma produção e combinação tecnológica variada, o que impede a utilização de certas metodologias por parte das PME's.

A partir do contexto apresentado, o estudo visa identificar formas de acesso ao setor 4.0 por parte das PME's de modo conciso, com pequenas incursões tecnológicas, como por exemplo a implementação de sensores em maquinas legadas para monitoramento remoto, e ainda associado a isso, a digitalização do processo, o que motiva a criação de um gêmeo digital, e ainda traz um processo de atualização das competências de acordo com a proposta de Ganzarain e Errasti (2016).

\subsection{O PROCESSO DE RETROFIT}

O Retrofit tem importância vital para as PME's migrarem em direção ao contexto da indústria 4.0, pois como indica Bakir, Bakir, e Engels (2018), esse método eleva a qualidade do processo produtivo com proveito e qualidade no detalhamento da operação, e além disso proporciona a utilização do maquinário existente com diminuição de custo de aquisição.

Sabe-se que o ingresso das empresas no contexto da indústria 4.0 deve ser gradual e planejada, principalmente as PME's, onde, como propõe Lins et al. (2019), os investimentos acabam por considerar aspectos econômicos, tecnológicos e socioeconômicos culturais. A admissão de elementos ligados a indústria 4.0 apresenta enormes desafios às empresas que miram entrar nesse processo, embora os maquinários não estejam atualizados, o caminho para uma modernização passa inevitavelmente por implementar dispositivos que traz conectividade e possibilite a intercomunicação entre o meio físico com o meio digital, como propõe Arjoni et al. (2018).

De acordo com Lins et al. (2019), algumas pesquisas levam-nos a pontuar questões comuns para se implementar um Retrofit adequado, que são: o equipamento deve oferecer condições para adaptabilidade; inserção de novas tecnologias e/ou soluções; não possuir restrições de cunho econômico;

Podemos considerar que muitas implementações de Retrofit estão associadas a aquisição de novos sensores e/ou atuadores, que tendo um julgamento lógico, estes dispositivos melhoram a capacidade de controle e gerenciamento do equipamento,

entretanto, outras diretrizes devem ser consideradas, principalmente econômicas e 
técnicas como propõe Bakir, Bakir, e Engels (2018). É de suma importância o alinhamento tecnológico em um parque industrial com os novos conceitos, pois como define R. G. Lins et al. (2017), a concorrência por mercados tornou-se muito forte e com abalizamento global isso indica atualização drástica e necessária das empresas.

Um dos problemas encontrados na questão de implementação do Retrofit é a dinâmica do design, onde conforme R. G. Lins et al. (2017), simplesmente não cabe adaptabilidade de novos dispositivos ou não possui espaço suficiente para novos equipamentos modernos onde possam melhorar o desempenho. A partir do que propõe Gao e Wang (2017), para maximizar a vida útil de um equipamento, deve-se ter um projeto que contemple o padrão para o pós vida de recuperar, reciclar, redesenhar, reduzir, remanufaturar e reutilizar, onde podemos incluir nessa dinâmica o Retrofit da máquina que indique essa necessidade. A figura 10 indica o método de aquisição de dados para a virtualização do processo em estudo.

Figura 10 - Aquisição de dados a partir do retrofit

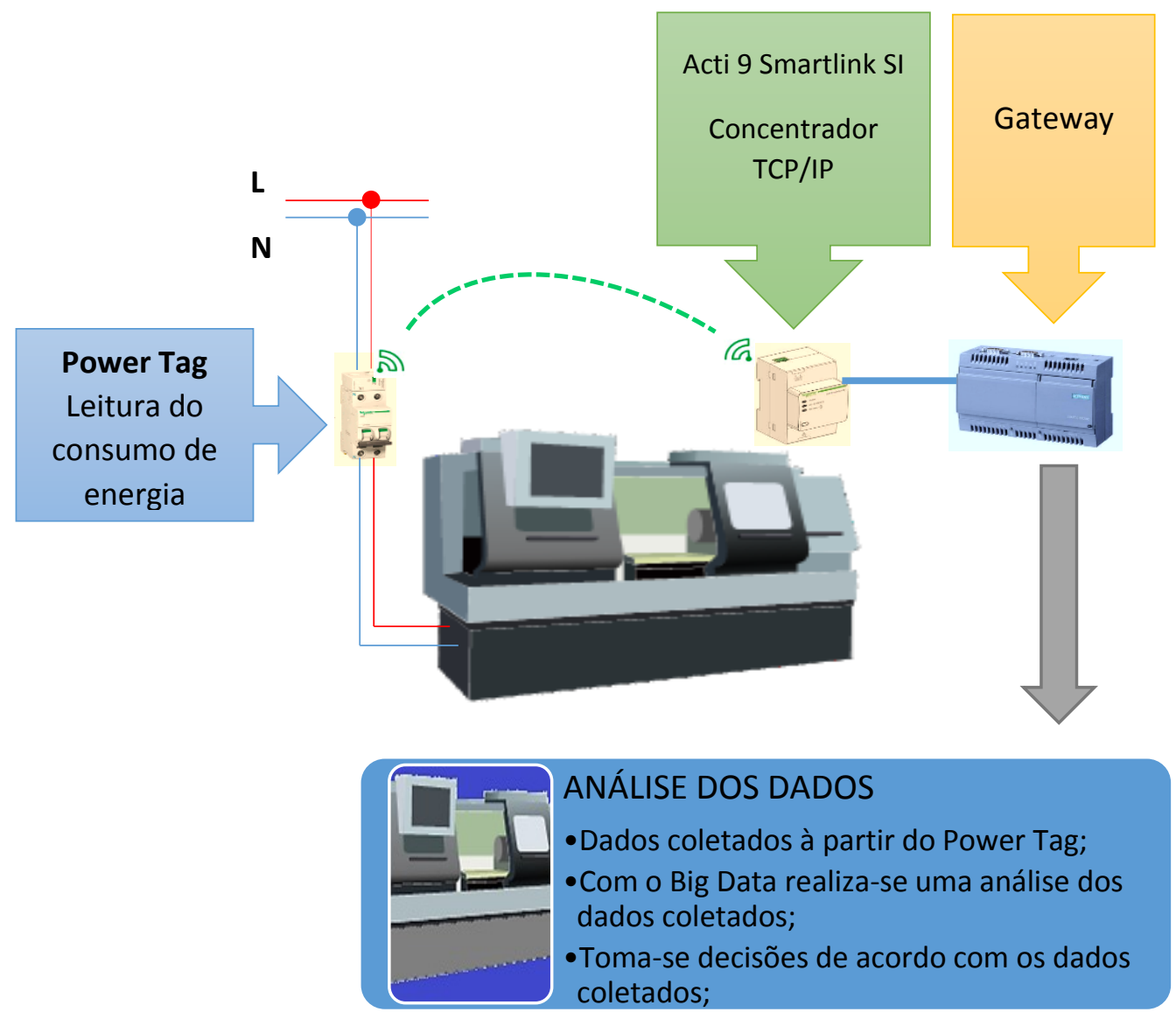

Fonte: Autor 
O modelo de uma máquina $\mathrm{CNC}$ comum, diversos elementos elétricos, eletrônicos e mecânicos realizam uma série de movimentos que originam dados analógicos ou digitais. Segundo R. G. Lins et al. (2017), os dados gerados podem ser inspecionados ou admitidos por uma plataforma digital, apropriando esses dados em modelos do contexto da Industria 4.0. Outro proveito a partir dos dados criados, ainda segundo R. G. Lins et al. (2017), é a geração de um gêmeo digital da própria máquina em questão, pois o modelo digital cria um espelho a partir do modelo real, no qual traz o benefício de maior controle e tomadas de decisões.

O Retrofit revela através dos dados, um novo modo dentro da conscientização sustentável, aprimorando os benefícios econômicos e ambientais em todos os níveis da cadeia produtiva, e indicando rentabilidades em materiais, energia, manutenção, assim como alude Gao e Wang (2017).

Por isso, a atualização deve ser acentuada e com investimentos pontuais na transformação do maquinário legado, até por que segundo Nsiah et al. (2018), os investimentos descoordenados e pouco efetivos podem minorar as oportunidades das PME's, como também sofrer em uma migração futura.

O processo de Retrofit está dividido em dispositivos dos equipamentos operando no chão de fábrica e os dispositivos inseridos nesses equipamentos legados, principalmente, como é o caso, a máquina não ter qualquer conectividade com IoT, CPS e Big Data, e é por isso que com a introdução de sensores que possuem esses atributos a máquina legada pode ser considerada com conectividade dentro do paradigma da Indústria 4.0, como indica Lins et al. (2019).

Algumas etapas cumprem-se na implantação de um processo de Retrofit, de acordo com Lins et al. (2019): integrar a comunicação existente adaptando-a as plataformas de IoT e CPS; observar o tamanho da rede para não incorrer no problema de escalabilidade; a conectividade deve apresentar-se em tempo real para garantir as tomadas de decisões instantâneas; a adoção de aplicativos para um real monitoramento a distância; possuir nuvem com acesso ao Big Data para conseguir armazenar, analisar e manusear os dados gerados.

O diagnóstico e prognóstico da condição de funcionamento da máquina é essencial para manter a saúde e direcionamento do aspecto produtivo, porém como aborda Gao e Wang (2017), a partir da análise em tempo real pode-se coletar os dados oriundos 
dos equipamentos e fornecer de forma adequada aos usuários através de softwares projetados para tal cometimento. Os dados com característica de baixa latência são gravados e analisados junto ao gateway, em uma linha que consolida o caminho até o banco de dados e torna as decisões mais viáveis, as otimizações mais efetivas e os processos mais rápidos, como propõe Bakir, Bakir, e Engels (2018).

O maquinário em linhas de produção deve possuir conectividade para integrarem um sistema que mantenha uma eficiência produtiva, entretanto, como analisa R. G. Lins et al. (2017), as arquiteturas de conexão apresentadas reúnem diferentes sistemas e protocolos, o que contribui para que a comunicabilidade entre os componentes seja mais descentralizada.

Para alavancar o Retrofit e participar do contexto da Indústria 4.0, deve-se basear a implementação em conectividade, aplicação e infraestrutura e ainda aliado a esse processo, introduzir aplicativos que reúnam condições de representar todo o contexto apresentado, onde, de acordo com Lins et al. (2019), agiliza posteriormente a instalação de novos dispositivos ou recursos na mesma planta.

Um exemplo de adequação do Retrofit em máquinas, são os CNC's que possuem características bem definidas de flexibilidade, seja em trocas de ferramentas ou posicionamentos da usinagem, o que não interfere na implementação do Retrofit, principalmente com relação a eficiência no consumo de energia enquanto realiza o trabalho, pois de acordo com Gao e Wang (2017), o consumo de energia está atrelado a vida útil da ferramenta e, portanto, torna-se necessário o monitoramento integral da máquina.

Para o projeto de Retrofit, estamos utilizando uma máquina CNC legada de cunho acadêmico, com sensores e gateways instalados para controle a distância via aplicativo. Como sugere Arjoni et al. (2018), a criação de um gêmeo digital será desenvolvido, onde visa operacionalizar a máquina virtualmente como acontece fisicamente.

O monitoramento da máquina $\mathrm{CNC}$ neste caso, aplica-se ao consumo de energia de acordo com o estado da mesma (Standby ou Usinando), onde segundo Gao e Wang (2017), a eficiência no consumo de energia pode ser avaliada através do consumo de corrente do motor gerando dados, e posteriormente os dados são enviados a uma plataforma de análise e convertidos em um aplicativo para visualizações. 


\section{FUNDAMENTAÇÃO TEÓRICA}

Esta fundamentação teórica está abalizada em dois pilares, que são: conectividade como ponto de partida para máquinas legadas participarem do contexto da Indústria 4.0, e o Retrofit para introduzir a conectividade necessária.

\subsection{DISPOSITIVOS PARA CONECTIVIDADE}

Os diversos dispositivos de uma planta fabril sempre foram produzidos por diferentes empresas, com diferentes protocolos, softwares e drivers proprietários, o que determina em muitos casos a falta de conectividade e integração dos múltiplos componentes.

O crescimento volumoso de dispositivos inteligentes que podem acessar a internet em plantas industriais impulsionou o crescimento do conceito de IIoT e possibilitou a criação de um ambiente conectado em todas as linhas da cadeia de suprimentos.

A partir da década de 1980 as redes de comunicações industriais desenvolveramse vertiginosamente em áreas como Tecnologia da informação e Tecnologias da Informação e Comunicação (TIC), onde este último segundo Wollschlaeger, Sauter, e Jasperneite (2017a), possibilitou a criação de aplicativos baseados em nuvem.

Entretanto, a automação tem como núcleo central as trocas e captações de informações e dados através de sensores e atuadores sem que haja uma interferência direta do homem, o que traz movimentos voltados para a WEB e transformando as redes industriais em potenciais polos de implementação da IoT (ou IIoT) e CPS, como descreve Wollschlaeger, Sauter, e Jasperneite (2017a).

As redes de automação baseadas em barramento de campo constituem a base da comunicação industrial e chegam nos níveis mais baixos da pirâmide de automação, trazendo confiabilidade na rede cabeada instalada e, por conseguinte denota uma maior resistência na utilização das redes sem fio por parte das empresas. Os controladores (ISO/IEC/IEEE) atuam dentro da arquitetura de uma rede estabelecida, onde auxiliam os sensores e atuadores a organizarem as respostas enquanto inseridos na máquina, através da conexão com um barramento, como indica Wollschlaeger, Sauter, e Jasperneite (2017a). 
De acordo com Wollschlaeger, Sauter, e Jasperneite (2017a), as redes sem fio baseiam-se em redes padronizadas como IEEE 802.11 e IEEE 802.15, e estas facilitam as conexões sem fio dentro da automação por não terem impedimentos em implementar novas plantas em um chão de fábrica.

O IEEE a partir da Ethernet padrão trabalha em melhorar a confiabilidade para dispositivos que funcionem em tempo real reduzindo a latência, tornar independente as taxas de transmissão de dados, minimizar falhas sem adicionar hardware para tal cometimento, maior e melhor segurança e ainda uma conectividade eficiente entre os diversos fabricantes.

A Ethernet Industrial e os enfoques industriais sem fio quando apontadas a transmissão de dados abastecem o sistema de comunicação sob a demanda dos aplicativos, mas segundo Wollschlaeger, Sauter, e Jasperneite (2017a), a flexibilização também contribui com esses sistemas em uma troca de dados nas camadas superiores sem a interferência de redes de comunicações que vem de camadas inferiores.

A IIoT cresce rapidamente em termos quantitativos e qualitativos, porém as redes sem fio necessitam melhorar campos que funcionem baseados em confiabilidade se comparados as topologias com fio, principalmente na questão da latência quando utilizado em malhas fechadas, o que deixa em níveis críticos a questão do tempo como demonstrado por Wollschlaeger, Sauter, e Jasperneite (2017a).

\subsection{GERENCIAMENTO DE DADOS}

As redes de comunicação e os sistemas de gerenciamento de dados são facilitadores tecnológicos para flexibilizar e dinamizar a conectividade em uma planta fabril, onde segundo Del et al. (2019), eles são a porta para o contexto da Indústria 4.0 em termos de conectividade, a saber: a infraestrutura de comunicação e o gerenciamento de dados.

Em determinados aspectos, o gerenciamento de dados e a conectividade devem ter interoperabilidade e serem elaborados a partir de parâmetros flexíveis e seguros com o viés de eficiência, aplicando controle rigoroso para a latência, confiabilidade e emissão de dados, a partir de aplicativos industriais, como descreve Del et al. (2019). 
O gerenciamento eficaz de uma rede de comunicação que integram decisões descentralizadas, depende de uma arquitetura hierárquica que administra os dados em circulação, onde por sua vez, pode originar a flexibilização das conexões sem fio, adicionando uma maior capacidade da rede em detectar problemas e reagir às modificações que ocorrem em ambientes industriais.

De acordo com Del et al. (2019), o gerenciamento de dados, como também da sua utilização em tempo real, proporciona uma forma mais disseminada dos dados nas ações de geração, armazenamento e acesso, o que pode com isso adequar as estratégias de comunicação especificas em cada camada quando os recursos são empregados de forma otimizada por setores de TI.

As diversas camadas que constituem a arquitetura organizacional da rede de comunicação trazem a dificuldade de gerenciamento dos dados em trânsito, o que permite condições de satisfação e aplicabilidade com várias estratégias de latência e confiabilidade.

Para que o desempenho da rede de comunicação processe as informações de forma satisfatória é necessária uma operação em conjunto com o fornecimento de dados, onde de acordo com Del et al. (2019), os dados podem não ser disponibilizados e replicados de forma ordenada ou ainda não atingirem uma área especifica devido a questões proprietárias.

Essa arquitetura descentralizada tem a manobrabilidade de decidir em que nós os dados podem trafegar e quais responsabilidades poderá trazer ao gerenciamento de dados, pois conforme Del et al. (2019), esse tipo de arquitetura é eficiente em ambientes industriais que tem a necessidade da implementação de uma rede que funcionará a partir da IIoT.

As efetivações dos aplicativos com a essência de conectividade e, portanto, com diversas frentes voltadas para diferentes tipos de nós da rede, não podem creditar em comunicações específicas, mas em aspectos como gerenciamento, distribuição e confiabilidade de dados, como indica Del et al. (2019). 


\subsection{GATEWAYS PARA GERENCIAR DADOS}

Os nós em um sistema proxy podem ser nomeados, o que ocasiona a diminuição da latência em termos de acessibilidade dos dados e ao mesmo tempo podem aumentar a conectividade, o armazenamento e a informação. Entretanto, quando são implementados aplicativos, os limites de latência em decorrência da entrega de dados são superiores de ponta a ponta, o que reflete em atraso de fornecimento de dados aos consumidores, como descreve Del et al. (2019).

Os nós de uma rede de comunicação atuam como coletores de dados provenientes, por exemplo, de um sensor, sendo que os dados coletados são retransmitidos aos nós dos gateways, e utilizando redes sem fio que possuem uma largura de banda maior e eficiente. Entretanto, segundo Del et al. (2019), os gateways têm a função de gerenciar e coletar dados (por exemplo, chão de fábrica) e retransmiti-los através dos vários nós ao controle central

A elaboração de um ambiente baseado em conectividade no contexto da indústria 4.0 torna-se complexo a partir da implementação de diversos aplicativos e diferentes dispositivos, pois de acordo com Del et al. (2019), precisam alinhar precisão, sincronismo e efetividade em termos da comunicabilidade, e ainda paralelo a isso, encontram a rápida necessidade da transição da estrutura de cabeamento já estabelecida para a estrutura das redes sem fio, onde este último baseia-se a IIoT.

Segundo Del et al. (2019), a conectividade que abrange os níveis mais altos na pirâmide de comunicação em relação aos aplicativos destacados, funciona em um tempo entre $5 \mathrm{~ms}$ até $20 \mathrm{~ms}$ devido a latência, o que proporciona uma maior confiabilidade em termos de taxa de transferência de dados e segurança mais efetiva.

\subsection{OPC UA E O GERENCIAMENTO DE NÓS}

Em meados da década de noventa do século 20, uma força tarefa foi designada para resolver o problema com o padrão Plug \& Play para drivers, tornando-o um sistema amigável em termos de acesso de dados para automação que eram fundamentados em Windows, como indica Mahnke, Leitner, e Damm (2009). Para tanto, houve muitos 
esforços em padronizar ainda mais os softwares de automação, principalmente em dispositivos que operam em chão de fábrica como por exemplo, sistemas de gerenciamento, interfaces de barramento e protocolos de redes de comunicações.

O OPC foi criado com o direcionamento industrial em que três especificações foram categorizadas e desenvolvidas: Alarme e Eventos, acesso a dados e acesso a dados históricos. O OPC agrupa as condições em nós de comunicação em meio aos sistemas com trocas de informações e modelagem de dados, onde descrevem os elementos disponíveis, como indica Mahnke, Leitner, e Damm (2009).

No início desse século foi criado o OPC UA, que pode ser usado pelos sistemas operacionais Mac da Apple e Linux, além do utilizado pelo Windows o OPC Classic, o que possibilitou a interconexão de diferentes dispositivos com diversos sistemas e softwares.

É importante destacar que o OPC UA possui todas as funções do OPC Classic, porém com tecnologias mais avançadas em termos de protocolos de automação, uma maior interoperabilidade nas conexões e trocas de dados, garantindo a eficiência operacional do setor industrial.

De acordo com entendimento de Mahnke, Leitner, e Damm (2009), o cliente OPC UA tem a liberdade de implementar funcionalidades que participam da camada de aplicativos, onde esses aplicativos podem conter suas informações e passá-las a aplicativos de terceiros denominado de cliente UA.

Uma das características especiais do OPC UA é a universalidade no desenvolvimento do padrão, como o apelo de fornecedores, clientes e principalmente desenvolvedores de softwares. Entretanto, essa universalidade conserva o benefício da interconectividade entre clientes e servidores, mas também entre servidores e servidores, proporcionando acesso aos dados em tempo real, um monitoramento aos alarmes e eventos de forma melhorada, como também acesso e aquisição aos dados históricos, além de outras aplicações relacionadas. A seguir, na figura 11 a apresentação da arquitetura básica do OPC UA. 
Figura 11 - Arquitetura básica do OPC UA

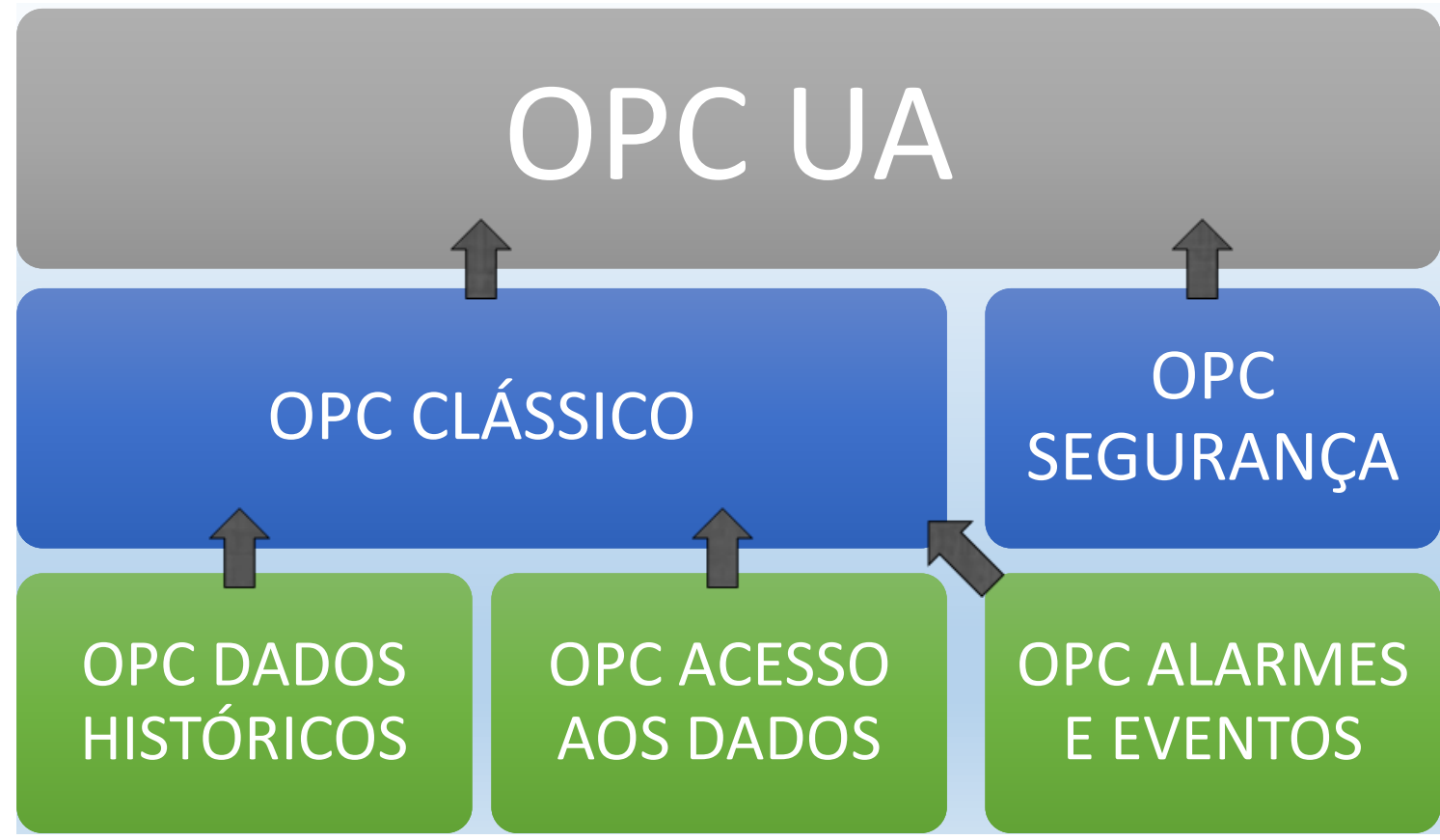

Fonte: Autor “Adaptado de” Mahnke, Leitner e Damm (2009), p. 27

Os protocolos de automação para a conectividade são compatíveis com todas as versões, inclusive o OPC UA, que já está altamente inserido no meio industrial e sua funcionalidade trabalha com todos os modelos de dados, porém, de acordo com Wollschlaeger, Sauter, e Jasperneite (2017a), a partir do provedor é necessário otimizar as tecnologias industriais para atender as condições particulares dos diferentes aplicativos.

Com a modelagem de dados pode-se determinar os objetos indispensáveis e sujeitar um modelo de informação com o OPC UA, onde segundo Mahnke, Leitner, e Damm (2009), esse conceito permite que um cliente tenha acesso aos dados menores sem o imperativo de conhecer todo o processo modelado através de um mapeamento protocolado, porém admitindo o acréscimo de novos protocolos no futuro.

Segundo Mahnke, Leitner, e Damm (2009), há um modelo de informação extensível e orientado a objetos comportando dados complexos dos aplicativos, padronizando informações pelas organizações e utilizando-se dos mecanismos e da infraestrutura do OPC UA para que esses dados sejam compartilhados.

É importante destacar que o OPC UA participa ativamente do processo da implementação do contexto de indústria 4.0, a partir de conceitos de independência na 
comunicação entre os vetores plataforma e fornecedor, segurança de dados e inteligência de dados descentralizadas, e abrem caminho para a IIoT (ou IoT), negócios inteligentes, fabricas inteligentes, entre outras.

\subsection{O RETROFIT COMO ADAPTABILIDADE DE DISPOSITIVOS}

As indústrias possuem o desafio imediato de planejar e avaliar a situação de migração para o contexto da indústria 4.0, em que suas linhas de produção com equipamentos legados, em muitos casos, não possuem uma solução viável, com abordagem ecológica e custos baixos para implementar essas novas tecnologias.

Em geral, os equipamentos em uma fábrica são de diferentes fornecedores, com diversas topologias de comunicação, além de soluções proprietárias em termos de softwares de gerenciamento de dados ou programas estabelecidos, dificultando a intercomunicação entre as diferentes máquinas.

O conceito de modernização de equipamentos legados cria uma solução de baixo custo no aspecto de investimento, além de promover a base fabril instalada ao status de reutilização com o acrescimento de novas tecnologias, onde conforme T. Lins e Oliveira (2020), supre o imperativo de adquirir um novo equipamento ou até mesmo construir um totalmente novo.

O Retrofit funciona como forma de adaptar novos dispositivos aos equipamentos legados, o que pode direcionar os mesmos ao contexto da indústria 4.0, porém as tecnologias inovadoras precisam ser avaliadas a partir do setor 4.0, como também os recursos a serem indicados para tal cometimento, pois os processos implementados atualmente são específicos para certos equipamentos, o que dificulta o procedimento a ser acometido, como indica T. Lins e Oliveira (2020).

A proposta de Retrofit pode ser realizada com uma adaptação de baixo custo, pois insere no equipamento legado tecnologias acessíveis como por exemplo, Sensores IoT, Gateways de comunicação, entre outros, mas também sistemas que utilizam desses dispositivos instalados como Digital Twin (Gêmeo Digital), Realidade aumentada, Serviço Web, para que a partir de toda essa gama de condições assistidas, possa gerenciar o equipamento e adquirir dados para as tomadas de decisões. 
De modo geral, os trabalhos acadêmicos pouco mencionam o Retrofit de um equipamento legado a condição de adaptabilidade a indústria 4.0, pois verificam em maior parte dos casos, que a reestruturação do equipamento deve seguir padrões definidos por seus fabricantes, e por isso mantém seus aspectos construtivos padronizados.

Como o contexto da indústria 4.0 apresenta três grandezas no processo da implementação e gerenciamento, que são, integração vertical, integração horizontal e engenharia de ponta a ponta na cadeia de valor, quando confrontados esses paradigmas criam a visualização que relaciona o ciclo de vida de um equipamento com a valorização que este passa a fornecer, como descreve Stock e Seliger (2016).

É importante destacar que a conectividade é parte fundamental em um Retrofit baseado no contexto da indústria 4.0, pois a comunicação entre os diversos equipamentos e a rede mundial de computadores através da IIoT e o CPS garantem a versatilidade nas decisões no chão de fábrica.

\subsection{A CONECTIVIDADE COMO BASE PARA O RETROFIT}

A finalidade desta pesquisa é realizar o Retrofit em máquinas, principalmente máquina $\mathrm{CNC}$, que em muitos casos não apresentam recursos voltados para o conceito de indústria 4.0.

De acordo com T. Lins e Oliveira (2020), os equipamentos que devem passar por um processo de Retrofit possuem baixo apelo de conectividade com a rede mundial de computadores (WEB), além de serem limitados na questão da intercomunicação sem fio e infraestrutura de aplicação de dispositivos alinhadas com a internet das coisas industriais (IIoT). O ponto de partida para realizar o Retrofit em um equipamento é avaliar o quanto de automatização a máquina possui, e quais tecnologias e recursos devem ser abordados para alavancar a sua inserção no modelo da Industria 4.0. O Retrofit consiste em determinar quais partes serão substituídas, a partir de um mapeamento detalhado da máquina sob análise, onde segundo Etz, Brantner, e Kastner (2020), coleta-se os dados do estado real do equipamento e problematiza as necessidades encontradas para posteriores soluções planejadas. A figura 12 sugere um mapeamento de uma máquina legada para implementar o Retrofit. 
Figura 12 - Mapeamento detalhado da máquina para análise do retrofit

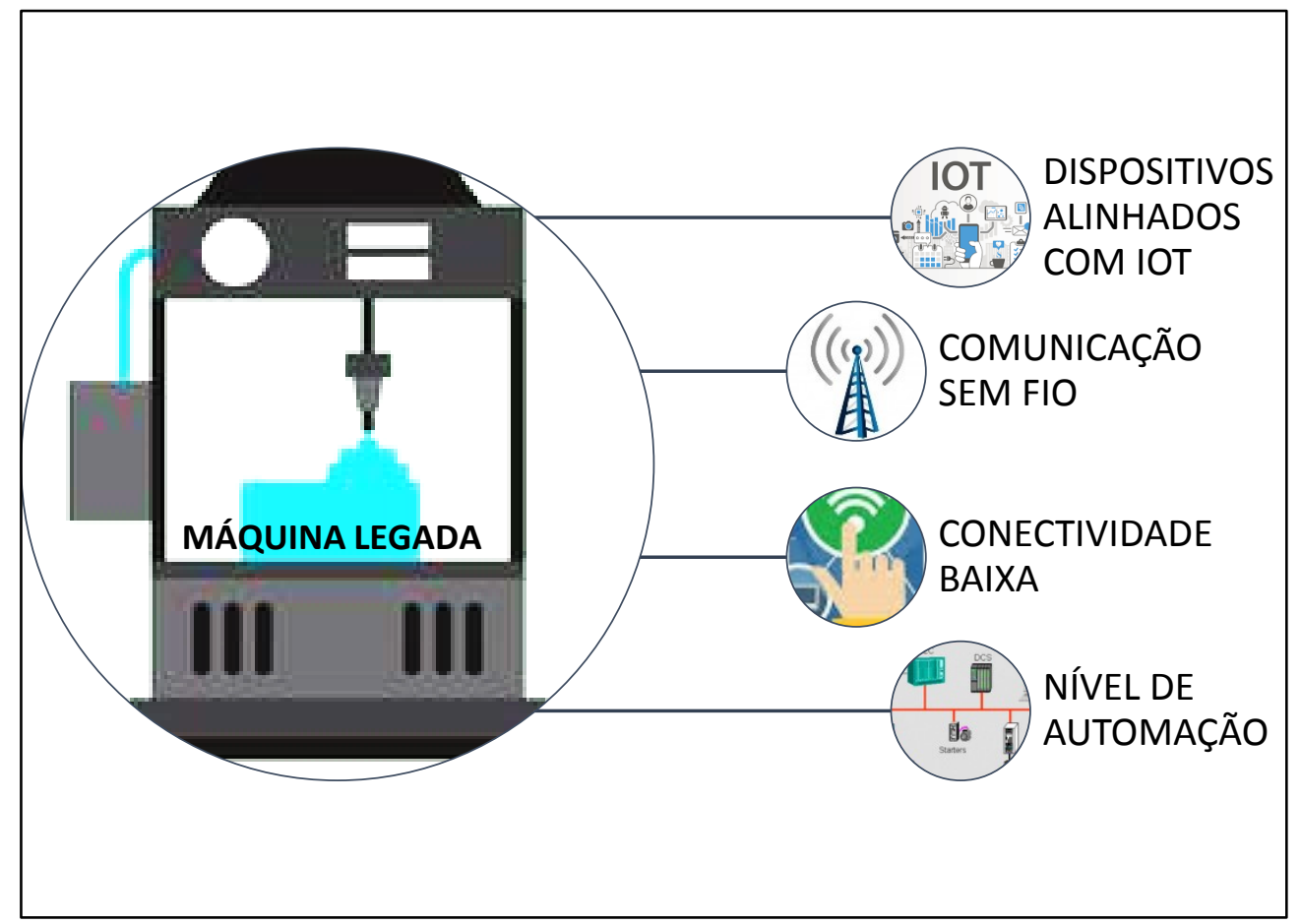

Fonte: Autor

O mapeamento do equipamento que se objetiva o Retrofit é o primeiro passo para levantar as características e as soluções que ele possui. Entretanto, conforme T. Lins e Oliveira (2020), a descrição que se constrói a partir do mapeamento determina qual a profundidade do investimento alocado para implementar a solução, como por exemplo, classificação dos imperativos e melhoramentos, analise dos protocolos de comunicação e redes de comunicação e gerenciamento unificado de rede (quando se implementa rede de comunicação). A metodologia abordada para o projeto de Retrofit traz as condições funcionais do equipamento, como também o modelo de dados em uma base para estruturar e atualizar as máquinas com prospecção para a indústria 4.0.

Alguns projetos de Retrofit visam a substituição total ou parcial de certos dispositivos instalados, como a substituição de CPU's para melhorar o processamento de dados, motores para uma performance melhor, fontes de energia para melhorar a eficiência energética, entre outras. Entretanto, com a demanda de tecnologias sem fio está rapidamente se estabelecendo como por exemplo, tablets, smartphones, entre outras, segundo Etz, Brantner, e Kastner (2020), o Retrofit pode alavancar o equipamento legado com a implementação de dispositivos que interajam com a WEB, através de arquiteturas 
de softwares aperfeiçoadas, sensores que se conectam à rede de comunicação, sem que isso interfira nos processos estabelecidos do maquinário.

O principal impacto a partir do Retrofit é a transformação digital que pode ser proporcionado agregando valor ao equipamento legado, melhorando a eficiência produtiva e reduzindo os defeitos bem como também as paradas não programadas. Entretanto, pode-se elencar algumas desvantagens pontuais na implementação do Retrofit, que são:

- Custo-benefício no que diz respeito ao tempo de resposta para o processo de renovação;

- Investimento em treinamento dependendo do projeto;

- A empresa deve estar posicionada na Industria 3.0 para facilitar a transição a indústria 4.0;

Um ponto importante em relação ao Retrofit é a adaptação às funcionalidades dos dispositivos sem fio, onde melhora o desempenho do monitoramento dos processos vigentes no equipamento, pois essa modernização é descentralizada em relação ao fabricante do equipamento, o que elimina a obrigatoriedade de softwares proprietários como fonte gerenciadora dos dados adquiridos.

O Retrofit pode contribuir em uma valoração sustentável com viés industrial, principalmente nas camadas econômicas, sociais e ambientais, a partir do desenvolvimento de projetos que, segundo Stock e Seliger (2016), possa abranger o ciclo de vida que contém as fases da reutilização, remanufatura, reciclagem, recuperação e descarte.

\section{MODELAMENTO DO PROBLEMA}

A finalidade deste estudo é realizar o Retrofit em máquinas legadas, com foco em conectividade, que em muitos casos não apresentam recursos voltados para o contexto da Indústria 4.0. Outra motivação é a abordagem sobre eficiência no consumo de energia, pois conforme menciona Gao e Wang (2017, p. 4) "Dados de energia medidos são analisados em conjunto com configurações de usinagem e qualidade dimensional das peças usinadas, para determinar a condição ideal de operação que permite a melhor eficiência energética”. 


\subsection{IMPLEMENTAÇÂO DE DISPOSITIVOS E LEVANTAMENTO DE DADOS}

Através de sensores instalados estrategicamente em máquinas, como por exemplo em um CNC legado, podem-se adquirir os dados necessários em relação ao consumo de energia, onde posteriormente usam-se estas informações para delinear manutenções, melhoria na eficiência do consumo de energia, entre outras. Quando há uma eficiência produtiva em relação aos recursos desprendidos, automaticamente o consumo de energia reduz, afirma Thoben, Wiesner, e Wuest (2017).

A aquisição de dados de funcionamento por meio de uma máquina legada CNC é a próxima etapa, onde com essas informações organizadas, pode-se construir um Gêmeo Digital com todos os parâmetros necessários para um melhor entendimento do processo. Após a implementação do Gêmeo Digital, será possível avaliar qual o nível de Retrofit aplicável ao CNC, seja em termos de comunicabilidade, sensoriamento, entre outros.

Agregado à redução do consumo de energia, pode-se identificar o monitoramento e coleta de dados, principalmente por meio de dispositivos adequados para tal aplicação. Considerando a gama de dispositivos de IoT que funcionam em novas frentes de trabalho, segundo Hill et al. (2018), a expectativa é aumentar a quantidade de dados gerados. A partir desse entendimento, adotar a decisão descentralizada para o processamento de dados no local e em tempo real pode ser a melhor forma de conter esse volume de dados. Portanto, o processo associado ao consumo de energia eficiente juntamente com a coleta de dados formará um dos pilares da indústria 4.0, a conhecida computação em nuvem (Cloud Computing).

A implementação de dispositivos chamados de Gateways, como também os Smart links, viabilizarão o acesso de máquinas $\mathrm{CNC}$ à nuvem, gerando dados com foco em consumo de energia para posteriormente analisá-los e utilizá-los na tomada de decisões. A perspectiva é a geração de grandes quantidades de dados, criando o desafio expressivo para uma contextualização e compreensão, no que se refere à sua aplicação.

Com os dados obtidos, e juntamente com a digitalização previamente realizada, pode-se entrar no modelamento de novos cenários, principalmente com base no funcionamento da máquina, prevendo por exemplo as manutenções preditivas ou paradas programadas. O panorama ideal é o fechamento de todo um ciclo, que pela sequência se dá pela digitalização do processo que a máquina trabalha, Retrofit com a implementação 
de dispositivos adequados, aquisição de dados e envio à nuvem, análise dos dados recebidos e, por fim, tomada de decisão baseado nesta última análise.

\subsection{DISPOSITIVO DE MEDIÇÃO DE PARÂMETROS DE ENERGIA}

O Acti 9 Smartlink SI D foi desenvolvido para realizar medições, controles e proteções a partir de soluções que estão associadas ao consumo de energia, mas também tem a função de concentrar os dados que são procedentes dos sensores sem fio chamados de PowerTags (Schneider Electric, 2016). O sistema de comunicação embarcado neste dispositivo tem a característica de trocas de dados em tempo real com as centrais de monitoramento através do protocolo de comunicação Modbus (Schneider Electric, 2016).

O Acti 9 Smartlink pode ser usado para diferentes sistemas de supervisão, como por exemplo quadros de distribuição, mas neste trabalho de pesquisa foi instalado para monitorar o $\mathrm{CNC}$ legado, direcionado a monitorar o consumo de energia, além de outras variáveis associadas à qualidade de energia consumida, como por exemplo, o Fator de Potência. O conjunto de monitoramento do consumo de energia consiste no Acti 9 Smartlink SI D e o Sensor de energia PowerTag.

O trabalho conjunto do dispositivo Acti 9 Smartlink e o sensor PowerTag traz vantagens e serviços como funções de cálculo, monitoramento do desequilíbrio de carga, monitoramento da perda de energia e tensão, gestão e regulamentação de energia e aplicativos de telemetria (Schneider Electric, 2016). Há a necessidade de instalação do software EcoStruxure Power Commission da empresa Schneider Electric em um PC para o comissionamento dos dispositivos Acti 9 e PowerTag, onde é construída não só a parametrização, mas também o carregamento dos dados provenientes deles.

O concentrador Acti 9 Smartlink possui conexão sem fio através do protocolo Modbus TCP/IP, o que permite um comissionamento mais eficiente e rápido, onde é realizado por meio de páginas Web do próprio dispositivo como também a configuração da rede pode ser alcançada pelo mesmo sistema (Schneider Electric, 2016).

O Acti 9 Smartlink recebe as informações de medição da rede (que neste estudo participa da medição da entrada de energia do CNC legado) a cada 5 segundos, onde essas informações vêm dos Sensores PowerTag que enviam os dados por meio de Rádio Frequência (RF) (Schneider Electric, 2016). Além das atualizações permanentes em termos de envios de dados, o sensor PowerTag possui alarmes recorrentes para níveis de 
cargas, como também envia um alarme quando o dispositivo está desligado (Schneider Electric, 2016). Uma das vantagens do concentrador Acti 9 é a possibilidade de configurar até vinte sensores PowerTag, até porque ele possui até 16 canais de RF. Porém, destacase um planejamento bem definido para a instalação de diversos sensores PowerTag, pois eles podem ter dificuldade de integração com o concentrador Acti 9 por não terem bem definido o canal de comunicação (Schneider Electric, 2016).

O comissionamento é construído via PC (ou Laptop) conectado através de um cabo Ethernet, permitindo acesso a página Web do dispositivo e configurando sistema de comunicação Ethernet para receber as mensagens pelo serviço Modbus TCP/IP caracterizado no modelo cliente/servidor (Schneider Electric, 2016). Este modelo cliente/servidor possui 4 tipos de mensagens, que são: Modbus Request (solicitação), indicação Modbus, Modbus Response (resposta) e Confirmação Modbus, como indicado na figura 13.

Figura 13 - Sistema de mensagens cliente/servidor pelo serviço Modbus

\begin{tabular}{|c|c|c|c|}
\hline \multirow{2}{*}{$\begin{array}{l}\text { Modbus } \\
\text { Cliente }\end{array}$} & Solicitação & Indicação & \multirow{2}{*}{$\begin{array}{l}\text { Modbus } \\
\text { Servidor }\end{array}$} \\
\hline & & & \\
\hline
\end{tabular}

Fonte: Autor "adaptado de" Schneider Electric (2016), p. 45

As informações que são trocadas em tempo real utilizam-se dos serviços de mensagens Modbus a partir do modelo cliente/servidor para interligar dispositivos com aplicativos, como também aplicativos e dispositivos que trabalham com HMI e SCADA, ou conectar a um PC para fornecer serviços online (Schneider Electric, 2016).

Entre o Acti 9 Smartlink da Schneider e o Siemens SIMATIC IOT 2040 (que será apresentado no próximo tópico) existe uma conexão de rede cabeada, onde a partir desta conexão os dados coletados no dispositivo Acti 9 Smartlink são organizados e enviados para IOT 2040, e posteriormente retransmitido para a nuvem através do nó Mindconnect disponível no Node-Red. 


\subsection{ACESSO AOS DADOS A PARTIR DA NUVEM}

O dispositivo SIMATIC IoT 2040 é a interface por trás da conectividade com a nuvem, porque cria um canal direto com ela, e ainda com um nível de segurança implementado pelo fabricante.

O MindSphere da empresa Siemens, é uma plataforma baseada em Internet das Coisas e totalmente aberta, com uma infraestrutura acessível a partir da nuvem, onde máquinas em qualquer parte do mundo possam se conectar digitalmente e ter uma análise instantânea de forma rápida, fácil e segura (Siemens 2018a).

Outra situação importante em relação a este sistema é a variedade de dispositivos conectados em um chão de fábrica, o que melhora em termos de produtividade construtiva de aplicativos e desenvolvimento de novos modelos (Siemens, 2018).

Em termos de conectividade, a plataforma permite que uma indústria conecte todos os dispositivos disponíveis associados à tecnologia da informação, com um sistema rigoroso de segurança a partir da plataforma (Siemens, 2018).

A figura 14 indica todo o mapeamento de conexões entre os dispositivos e o MindSphere. 
Figura 14 - Mapeamento e implementação das conexões entre os dispositivos

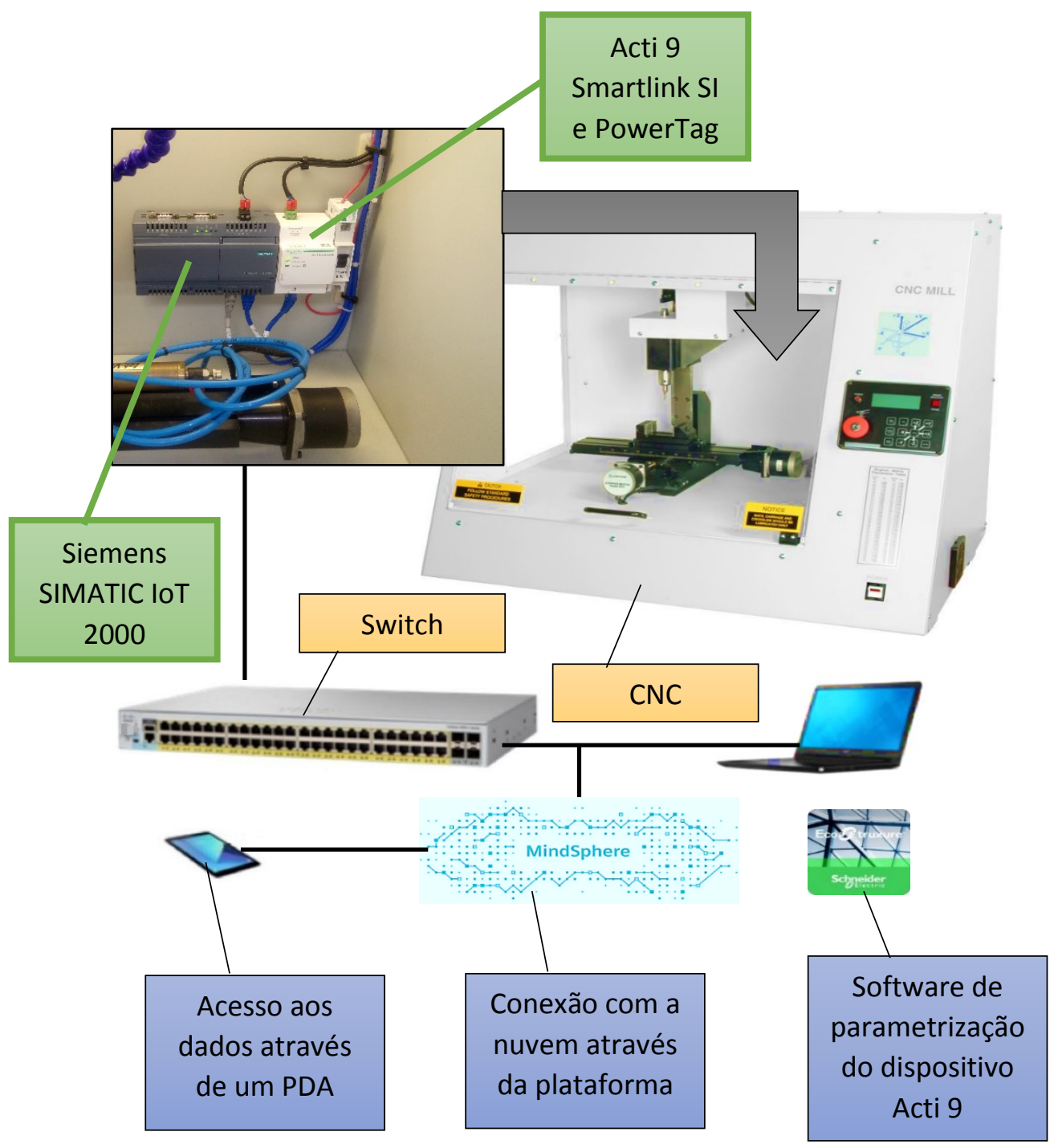

Fonte: Autor

O MindSphere é um sistema elaborado que tem a capacidade de realizar a conexão com diversos protocolos e padrões de comunicação, pois como um sistema aberto o gerenciamento é mais desenvolto e flexível. Também possui conexão facilitada com o sistema ERP (Planejamento de Recursos Empresariais), MES (Sistemas de Execução de Manufatura, SCADA (Controle de Supervisão e Aquisição de Dados), entre outros (Siemens, 2018).

Uma característica importante é a facilidade de suportar diversos protocolos de comunicação, propiciando uma conectividade simplificada, e patrocinando o ingresso de qualquer empresa nessa plataforma. O MindSphere funciona com o PaaS (Plataforma aberta de Serviço), gerando uma parceria entre os diversos ramos industriais e em diversas 
camadas produtivas. Em termos de visualização de dados ou uma simples análise, a plataforma disponibiliza as informações para que o usuário final possa realizar as devidas alterações no processo diante do diagnostico elaborado (Siemens, 2018).

Os dados trafegam em direção à nuvem por qualquer protocolo disponível, como HTTPS ou MQTT, mas também os protocolos de dispositivo participam dessa opção de conectividade, tal como OPC UA, CoAP, Modbus, LoRaWAN, 6LowPan, entre outros. A melhor opção em termos de protocolo é o OPC UA, pois a conectividade entre as máquinas e a nuvem é muito mais global (Siemens, 2018).

A configuração do caminho dos dados pode ser construída através de mapas gráficos, como por exemplo o Node-Red, tornando-o mais flexível e direcionando-o rapidamente a plataforma em nuvem MindSphere da Siemens.

É importante destacar que o MindSphere trabalha com segurança cibernética de alto padrão, baseada em sistemas IEC 62443 e ISO/IEC 27001 e BSI, referendados pelo Escritório Federal Alemão para Segurança da Informação. Os dados, tanto em movimento ou em repouso em um servidor, são criptografados e usam SSL de 256 bits/Criptografia TLS ou superior (Siemens, 2018b).

O dispositivo SIMATIC IoT 2040 utiliza um firewall interno e específico e totalmente vedada o acesso por clientes nos parâmetros de configuração. Por outro lado, o Mindconnect possui acesso em sistemas de automação apenas pelo viés de leitura para drivers de aquisição de dados. Portanto, o MindSphere recebe apenas os dados autorizados ou validados, principalmente após passar pelo firewall do dispositivo SIMATIC IoT 2040 e a criptografia mencionada anteriormente. Os dados são acessíveis em qualquer momento na plataforma MindSphere pelos detentores do projeto, mas não tem acesso aos dados sistemas não autorizados (Siemens 2018b).

\subsection{GERAÇÃO E LEITURA DOS DADOS DE ENERGIA}

O Concentrador Acti 9 Smartlink Schneider é o dispositivo responsável pela conformação dos dados que tem a procedência do PowerTag Schneider, no qual está acoplado diretamente a linha de energia que alimenta a máquina CNC. Entretanto, a configuração do dispositivo torna-se um passo importante para ler e enviar os dados 
corretamente em direção ao dispositivo Siemens SIMATIC IoT 2040 incorporado ao projeto.

Após a instalação do Concentrador Acti 9, isto é, conectado a linha elétrica da máquina $\mathrm{CNC}$, conecta-se o dispositivo ao microcomputador (ou Laptop) através de um cabo de rede para configurar e comissionar o dispositivo. No momento em que acontecer essa conexão, no ponto de rede do microcomputador surgirá o ícone mySmartLink-xxx, que permitirá acesso direto a página de comissionamento. No entanto, também pode-se instalar o software de comissionamento EcoStruxure Power Commission para que possa ter acesso sem a necessidade de entrar pelo dispositivo exibido na rede. Assim que o software está instalado, abre-se uma tela para detecção do dispositivo, e desta forma se estabelece a conexão. A figura 15 apresenta essa situação.

Figura 15 - Programa para comissionar o Acti 9 Smartlink

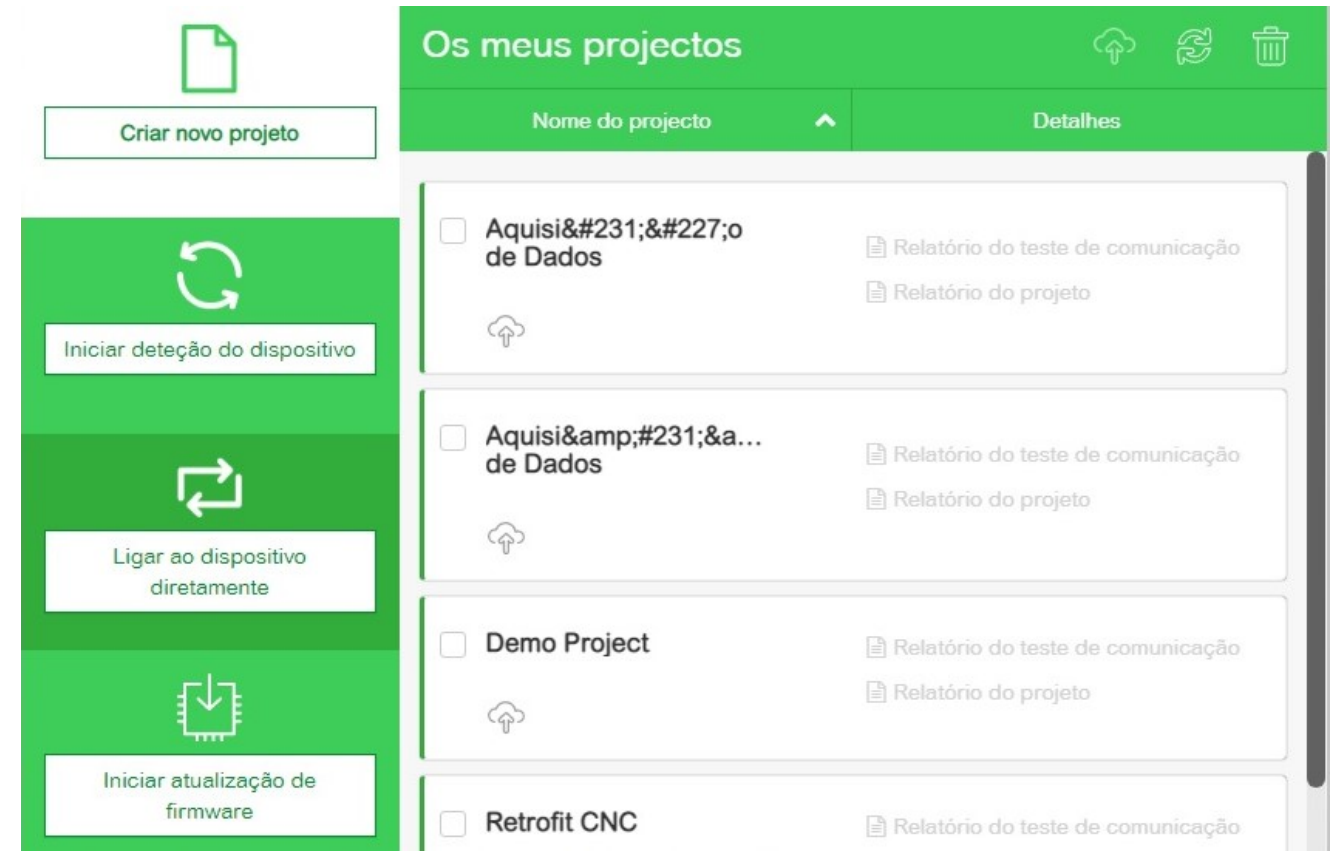

Fonte: Programa EcoStruxure Power Commission, 2021 
Depois de detectar o dispositivo Acti 9 Smartlink, o programa abre uma tela com a "Vista do Quadro de Distribuição" e a "Vista de Comunicação", onde realizam-se algumas configurações iniciais, que são: conexão com dispositivos sem fio, verificação do dispositivo em relação as ligações com as PowerTags para análise das leituras de energia, download de firmware e acionamento do dispositivo remotamente. A figura 16 apresenta essa configuração.

Figura 16 - Comissionamento do Acti 9 Smartlink e PowerTag

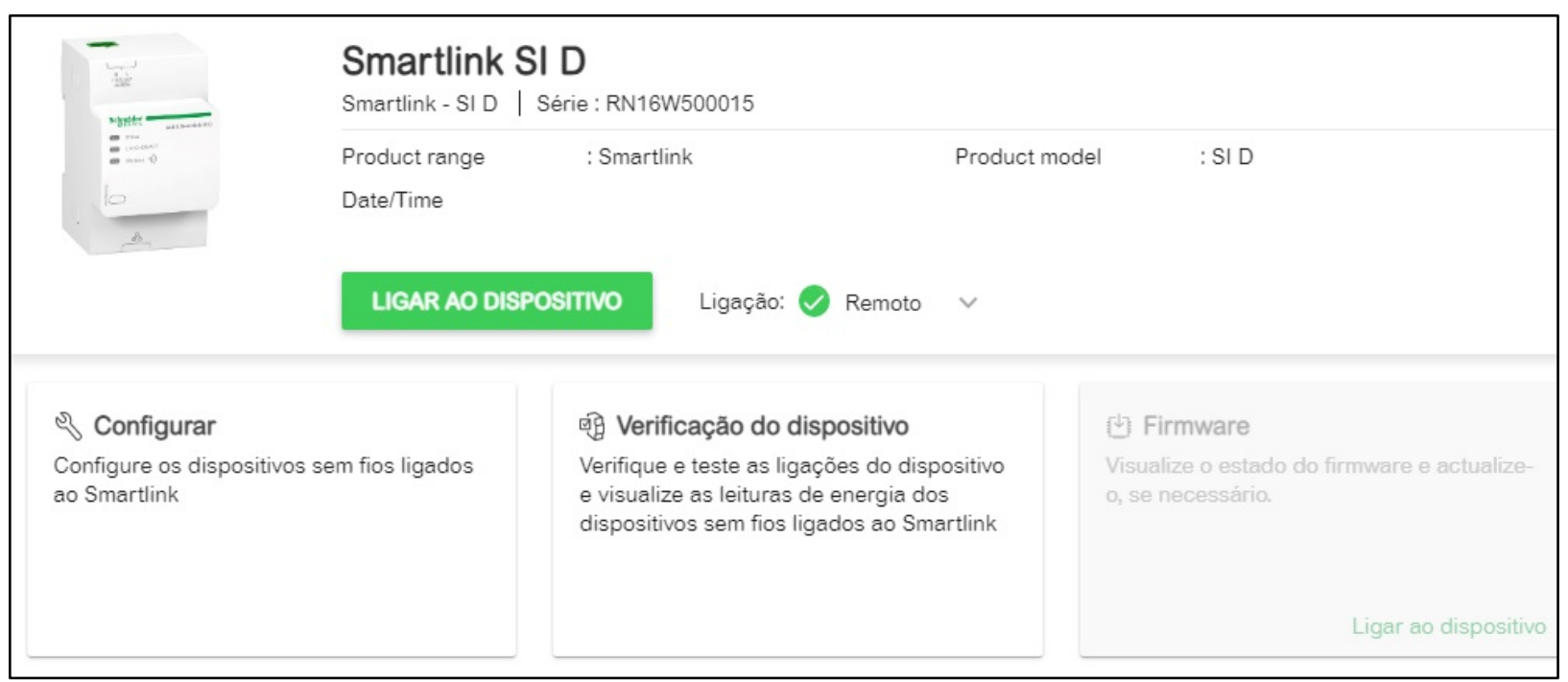

Fonte: Programa EcoStruxure Power Commission, 2021

Os parâmetros para a configuração da PowerTag seguem a sequência: nome do ativo, classificação do disjuntor associado, Sequência de fase, endereço Modbus, entre outros. Nessa pesquisa, será utilizada apenas uma PowerTag, o que facilita a configuração e a detecção é automática.

A próxima ação é a configuração do Modbus TCP/IP do Acti 9 Smartlink para poder comunicar e enviar os dados que são coletados através da PowerTag. A habilitação do filtro Modbus TCP/IP permite acesso a gravação de intervalos de endereços entre o IP Global e o IP Listado. Entretanto, é preciso acrescentar a “Exceção” para nível de acesso. Nesse ponto, pode-se inserir um máximo de dez endereços de IP no quadro "Exceção", permitindo a esses IP's o acesso a gravação. Para finalizar a configuração do Modbus TCP/IP, na área de Intervalo de endereços insere-se o IP desejado e acrescenta-se o nível de acesso.

Com o acesso resolvido abre-se a possibilidade de captação dos dados medidos, como também a conformação dos dados. Esses valores são direcionados para o formato 
de tabela Modbus, onde é feita a organização dos dados para um posterior envio. A tabela 1 apresenta a organização dos dados na conformação Modbus:

Tabela 1 - Descrição da organização dos dados na tabela Modbus

\begin{tabular}{|c|c|}
\hline DESIGNAÇÃO & DESCRIÇÃO \\
\hline Endereço & $\begin{array}{l}\text { Registro de } 16 \text { bits possibilitando ao usuário o acesso as variáveis que } \\
\text { estão em notação decimal }\end{array}$ \\
\hline $\mathbf{N}^{\mathbf{0}}$ & $\begin{array}{l}\text { Registros de } 16 \text { bits que necessitam de leitura /gravação para ter acesso às } \\
\text { informações }\end{array}$ \\
\hline $\mathbf{R W}$ & Registro designado como leitura (R) ou leitura e gravação (RW) \\
\hline $\mathbf{X}$ & $\begin{array}{l}\text { Fator de escala: está dividida em três escalas } \\
\text { - Escala X1: o valor registrado é o correto; } \\
\text { - Escala 10: o registro contém o valor multiplicado por } 10 ; \\
\text { - Escala } 0,1: \text { o registro contém o valor multiplicado por } 0,1 ;\end{array}$ \\
\hline Unidade & Unidade de medida de informação \\
\hline Tipo & Tipos de dados \\
\hline Intervalo & Faixa de valores permitidos para uma variável \\
\hline Valor Padrão & Valor padrão para uma variável \\
\hline Svd & Salva os valores em caso de ausência de energia \\
\hline Código da Função & Códigos que podem ser usados nos registros \\
\hline Descrição & Informações sobre o registro \\
\hline
\end{tabular}

Fonte: Autor “adaptado de" Schneider Acti 9 Smartlink - User Manual (2018), p. 74

De todas as informações contidas na tabela 1, o "Tipo de Dados" (associado ao endereço) possui uma relevância maior, pois é a forma como os dados serão conformados e enviados para o Acti 9 Smartlink. Nessa pesquisa será utilizado o modelo Float32, pois garante uma precisão maior nas medições, com intervalo maior de casas decimais. Outro item importante é o RW, que permite a leitura dos dados que são procedentes da PowerTag e determina o valor real que será enviado para o próximo dispositivo. A tabela 2 apresenta as possibilidades de registros para os dados em termos de valores. 
Tabela 2 - Descrição dos valores possíveis que podem ser movimentados pelo Modbus

\begin{tabular}{|c|c|c|}
\hline NOME & DESCRIÇÃO & INTERVALO \\
\hline UINT & $\begin{array}{l}\text { Inteiro e não assinado de } 16 \\
\text { bits ( } 1 \text { palavra) }\end{array}$ & $0 \ldots .65535$ \\
\hline INT & $\begin{array}{l}\text { Inteiro e assinado } 16 \text { bits } \\
\text { (1 palavra) }\end{array}$ & $-32768 \ldots+32767$ \\
\hline UINT32 & $\begin{array}{l}\text { Inteiro e não assinado de } 32 \\
\text { bits ( } 2 \text { palavras) }\end{array}$ & $0 \ldots 4294967295$ \\
\hline INT32 & $\begin{array}{l}\text { Inteiro e assinado de } 32 \text { bits ( } 2 \\
\text { palavras) }\end{array}$ & $-2147483648 \ldots+2147483647$ \\
\hline INT64 & $\begin{array}{l}\text { Inteiro e assinado de } 64 \text { bits ( } 4 \\
\text { palavras) }\end{array}$ & $\begin{array}{l}-9223372036854775808 \ldots 223372036854 \\
775807\end{array}$ \\
\hline Float32 & Valor de 32 Bits & $-3.4028 \mathrm{E}+38 \ldots+3.4028 \mathrm{E}+38$ \\
\hline ASCII & $\begin{array}{l}\text { Caractere alfanumérico de } 8 \\
\text { bits }\end{array}$ & Tabela de caracteres ASCII \\
\hline BITMAP & $\begin{array}{l}\text { Campo de } 16 \text { bits } \\
\text { (1 Palavra) }\end{array}$ & \\
\hline DATE & $\begin{array}{l}\text { Formato de acordo com o } \\
\text { padrão TI081 }\end{array}$ & \\
\hline
\end{tabular}

Fonte: Autor "adaptado de" Schneider Acti 9 Smartlink - User Manual (2018), p. 74

Os controladores programáveis Modbus mestres são referenciados por endereços do modelo de dados. Também são fornecidos ao controlador a regra de endereçamento que segue o molde de Endereço do modelo de dados $=$ endereço +1 . Porém, se o controlador estiver referenciado por endereços de protocolos, o endereçamento fica a cargo dos endereços Modbus. A tabela 3 mostra um modelo de identificação para o sistema Modbus. 
Tabela 3 - Comportamento e constituição do dado no transporte

\begin{tabular}{|c|c|}
\hline DESIGNAÇÃO & DESCRIÇÃO \\
\hline ENDEREÇO & 100 \\
\hline $\mathbf{N}^{0}$ & 6 \\
\hline $\mathbf{R W}$ & \\
\hline $\mathbf{X}$ & \\
\hline UN & \\
\hline TIPO & ASCII \\
\hline INTERVALO & \\
\hline VALOR PADRÃO & $\mathrm{N} / \mathrm{A}$ \\
\hline Svd & Y \\
\hline CÓDIGO DA FUNÇÃO & $03,100-4$ \\
\hline DESCRIÇÃO & $\mathrm{N}^{\mathrm{o}}$ de série em 12 caracteres em ASCII; 11 dígitos alfanuméricos. \\
\hline
\end{tabular}

Fonte: Autor “adaptado de” Schneider Acti 9 Smartlink - User Manual (2018), p. 77

No Acti 9 Smartlink, o ID do escravo Modbus para realizar a leitura da tabela de identificação é 255. Além da tabela de identificação do Modbus fazer parte do Acti 9 Smartlink, o dispositivo ainda dispõe de mais duas tabelas, a saber: tabela de status e a tabela de data e hora. Pode-se destacar também a tabela que traz as medições de Corrente, Tensão e Potência, que seria uma espécie de "sub tabela de medição", pois aloca as medições em endereços específicos. A tabela 4 apresenta o endereçamento das medições de corrente, tensão e potência. 
Tabela 4 - Endereçamento dos dados de medição da corrente, tensão e potência

\begin{tabular}{|c|c|}
\hline DESIGNAÇÃO & DESCRIÇÃO \\
\hline & Dados de medição de Corrente \\
\hline ENDEREÇO & 2999 \\
\hline $\mathbf{N}^{\mathbf{0}}$ & 2 \\
\hline RW & $\mathrm{R}$ \\
\hline $\mathbf{X}$ & \\
\hline UN & A \\
\hline TIPO & Float32 \\
\hline INTERVALO & \\
\hline VALOR PADRÃO & 0xFFC00000 \\
\hline Svd & $\mathrm{N}$ \\
\hline CÓDIGO DA FUNÇÃO & $03,100-4$ \\
\hline DESCRIÇÃO & Corrente RMS na fase \\
\hline & Dados de medição de Tensão \\
\hline ENDEREÇO & 3019 \\
\hline $\mathbf{N}^{\mathbf{0}}$ & 2 \\
\hline RW & $\mathrm{R}$ \\
\hline $\mathbf{X}$ & \\
\hline UN & $\mathrm{V}$ \\
\hline TIPO & Float32 \\
\hline INTERVALO & \\
\hline VALOR PADRÃO & 0xFFC00000 \\
\hline Svd & $\mathrm{N}$ \\
\hline CÓDIGO DA FUNÇÃO & $03,100-4$ \\
\hline DESCRIÇÃO & Tensão RMS na fase-fase \\
\hline & Dados de medição de Potência \\
\hline ENDEREÇO & 3053 \\
\hline $\mathbf{N}^{\mathbf{0}}$ & 2 \\
\hline RW & $\mathrm{R}$ \\
\hline $\mathbf{X}$ & \\
\hline UN & $\mathrm{W}$ \\
\hline TIPO & Float32 \\
\hline INTERVALO & \\
\hline VALOR PADRÃO & 0xFFC00000 \\
\hline Svd & $\mathrm{N}$ \\
\hline CÓDIGO DA FUNÇÃO & $03,100-4$ \\
\hline DESCRIÇÃO & Potência na fase \\
\hline
\end{tabular}

Fonte: Autor “adaptado de” Schneider Acti 9 Smartlink - User Manual (2018), p. 79 
Por convenção, o endereçamento da corrente medida fica entre 2999 a 3003, para a medida de tensão está entre 3019 a 3031 e, por fim, o endereçamento para a medição da potência fica entre 3053 a 3059 .

Por fim, a comunicação entre o Acti 9 Smartlink e o SIMATIC IoT 2040 é realizada por um sistema Modbus TCP/IP baseado em cliente/servidor que estão conectados em uma mesma rede Ethernet TCP/IP. O modelo segue a seguinte arquitetura:

- Solicitação do Modbus: a mensagem é direcionada ao cliente para ter a inicialização da comunicação;

- Indicação Modbus: a mensagem é recebida pelo servidor;

- Modbus Resposta: o servidor envia a mensagem de resposta;

- Confirmação do Modbus: o cliente recebe a resposta.

Dessa forma, as mensagens com os dados são solicitadas pelo SIMATIC IoT 2040, e ao receber a solicitação Acti 9 Smartlink envia os dados imediatamente.

\subsection{A CONSTRUÇÃO DO FLUXO NO NODE-RED}

O Node-red é uma ferramenta que possibilita a construção de fluxos a partir de nós para a comunicação entre dispositivos e a nuvem, como também entre dispositivos e dispositivos, ou ainda entre dispositivos e máquinas. Nessa pesquisa, o node-red está sendo incorporado entre os dispositivos (Acti 9 Smartlink e SIMATIC IoT 2040) e o MindSphere, que é a plataforma baseada em nuvem.

Com o node-red previamente instalado no dispositivo SIMATIC IoT 2040, o acesso que se consegue é relativamente simplificado, pois é preciso digitar em qualquer browser o endereço que aponta para o host do node-red. Geralmente o endereço é http://192.168.200.1:1880. Também se faz necessária a conexão física com o dispositivo SIMATIC IoT 2040 através de um cabo de rede LAN (Local Area Network). Entretanto, como um dos passos iniciais para ter acesso ao node-red instalado no dispositivo SIMATIC IoT 2040, utiliza-se a ferramenta Putty para poder acessar o root do sistema do dispositivo e então iniciá-lo. As figuras 17 e 18 apresentam esses primeiros passos. 
Figura 17 - Programa Putty como configuração de acionamento do Nod-red

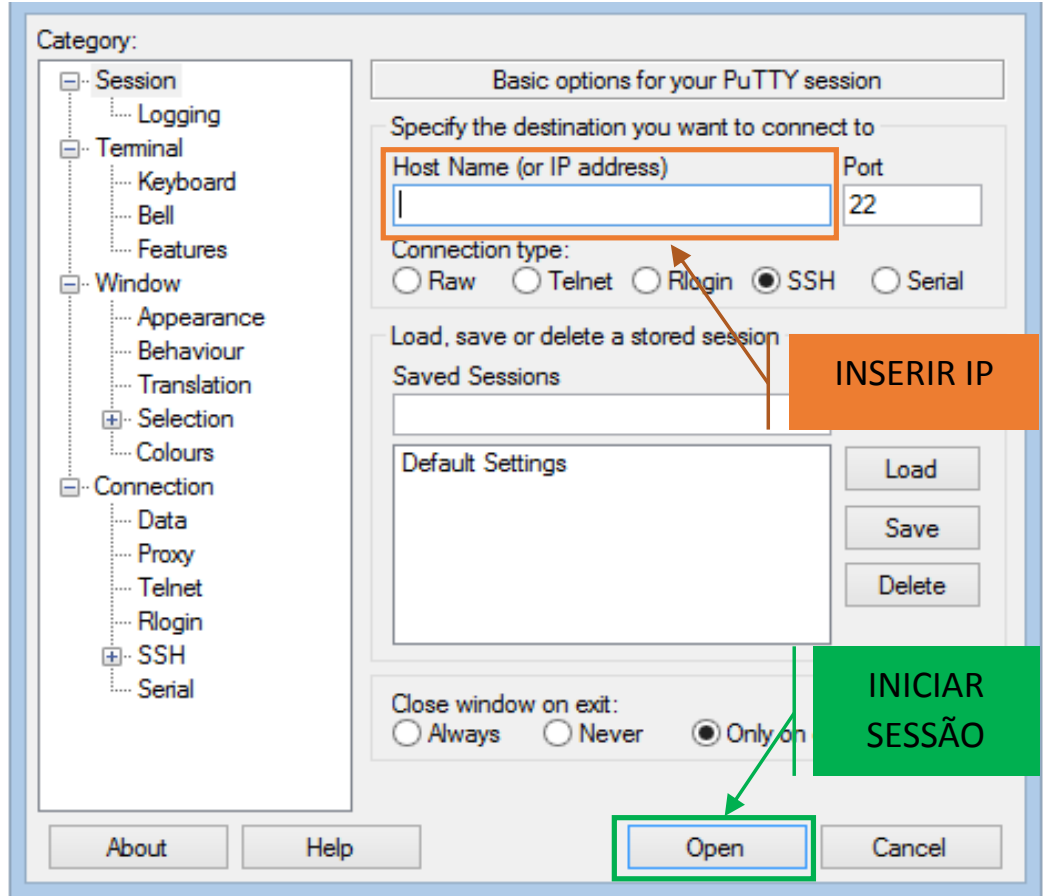

Fonte: Programa Putty, 2020

Quando inicia o prompt do dispositivo, o sistema solicita uma senha para ter acesso ao mesmo, e poder iniciar a operação do node-red. Os comandos são:

- login as: root

- root@iot2000: node-red

Figura 18 - Entrada de login e start do node-red

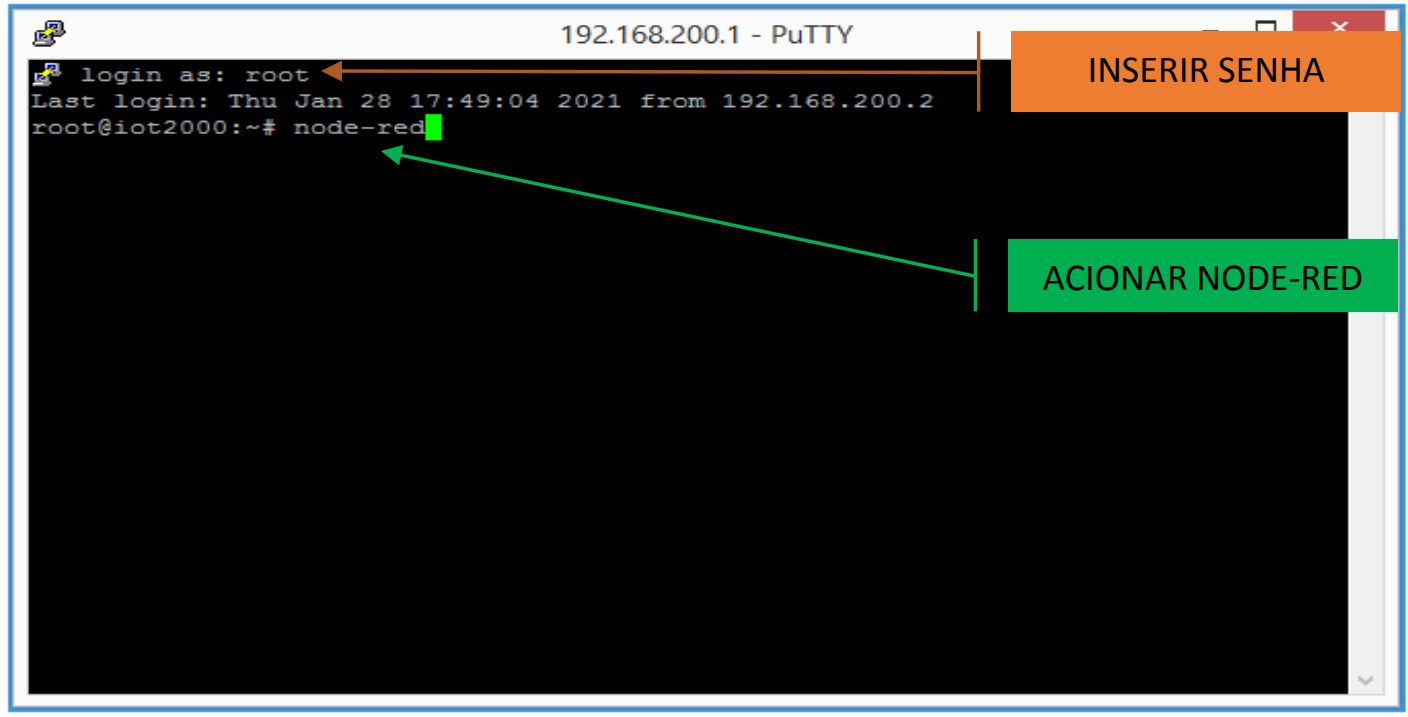

Fonte: Programa Putty, 2020 
A construção do fluxo através dos nós é a próxima etapa, em que a característica de construção passa por dispor os nós em um fluxo que conecte o dispositivo a nuvem. Nessa pesquisa, os nós foram determinados com o direcionamento de captar as medidas elétricas procedentes do Acti 9 Smartlink, transformar essas medidas em valores constantes, e por fim organizá-las em mensagens capazes de serem enviadas como pacotes de dados para a nuvem. A figura 19 apresenta a construção desse fluxo de dados no programa Node-Red.

Figura 19 - Fluxo do programa que adquire os dados e envia para o MindSphere

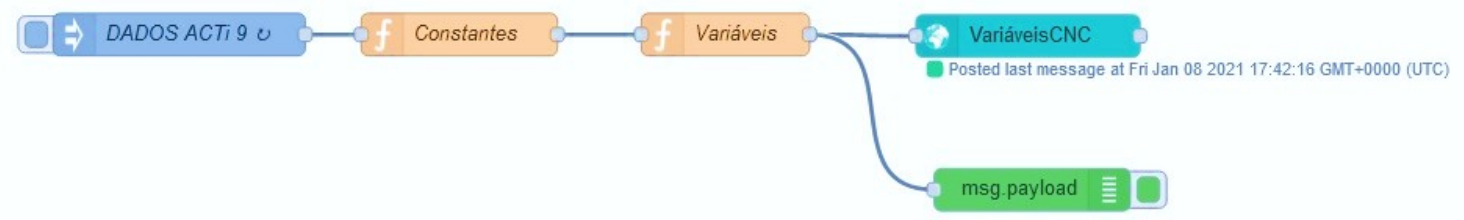

Fonte: Programa Node-Red, 2021

O bloco "DADOS ACTI 9", que é um bloco com a função de injetar dados, está realizando a função de adquirir os dados do Acti 9 Smartlink e enviá-los para o bloco “Constantes”. Entretanto, esse tipo de bloco está sendo utilizado em substituição ao bloco "Modbus Read", que apresenta as condições necessárias para realizar o processo de obtenção dos dados, pois esse bloco tem uma aba onde configura-se o IP do dispositivo (no caso Acti 9 Smartlink) que seria o elo entre os dois aparelhos. Acabou sendo necessária essa substituição devido a problemas técnicos de conectividade com o Acti 9 Smartlink, inviabilizando assim a utilização do bloco "Modbus Read”. O problema com o Acti 9 Smartlink foi na parametrização para colocá-lo no "modo" fábrica, onde o dispositivo não permitia o esse posicionamento, dificultando a inserção do link de comunicação com o Siemens IoT 2040. A fim de contribuir com trabalhos futuros, a figura 20 apresenta como ficaria a configuração com a utilização do bloco "Modbus Read". 
Figura 20 - Configuração do bloco Modbus Read

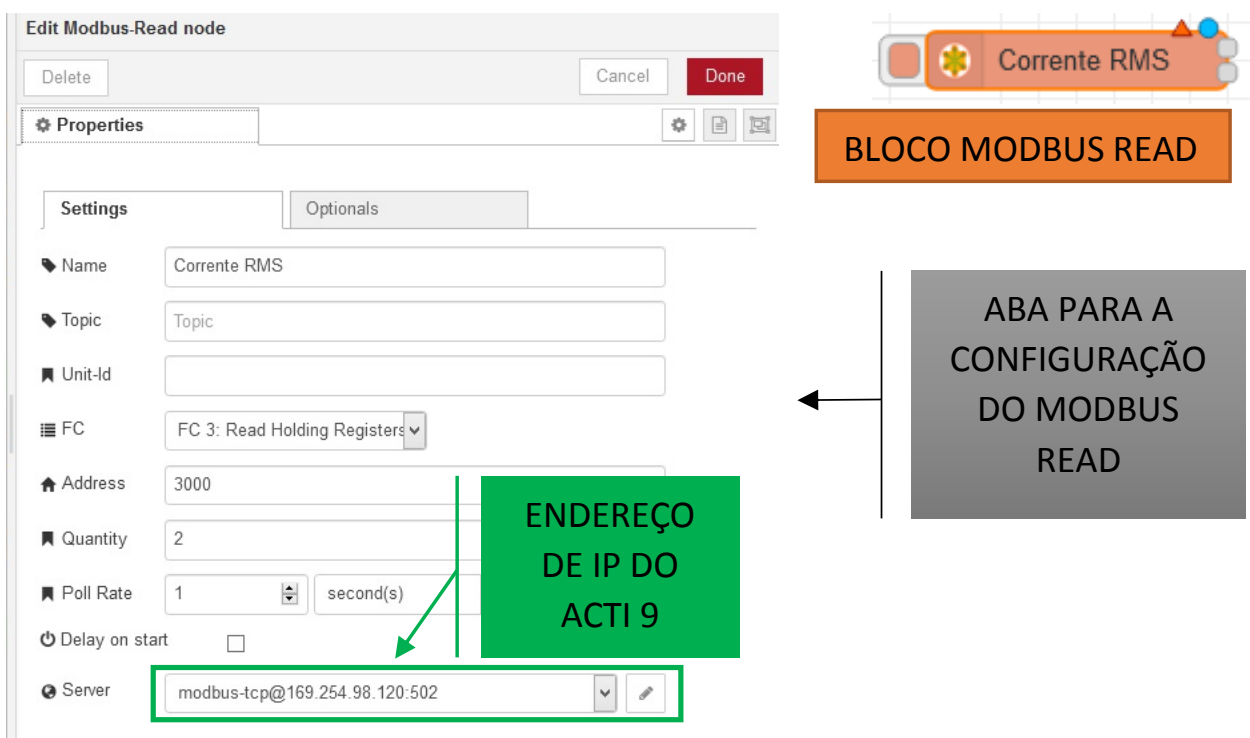

Fonte: Programa Node-Red, 2020

Por outro lado, o bloco "Constantes" possui a função de conformar os dados em elementos que descrevam as medidas procedentes do bloco anterior (DADOS ACTI 9), para posteriormente enviar os dados organizados ao bloco "Variáveis". A função desenvolvida dentro do bloco "Constantes" tem os seguintes passos:

- a primeira constante elaborada é a tensão, que utiliza uma flutuação de medição entre $120 \mathrm{~V}$ e $130 \mathrm{~V}$;

- a segunda constante é a corrente, que foi limitada em 3 ampères, devido a corrente de pico enquanto a máquina $\mathrm{CNC}$ está realizando usinagem.

- a terceira constante é a potência, que foi obtida multiplicando-se a tensão pela corrente.

Após esse processo, classifica-se em uma constante com a atribuição de "const values", e a envia através de mensagem para o próximo bloco com a denominação de “msg.payload=values". A figura 21 mostra a construção dessa função de medição no nó "Constantes". 
Figura 21 - Construção da Função Constantes

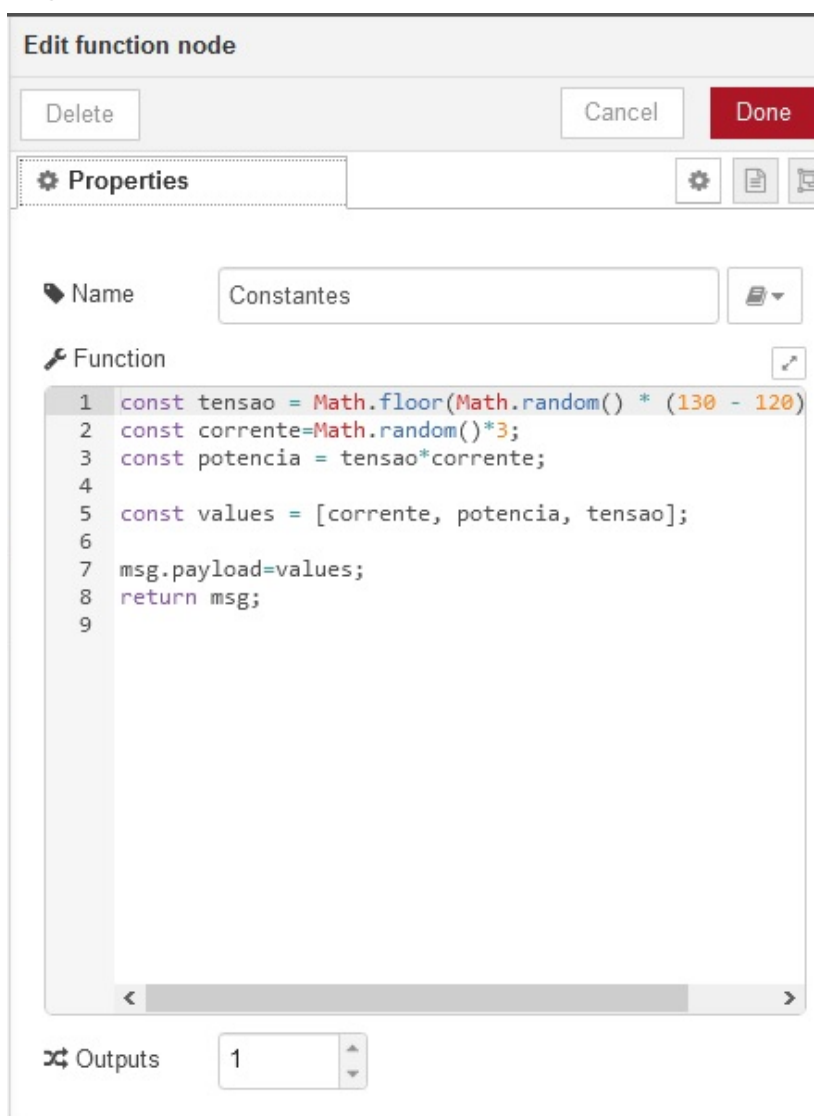

Fonte: Programa Node-Red, 2020

A partir do momento que o bloco "Constantes" envia a mensagem, entra em cena o bloco "Variáveis", onde este possui a função de enviar a mensagem para o próximo bloco em partes separadas, forçando a leitura posteriormente no MindSphere, de acordo com as variáveis criadas a partir do Asset. A função em si consiste em abrir em três mensagens dentro do vetor "const values" e direcioná-las de acordo com sua especificação. Primeiramente aponta-se o dado na variável criada no Asset (por exemplo, corrente), e se atribui um "value" ou a sequência que será enviada a mensagem (no caso da corrente a posição é [0]). A figura 22 apresenta como esta função é implementada neste nó. 
Figura 22 - Construção da Função Variáveis

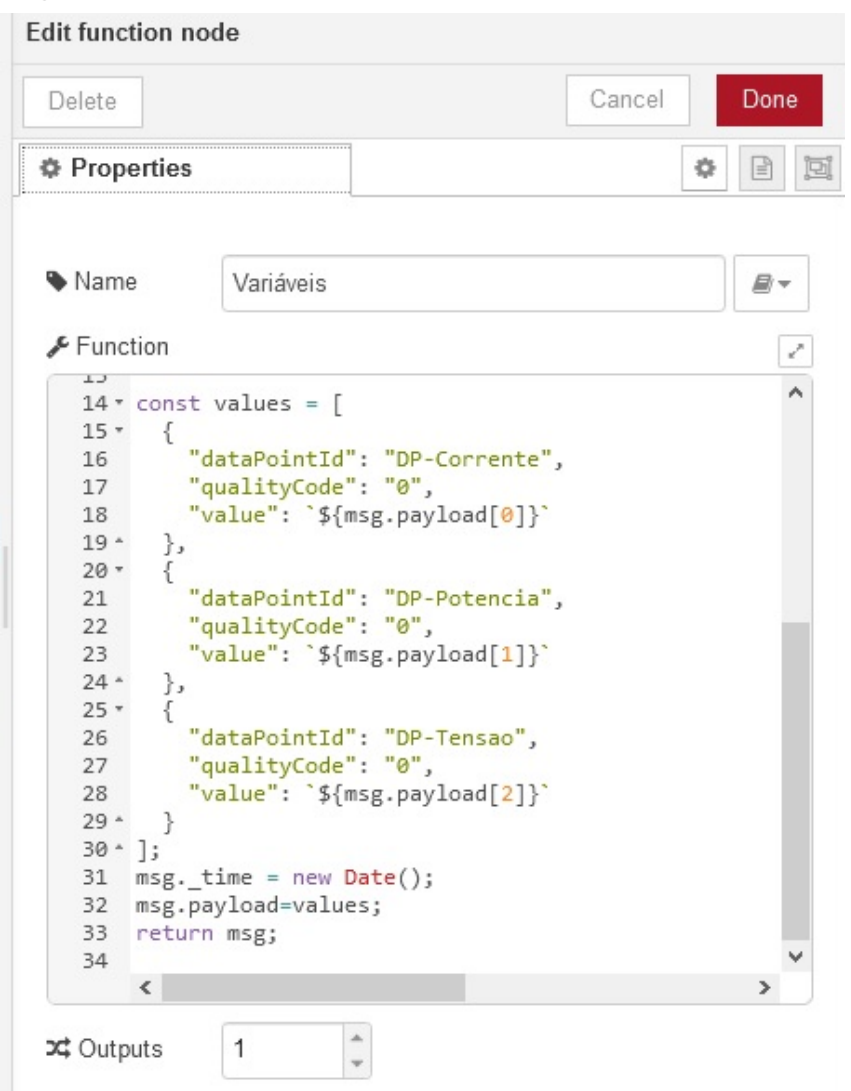

Fonte: Programa Node-Red, 2020

O próximo passo é a conexão com a plataforma MindSphere, e esta fica a cargo do nó "VariáveisCNC", que será descrito no próximo tópico, pois é um bloco que possui o status de conectividade com a plataforma.

\subsection{CONECTIVIDADE ENTRE NODE-RED E O MINDSPHERE}

Como descrito anteriormente, o Node-Red é uma ferramenta que possibilita a criação de nós, onde esses nós podem ser associados em blocos, os quais permitem a conectividade com outras ferramentas, programas, e em um nível mais amplo, com as plataformas de nuvens disponíveis na web.

O MindSphere é a nuvem utilizada para o desenvolvimento desta pesquisa onde os dados são recebidos para consultas ou implementação de novas soluções. Para a conexão entre o Node-Red e o MindSphere são imprescindíveis bibliotecas que desempenham esse papel de interligar os dispositivos físicos com a nuvem. A biblioteca que utilizada para esse cometimento é a mindconnect-nodejs, que possibilita aos usuários 
do Node-Red, de forma muito intuitiva e direta, a transposição dos arquivos, eventos e séries temporais para o MindSphere.

O nó mindconnect-nodejs deve ser instalado previamente no Node-Red por linha de comando (cmd ou prompt de comando) ou pelo instalador do próprio Node-Red. Por linha de comando digita-se: npm install@mindconnect/node-red-contrib-mindconnect.

Outra possibilidade para a instalação do mindconnect-nodejs é utilizar no programa Node-Red, através do caminho Manage palette, a opção que abre o segmento User Settings. Nesse segmento, abre-se a aba Install e digita-se "mindconnect" para poder acessar o nó indicado, onde este será exibido no palette a biblioteca em questão. A figura 23 descreve essa opção.

Figura 23 - Instalação da biblioteca mindconnect

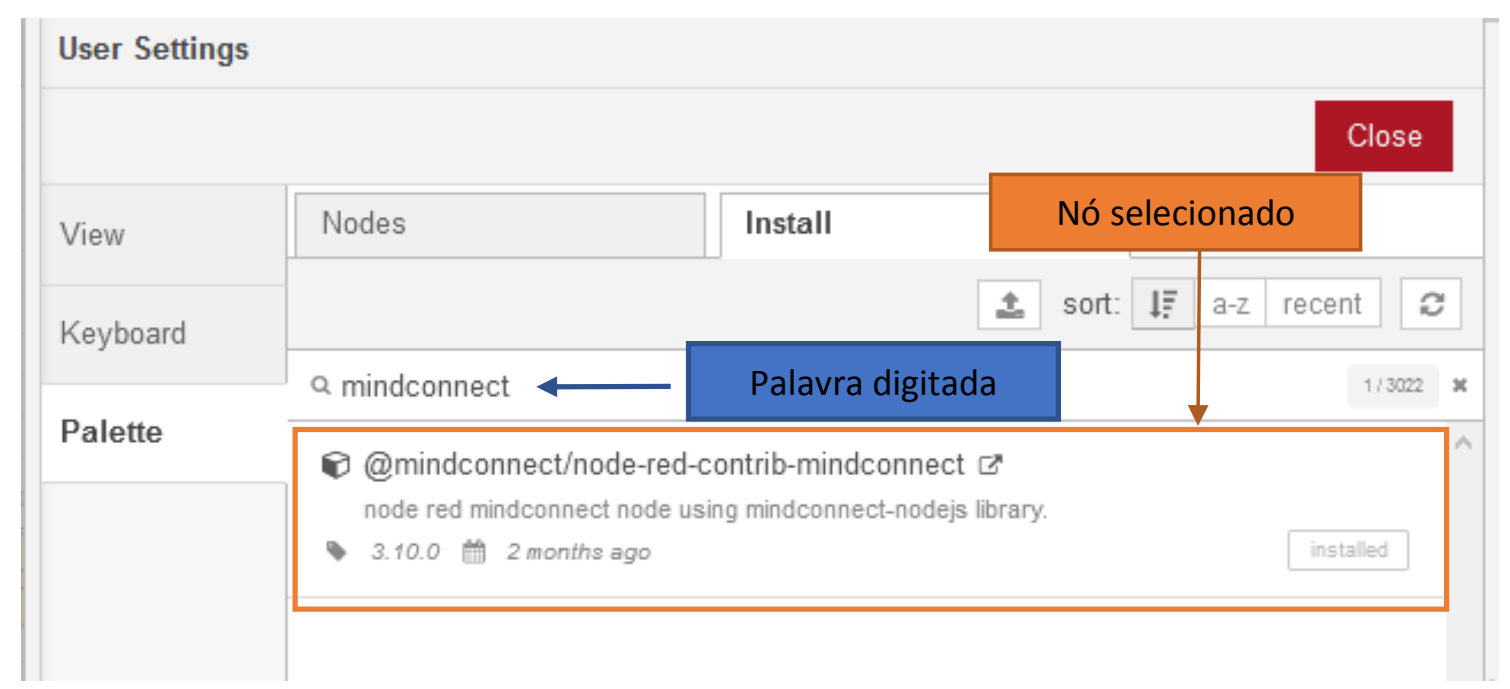

Fonte: Programa Node-Red, 2021

Paralelamente a este processo, faz-se necessária a criação de ativos (Asset) no MindSphere para que os dados provindos do Node-Red sejam lidos pela plataforma em questão. Para criar um Asset deve-se ter acesso ao MindSphere através de um Tenant, que é um gerenciador de acesso a plataforma, no qual somente a equipe de trabalho terá essa possibilidade de acesso.

A partir do momento que o acesso ao MindSphere está equacionado, ao entrar na plataforma encontra-se a aba Asset Manager, onde se constrói um ativo que vai receber os dados provindos do nó Mindconnect (associado ao fluxo construído no Node-Red). A figura 24 mostra a Homepage da plataforma MindSphere. 
Figura 24 - Acesso a página inicial da plataforma MindSphere

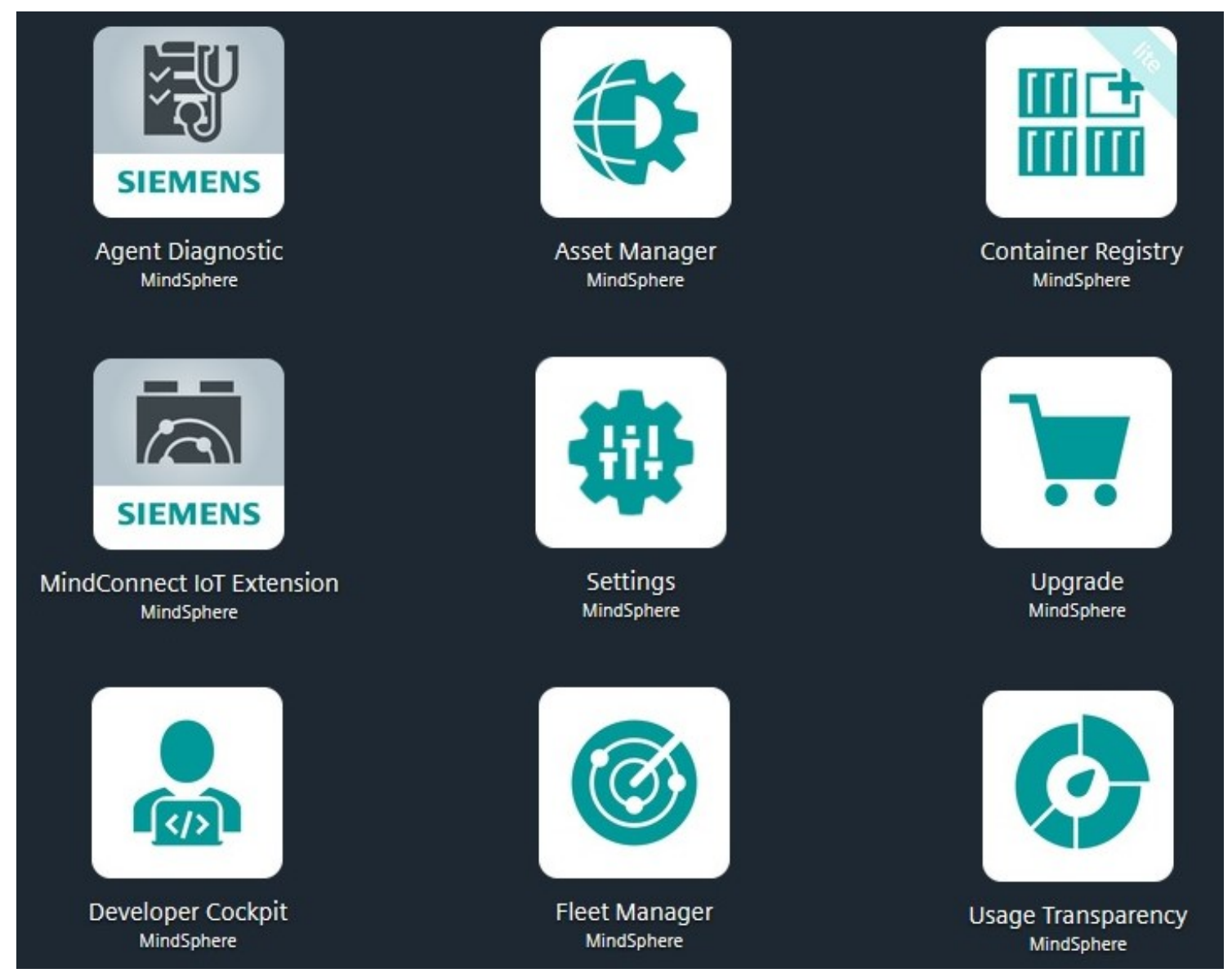

Fonte: Programa MindSphere, 2021

O Asset Manager possui cinco subcategorias que denotam as especificidades que o ativo criado pode apresentar. As subcategorias são:

$\begin{array}{ll}\text { - } & \text { Assets; } \\ \text { - } & \text { Types; } \\ \text { - } & \text { Aspects; } \\ \text { - } & \text { Connectivity. }\end{array}$

O ativo é construído a partir das três primeiras subcategorias que possuem uma relevância construtiva maior em relação a Connectivity e Sharings. A primeira subcategoria é a Assets, onde na verdade essa é a última a ser verificada, pois se trata da finalização e conexão do ativo com outras plataformas ou outros ativos. Em Aspects devem ser definidas, por exemplo, as variáveis que o ativo vai dispor, e que podem ser 
utilizadas por outros ativos dentro do próprio Tenant. Nessa pesquisa foi desenvolvida o Aspect EletricVariaveis que abrange as variáveis Corrente, Tensão e Potência, com suas respectivas unidades de medidas e com o tipo de dado relacionado para esse Aspect, que no caso é o Double.

Em Types, podem-se configurar tipos de ativos com semelhantes atributos dos Aspects, mas com mais especificidades, como por exemplo, incluir os Aspects criados anteriormente em Types e determinar mais variáveis específicas dentro destes a partir dos Aspects. A figura 25 exemplifica essa descrição.

Figura 25 - Criando Types e Incluindo Aspects

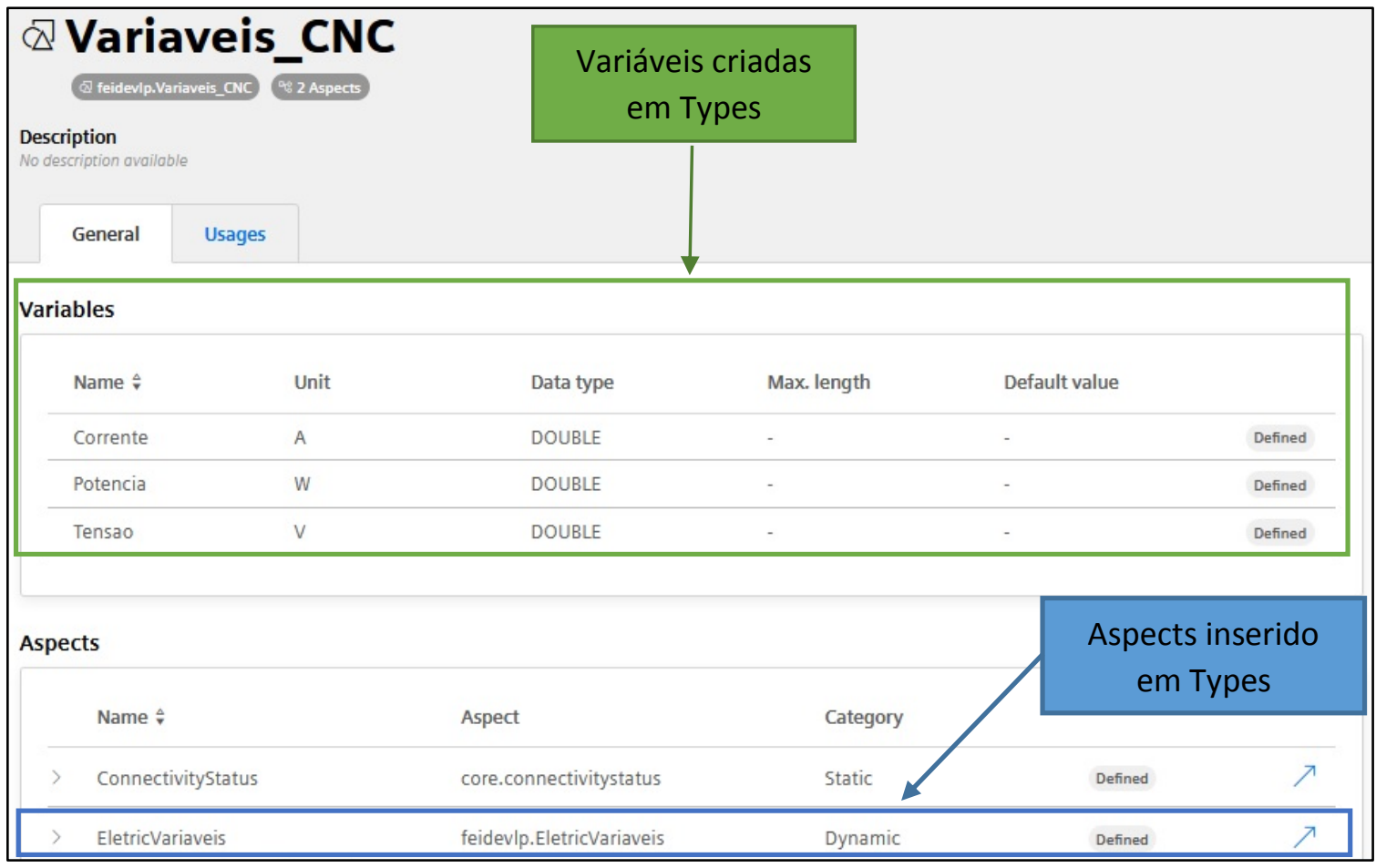

Fonte: Programa MindSphere, 2021

Um Asset representa digitalmente um ativo físico (por exemplo máquina $\mathrm{CNC}$ ) ou um sistema de automação (por exemplo PLC), e como foi indicado anteriormente, esse ativo conecta-se ao MindSphere. Na subcategoria Asset cria-se um ativo com a biblioteca MindConnect Lib, onde esse ativo terá conexão com essa biblioteca, mas posteriormente precisa gerar os processos necessários para a interligação do dispositivo. Em MindConnect Lib deve-se acionar a seta que indica a conexão com o Plugin e explorar a biblioteca para estabelecer os parâmetros necessários. As figuras 26 e 27 indicam os processos. 
Figura 26 - Processo para acessar a biblioteca MindConnect Lib

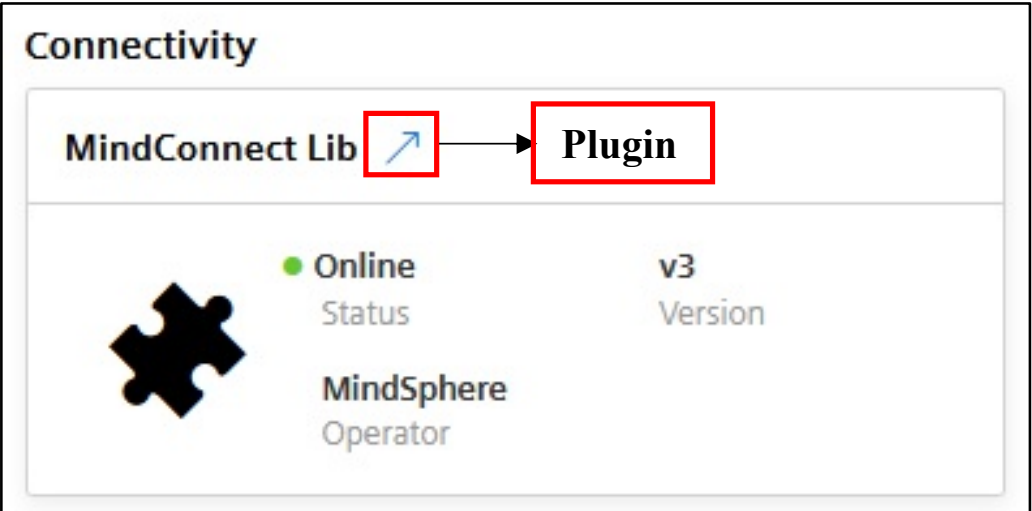

Fonte: Programa MindSphere, 2021

Acionando o Plugin, automaticamente o sistema direciona para a biblioteca do MindConnect Lib no processo de geração de chave de segurança compartilhada (SHARED_SECRET) de 256 bits e majoritariamente direcionados a equipamentos leves.

Figura 27 - Processo para gerar a Chave de Segurança

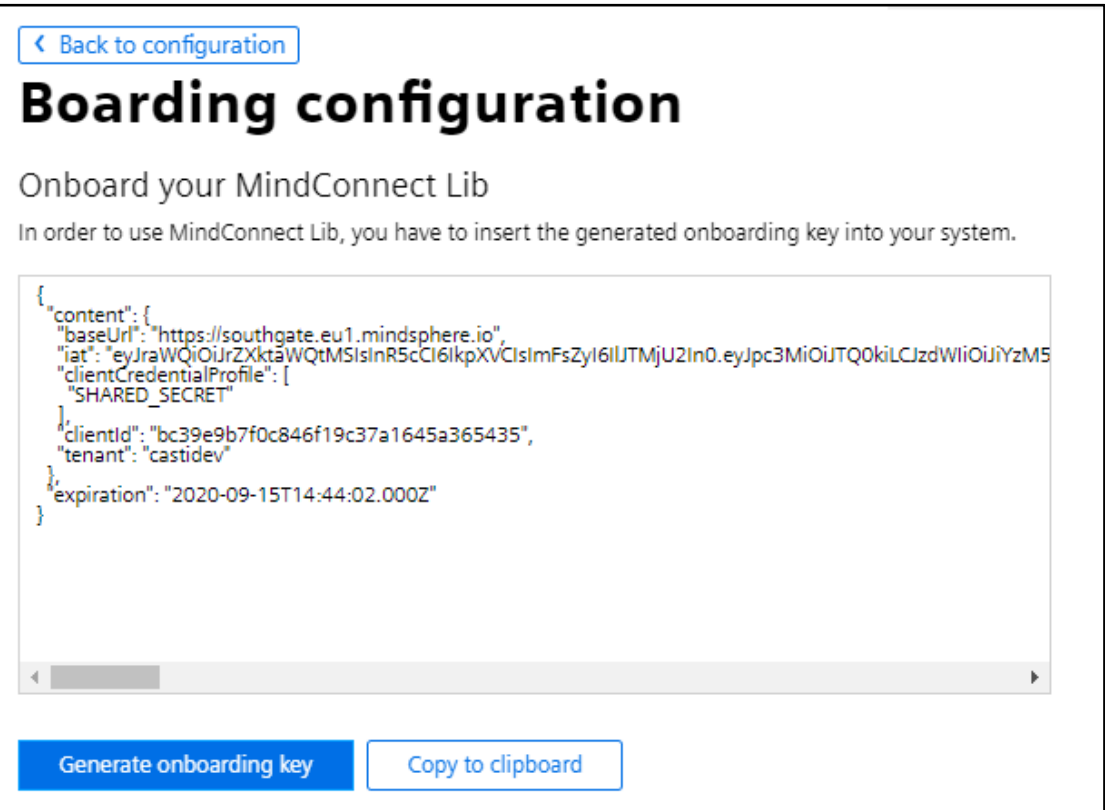

Fonte: Programa MindSphere, 2021

Depois de Gerar a chave de segurança, deve-se voltar ao Node-Red para inserir a codificação no nó Mindconnect e finalizar a conexão entre o dispositivo físico e a plataforma MindSphere. 
Abrindo o nó Mindconnect, encontra-se a aba "Edit mindconnect node", onde essa página possui uma caixa que insere a chave de segurança obtida no Mindconnect Lib. Para validar a conexão deve-se aplicar "Done" e depois "Deploy". Após esse processo, abre-se o nó novamente para configurar a aba "Agent Configuration", onde indica-se o link com o ativo disposto no Asset Manager, que nesse caso foi denominado como VariaveisCNC. A figura 28 a seguir indica o processo.

Figura 28 - Configuração do nó Mindconnect

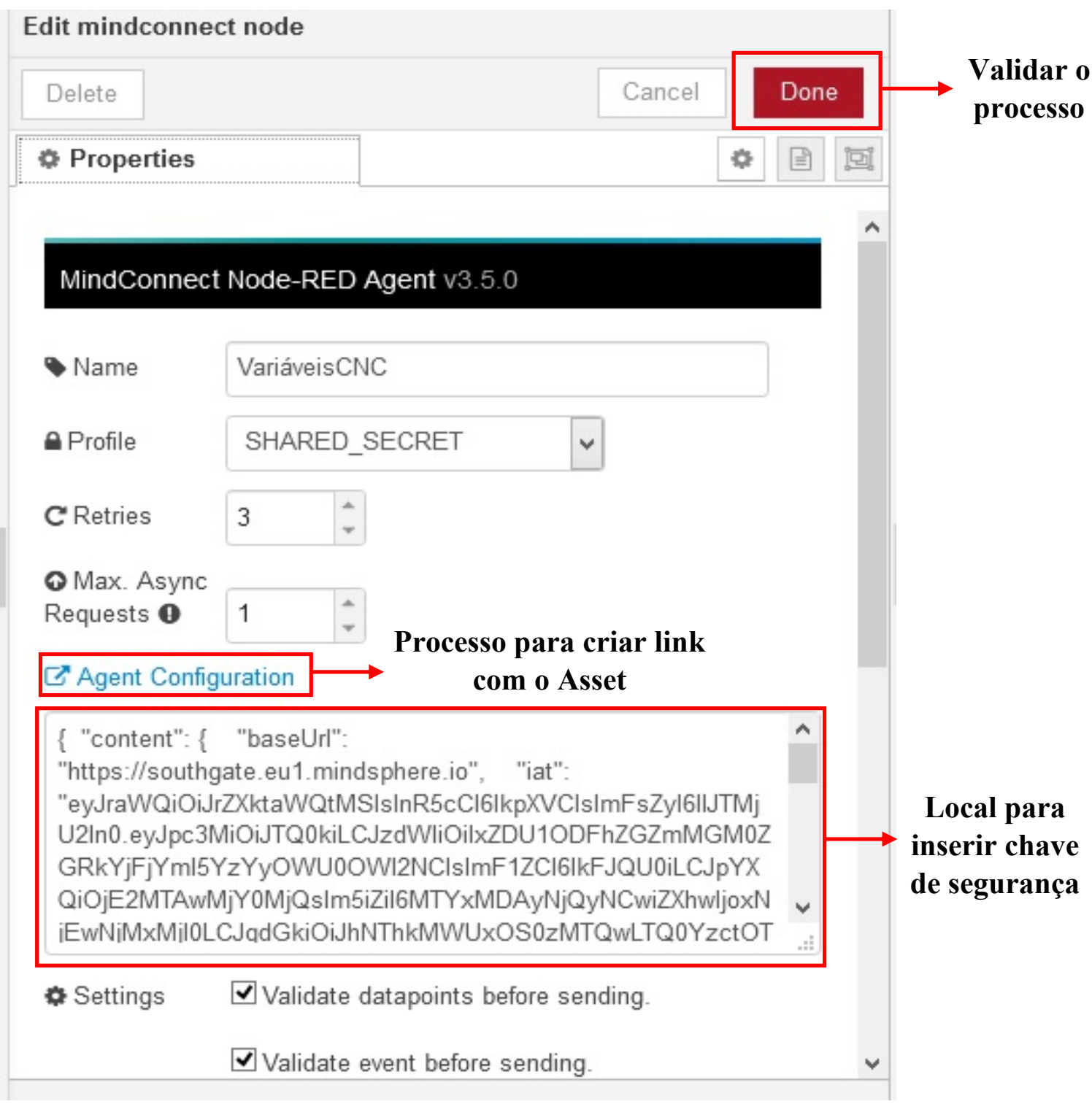

Fonte: Programa Node-Red, 2021

O Agent Configuration realiza um mapeamento 1:1 entre o Node-Red e o ativo que se encontra no MindSphere. Portanto, o que estiver configurado no Asset Manager aparecerá automaticamente em uma lista dentro do Agent Configuration, onde se faz 
necessário acionar aquele que corresponda ao projeto para obter a conectividade necessária. O mais importante é que todos os parâmetros para estabelecer essa conexão será gerada automaticamente entre o nó e o ativo, o que torna essa ferramenta primordial para essa pesquisa.

Assim que estabelece essa conexão, ao retornar ao MindSphere, nota-se que o dispositivo estará no status online, indicado por um círculo verde ao lado da palavra, como também a imagem de dispositivos web conectados. A figura 29 mostra essas indicações.

Figura 29 - Verificação do status online do dispositivo

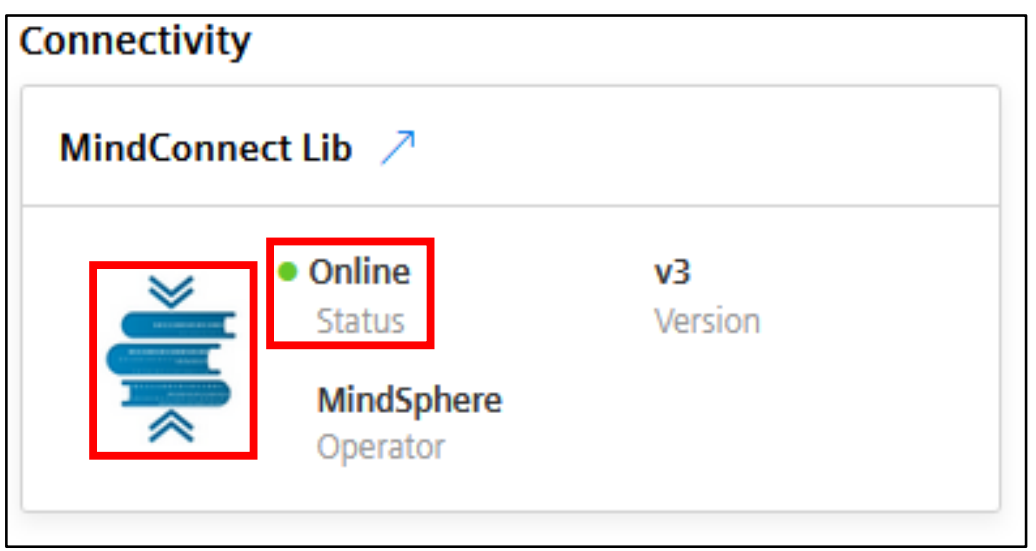

Fonte: Programa MindSphere, 2021

A partir desse momento deve-se construir o fluxo com os nós que irão realizar a aquisição de dados provindos do Acti 9 Smartlink e enviá-los para a plataforma MindSphere. A primeira ação foi separar os dados em Corrente, Tensão e Potência através do nó Function, onde este fornece as condições matemáticas para a separação dos dados. Primeiramente, definiu-se um nó de nome "Constantes", e nesse nó cada grandeza elétrica torna-se uma constante, onde estas receberão os valores quantificados para que posteriormente possam enviá-los separadamente ao próximo nó, que no nesse estudo também é uma função. Em contrapartida, como o Node-Red trabalha com envios de mensagens com cargas (msg.payload) o nó "Variaveis" direciona cada mensagem com seus respectivos valores separadas em nomes e com suas cargas para o MindSphere. A construção dessas mensagens segue o modelo de programação do JavaScript, e o envio de dados é consolidado na forma "ponto de dados", onde o nó é validado, ou seja, verifica-se os dados são válidos para a ação do agente de configuração. 
Após iniciar o envio de dados, deve-se verificar na plataforma MindSphere se eles estão sendo convertidos nas informações que o projeto delimitou. Para esse cometimento deve-se acessar o Fleet Manager e examinar toda uma gama de possibilidade que os dados estão gerando, a partir de gráficos, estatísticas ou série de dados, e principalmente se o envio de dados apresenta a periodicidade desejada. Ao acessar o Fleet Manager, a primeira situação é analisar se os Assets criados estão online, como também se estão recebendo a série de dados provindos do nó Mindconnect, no qual está conectado ao dispositivo SIMATIC IoT 2040. Nessa pesquisa foram criados dois Assets, onde o CNC_Eletric_info demonstra que o dispositivo está online, e o EletricVariáveis é responsável por confirmar o recebimento de dados. A seguir, a figura 30 apresenta esse cenário.

Figura 30 - Visualização de dados através de gráficos

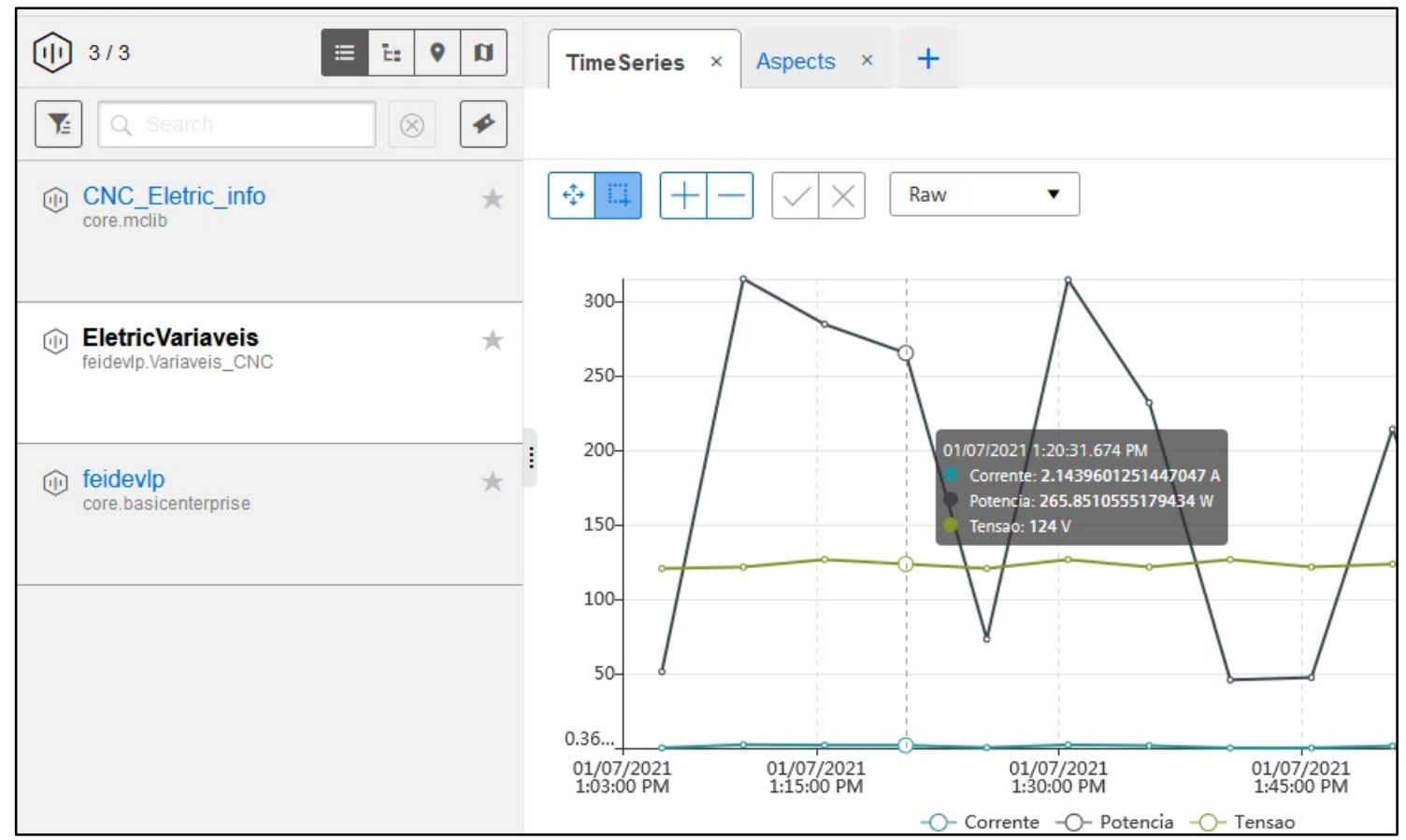

Fonte: Programa MindSphere, 2021

A próxima etapa é analisar os dados e criar o cenário de consumo de energia da máquina $\mathrm{CNC}$ legada para poder delinear novas prospecções futuras. 


\subsection{RESULTADOS E DISCUSSÕES}

Na plataforma do MindSphere serão concentrados os dados provenientes do SIMATIC IoT 2040, e o acesso a esses dados é alcançado pelo Fleet Manager. Entretanto, os dados são dispostos através de gráficos, e estes mostram toda a evolução do funcionamento da máquina $\mathrm{CNC}$ legada com atualizações a cada quinze minutos. A figura 31 apresenta em exemplo dessa visualização.

Figura 31 - Gráfico com as grandezas elétricas gerado a partir do CNC legado

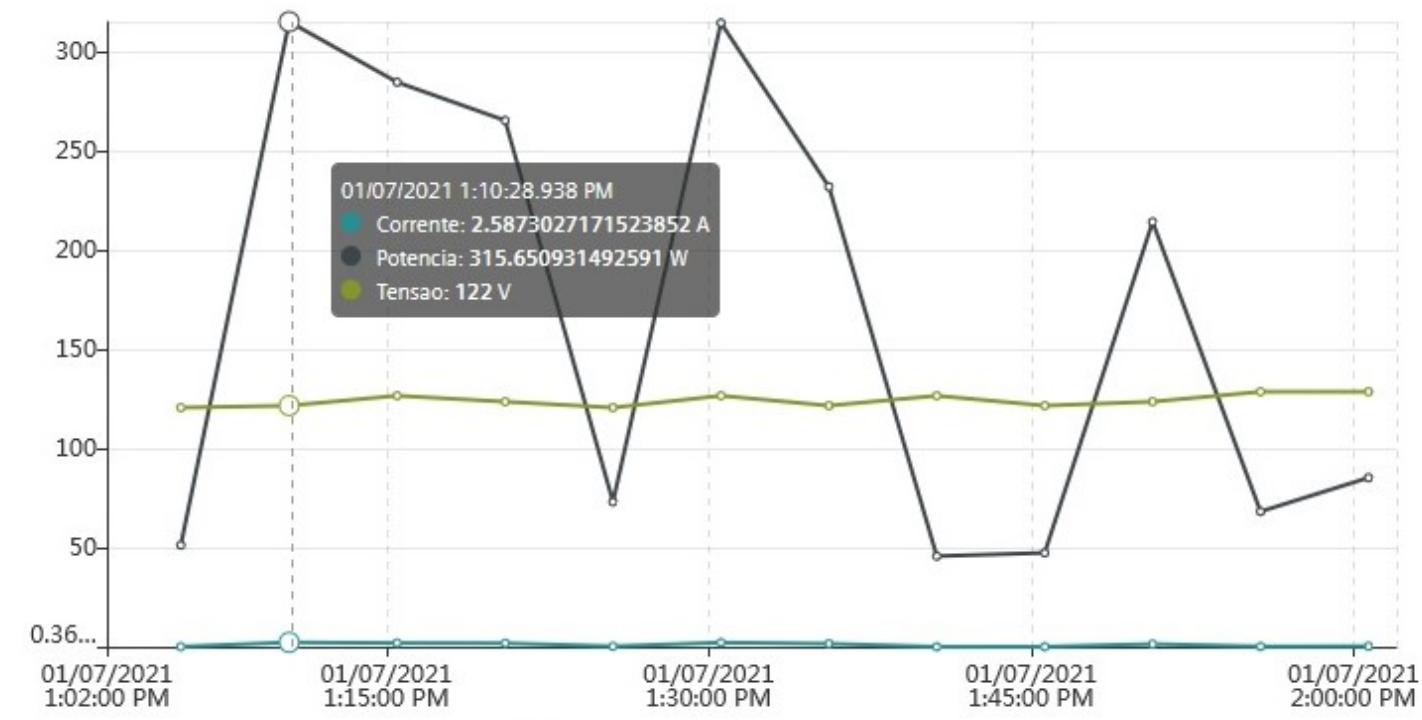

Fonte: Programa MindSphere, 2021

Esse tipo de visualização permite um acompanhamento restrito, pois com o gráfico não é possível ter uma média no consumo de corrente e tensão, e por conseguinte de potência. Por isso há a necessidade da construção de uma tabela para um acompanhamento e monitoramento mais eficaz, além de permitir um período mais longo na questão da análise. Como o processo está sendo simulado, é indicado o "Modo de espera" quando o CNC está fora de operação, funcionando quando se "Liga" a máquina, e aponta o instante em que se "Desliga" a máquina CNC. Também, podem-se classificar as médias do consumo de corrente, tensão e potência, e ainda determinar o desvio padrão para cada grandeza. As tabelas 5 a 8 apresentam uma concentração e detalhamento dos dados da máquina $\mathrm{CNC}$, em um determinado período. 
Tabela 5 - Leitura das Medições elétricas a partir do gráfico no MindSphere no dia $11 / 01 / 2021$

\section{DATA HORÁRIO CORRENTE TENSÃO POTÊNCIA OBSERVAÇÃO}

\begin{tabular}{|c|c|c|c|c|c|}
\hline & & (A) & (V) & \multicolumn{1}{c}{ (W) } & \\
\hline $\mathbf{1 1 / 0 1 / 2 0 2 1}$ & $7: 48$ & 0,30 & 125 & 38,66 & Modo de espera \\
\hline $\mathbf{1 1 / 0 1 / 2 0 2 1}$ & $\mathbf{8 : 0 3}$ & $\mathbf{1 , 9 5}$ & $\mathbf{1 2 6}$ & $\mathbf{2 4 6 , 0 3}$ & Liga \\
\hline $\mathbf{1 1 / 0 1 / 2 0 2 1}$ & $8: 08$ & 2,64 & 127 & 335,46 & \\
\hline $\mathbf{1 1 / 0 1 / 2 0 2 1}$ & $9: 03$ & 2,95 & 121 & 357,50 & \\
\hline $\mathbf{1 1 / 0 1 / 2 0 2 1}$ & $10: 08$ & 2,65 & 125 & 332,49 & \\
\hline $\mathbf{1 1 / 0 1 / 2 0 2 1}$ & $11: 03$ & 0,05 & 129 & 6,63 & Modo de espera \\
\hline $\mathbf{1 1 / 0 1 / 2 0 2 1}$ & $12: 09$ & 0,69 & 123 & 85,15 & Modo de espera \\
\hline $\mathbf{1 1 / 0 1 / 2 0 2 1}$ & $13: 04$ & 0,26 & 126 & 33,05 & Modo de espera \\
\hline $\mathbf{1 1 / 0 1 / 2 0 2 1}$ & $14: 04$ & 2,97 & 123 & 365,38 & \\
\hline $\mathbf{1 1 / 0 1 / 2 0 2 1}$ & $15: 09$ & 1,79 & 128 & 229,23 & \\
\hline $\mathbf{1 1 / 0 1 / 2 0 2 1}$ & $16: 10$ & 2,20 & 121 & 266,90 & \\
\hline $\mathbf{1 1 / 0 1 / 2 0 2 1}$ & $\mathbf{1 7}: \mathbf{0 0}$ & $\mathbf{0 , 7 4}$ & $\mathbf{1 2 1}$ & $\mathbf{8 9 , 8 2}$ & Desliga \\
\hline MÉDIA & - & 1,87 & 125 & 237,63 & \\
\hline DESVPAD & - & 1,12 & 2,78 & 138,86 & \\
\hline
\end{tabular}

Fonte: Autor

A simulação indicada na tabela 5 trabalha com um turno de 8 horas e medições espaçadas em aproximadamente de 1 hora. Observa-se que ao inserir os três "Modo espera" no turno de trabalho, em um momento específico, a média de consumo de corrente e potência só não são melhores que as medições da tabela 6, pois nesta o "Modo espera" foi utilizado em quatro medições. 
Tabela 6 - Leitura das Medições elétricas a partir do gráfico no MindSphere no dia $18 / 01 / 2021$

DATA HORÁRIO CORRENTE TENSÃO POTÊNCIA OBSERVAÇÃo

\begin{tabular}{|c|c|c|c|c|c|}
\hline & & (A) & (V) & $(W)$ & \\
\hline $18 / 01 / 2021$ & $7: 54$ & 0,66 & 129 & 85,88 & Modo de espera \\
\hline $18 / 01 / 2021$ & 8:04 & 2,65 & 120 & 318,77 & Liga \\
\hline $18 / 01 / 2021$ & $8: 09$ & 1,34 & 123 & 165,13 & \\
\hline $18 / 01 / 2021$ & $9: 04$ & 0,78 & 121 & 95,40 & Modo de espera \\
\hline $18 / 01 / 2021$ & $10: 00$ & 1,87 & 120 & 224,72 & \\
\hline $18 / 01 / 2021$ & $11: 05$ & 2,19 & 127 & 2,19 & \\
\hline $18 / 01 / 2021$ & $12: 00$ & 0,15 & 126 & 20,02 & Modo de espera \\
\hline $18 / 01 / 2021$ & $13: 05$ & 2,72 & 121 & 330,06 & \\
\hline $18 / 01 / 2021$ & $14: 05$ & 0,48 & 121 & 58,50 & Modo de espera \\
\hline $18 / 01 / 2021$ & $15: 01$ & 0,65 & 128 & 83,73 & Modo de espera \\
\hline $18 / 01 / 2021$ & $16: 11$ & 2,57 & 120 & 309,15 & \\
\hline $18 / 01 / 2021$ & $17: 21$ & $\mathbf{0 , 0 3}$ & 126 & 4,78 & Desliga \\
\hline MÉDIA & - & 1,06 & 122 & 90,64 & \\
\hline DESVPAD & - & 1,01 & 3,45 & 124,63 & \\
\hline
\end{tabular}

Fonte: Autor

As medições simuladas a partir da tabela 6 indicam o melhor desempenho no consumo de corrente e potência entre todas as tabelas de simulação, pois em um turno de trabalho que consiste em oito horas de funcionamento, foram inseridas quatro situações de "Modo espera", o que prescreve um funcionamento limitado a metade do turno. 
Tabela 7 - Leitura das Medições elétricas a partir do gráfico no MindSphere no dia $25 / 01 / 2021$

\section{DATA HORÁRIO CORRENTE TENSÃO POTÊNCIA OBSERVAÇÃo}

\begin{tabular}{|c|c|c|c|c|c|}
\hline & & $(\mathbf{A})$ & $(\mathbf{V})$ & $\mathbf{( W )}$ & \\
\hline $\mathbf{2 5 / 0 1 / 2 0 2 1}$ & $7: 50$ & 0,52 & 122 & 63,83 & Modo de espera \\
\hline $\mathbf{2 5 / 0 1 / 2 0 2 1}$ & $\mathbf{8 : 0 0}$ & $\mathbf{2 , 4 5}$ & 128 & 313,96 & Liga \\
\hline $\mathbf{2 5 / 0 1 / 2 0 2 1}$ & $8: 05$ & 2,92 & 126 & 368,22 & \\
\hline $\mathbf{2 5 / 0 1 / 2 0 2 1}$ & $9: 05$ & 2,15 & 127 & 273,89 & \\
\hline $\mathbf{2 5 / 0 1 / 2 0 2 1}$ & $10: 00$ & 1,82 & 124 & 226,47 & \\
\hline $\mathbf{2 5 / 0 1 / 2 0 2 1}$ & $11: 05$ & 0,09 & 121 & 10,90 & Modo de espera \\
\hline $\mathbf{2 5 / 0 1 / 2 0 2 1}$ & $12: 00$ & 2,86 & 126 & 360,55 & \\
\hline $\mathbf{2 5 / 0 1 / 2 0 2 1}$ & $13: 01$ & 2,89 & 123 & 356,09 & \\
\hline $\mathbf{2 5 / 0 1 / 2 0 2 1}$ & $14: 06$ & 1,54 & 120 & 185,59 & \\
\hline $\mathbf{2 5 / 0 1 / 2 0 2 1}$ & $15: 06$ & 0,96 & 126 & 121,62 & Modo de espera \\
\hline $\mathbf{2 5 / 0 1 / 2 0 2 1}$ & $16: 01$ & 2,50 & 123 & 308,24 & \\
\hline $\mathbf{2 5 / 0 1 / 2 0 2 1}$ & $\mathbf{1 7 : 0 7}$ & $\mathbf{0 , 0 9}$ & $\mathbf{1 2 9}$ & $\mathbf{1 2 , 7 2}$ & Desliga \\
\hline MÉDIA & - & 1,99 & 125 & 250,18 & \\
\hline DESVPAD & - & 1,08 & 2,84 & 135,39 & \\
\hline
\end{tabular}

Fonte: Autor

Com apenas duas inserções do "Modo de espera", as medições simuladas na tabela 7 trouxeram um ganho em relação à média de consumo de corrente e potência apenas a média da tabela 8 , que não apresenta no turno de trabalho nenhum "Modo de espera". 
Tabela 8 - Leitura das Medições elétricas a partir do gráfico no MindSphere no dia $01 / 02 / 2021$

\section{DATA HORÁRIO CORRENTE TENSÃO POTÊNCIA OBSERVAÇÃo}

\begin{tabular}{|c|c|c|c|c|c|}
\hline & & (A) & (V) & (W) & \\
\hline $01 / 02 / 2021$ & $7: 55$ & 0,08 & 128 & 10,36 & Modo de espera \\
\hline $01 / 02 / 2021$ & 8:00 & 2,69 & 121 & 326,21 & Liga \\
\hline $01 / 02 / 2021$ & 8:05 & 1,49 & 120 & 179,22 & \\
\hline $01 / 02 / 2021$ & 9:05 & 1,66 & 126 & 209,97 & \\
\hline $01 / 02 / 2021$ & 10:00 & 2,71 & 123 & 334,08 & \\
\hline $01 / 02 / 2021$ & $11: 00$ & 1,44 & 127 & 183,32 & \\
\hline $01 / 02 / 2021$ & 12:01 & 2,62 & 129 & 338,73 & \\
\hline $01 / 02 / 2021$ & 13:06 & 2,88 & 121 & 348,62 & \\
\hline $01 / 02 / 2021$ & $14: 01$ & 2,41 & 128 & 309,55 & \\
\hline $01 / 02 / 2021$ & $15: 01$ & 2,45 & 126 & 309,50 & \\
\hline $01 / 02 / 2021$ & $16: 07$ & 1,57 & 124 & 195,22 & \\
\hline $01 / 02 / 2021$ & $17: 22$ & 0,34 & 124 & 43,15 & Desliga \\
\hline MÉDIA & - & 2,04 & 125 & 259,74 & \\
\hline DESVPAD & - & 0,93 & 3,06 & 116,03 & \\
\hline
\end{tabular}

Fonte: Autor

As tabelas foram elaboradas a partir de quatro datas com um intervalo de uma semana entre as datas. Também, as medições seguiram dentro de um padrão de funcionamento de aproximadamente sete horas. Outra situação que se pode constatar, é que as medições estão em um intervalo de uma hora aproximadamente, exceto a primeira medição do dia que ocorreu geralmente entre cinco e quinze minutos antes do início das operações, com interesse expressivo em determinar que a máquina está em modo de espera.

A tabela 5 apresenta a situação em que o "Modo de Espera" é posto três vezes entre as medições, o que permitiu constatar que a média de consumo da corrente ficou em 1,87 A e com um desvio padrão de 1,12 A. Isso demonstra, que a máquina legada trabalhou abaixo da corrente limite $3 \mathrm{~A}$.

A análise da tabela 6 leva-nos a perceber que quando insere quatro modos de espera na operação da máquina $\mathrm{CNC}$ legada, a média de consumo de corrente, tensão e potência atenua ainda mais em relação as medições da primeira tabela. Um exemplo é a corrente que nesta medição da tabela 6 foi $46 \%$ menor que na medição da tabela 5 . 
Na tabela 7, retiraram-se dois modos de espera em relação as medições da tabela 6 , e percebeu-se que a média das grandezas medidas aumentaram consideravelmente. Desta vez a média da corrente medida chegou à 1,99 A. Esse valor é quase o dobro da medida da tabela 6 , e 7 \% maior em relação a tabela 5 .

Em compensação, na tabela 8 não foi inserido o "Modo de espera" no decorrer das medições, e portanto a máquina $\mathrm{CNC}$ legada trabalhou sem paradas. Ficou evidente que a média de consumo de corrente é maior que nas medições das tabelas anteriores, chegando a ser $3 \%$ acima da maior medida encontrada a partir de medições anteriores.

Outro detalhe importante é que a tensão tem pouca variação em sua média, sendo menor apenas na medição da tabela 7 quando foi inserido quatro modo de espera. Por outro lado, a potência teve uma variação de $169 \mathrm{~W}$ entre a menor medição que aconteceu na segunda tabela, e a maior medição que incidiu na tabela 8 .

\section{CONCLUSÃO}

Essa pesquisa foi motivada em apresentar uma solução viável para inserção de máquinas legadas no contexto da indústria 4.0 baseada em conectividade e, por conseguinte, chamar a atenção das empresas que o Retrofit é o caminho mais curto para esse cometimento.

Com o mapeamento da máquina legada e a inserção de sensores, foi possível coletar dados do consumo energético e monitorar a operação com base nesses dados. Isso pode ter um ganho maior se os dados forem utilizados para planejar manutenções, basear a operação de fabricação, monitorar o consumo de energia, entre outros.

Para o monitoramento efetivo do consumo de energia, foi implementado o gateway SIMATIC IoT 2040, o Acti 9 Smartlink e o PowerTag, onde o trabalho em conjunto desses três dispositivos, mais a utilização da plataforma MindSphere, trouxe a possibilidade de verificar em tempo real alguns parâmetros elétricos da máquina.

O dispositivo PowerTag realiza a leitura do consumo de energia, e como é baseado na tecnologia ZigBee, envia os dados da leitura em tempo real para o Acti 9 Smartlink sem a necessidade de instalação de fios. Isso para o meio industrial é muito positivo, pois pode-se implementar essa tecnologia em qualquer ambiente sem a necessidade de 
readequação da planta produtiva em termos de estrutura de cabeamento. Outro fator importante é o fácil comissionamento do Acti 9 Smartlink, sendo muito intuitivo e com poucas passagens para o total funcionamento. Há que se mencionar o problema que essa pesquisa enfrentou com a desconfiguração do dispositivo Acti 9 Smartlink, onde ao aplicar o reset para que o dispositivo entrasse no "Modo Fábrica", e assim pudesse reconfigurar a comunicação com PowerTag e conformar o protocolo de comunicação Modbus, o dispositivo não permitiu o acesso e permaneceu no estado "Modo Fábrica". Também por isso, não foi possível a construção do gêmeo digital, pois o tempo dispendido na solução do problema de parametrização do Acti 9 Smartlink encurtou a possível construção dele, apontando como sugestão para trabalhos futuros.

Com o MindSphere foi possível a visualização dos dados provenientes do SIMATIC IoT 2040, mas também em trabalhos futuros, pode-se implementar outras funções, como por exemplo, controle do dispositivo à distância, controle de set-point para inserir alarmes, mapeamento do funcionamento em uma planta produtiva, entre outras.

A comunicação entre o dispositivo SIMATIC IoT 2040 e a plataforma MindSphere foi construída através do software Node-red. O Node-red apresenta para a pesquisa a facilidade de construção dos fluxos para interconectividade entre os dispositivos físicos e a plataforma MindSphere, sendo que, é uma ferramenta gráfica baseada em Java Script e que permitiu a configuração dos nós a partir da necessidade do projeto.

O acompanhamento dos dados gerados acontece através da plataforma MindSphere, mais precisamente pelo Fleet Manager, onde os dados estão dispostos em gráficos atualizáveis com o processamento em tempo real, fornecendo estatísticas ou série de dados.

As tabelas foram elaboradas com a intenção de dispor os dados de forma organizada e que traduzissem a real condição de operação da máquina legada em uma jornada de trabalho. Ficou evidenciado que enquanto a máquina legada trabalha em uma jornada completa, sem adicionar o "Modo de espera", leva a um consumo de energia $3 \%$ acima de qualquer medição anterior. Esse tipo de dado pode ser aplicado no controle da fabricação de qualquer produto, principalmente se enfatizar a adoção do "Modo de espera" para diminuir o consumo de energia. Outra possibilidade a partir dos dados coletados, é programar manutenções de acordo com a forma adotada de fabricação, pois ficou claro que inserir "Modo de espera" diminui o consumo de energia e, por 
conseguinte, o desgaste através da operabilidade adotada também reduzirá as manutenções.

Como forma de ampliar o desenvolvimento da pesquisa e propiciar uma conectividade mais efetiva entre os dispositivos, deve-se estudar a inclusão da nova tecnologia $5 \mathrm{G}$ para aumentar a operabilidade dos instrumentos envolvidos, como também expandir os métodos de acesso com a Internet das coisas, Big Data, Machine-to-Machine, celulares, entre outros. 


\section{REFERÊNCIAS}

Aazam, Mohammad, Sherali Zeadally, e Khaled A. Harras. 2018. "Deploying Fog Computing in Industrial Internet of Things and Industry 4.0". IEEE Transactions on Industrial Informatics 14 (10): 4674-82. https://doi.org/10.1109/TII.2018.2855198.

Arjoni, Diego Hernandez, Fernando Silveira Madani, Guilherme Ikeda, Gustavo De M. Carvalho, Loredana B. Cobianchi, Luiz F.L.R. Ferreira, e Emilia Villani. 2018. "Manufacture equipment retrofit to allow usage in the industry 4.0". In Proceedings - 2017 2nd International Conference on Cybernetics, Robotics and Control, CRC 2017, 2018-Janua:155-61. Institute of Electrical and Electronics Engineers Inc. https://doi.org/10.1109/CRC.2017.46.

Bakir, Dennis, Robin Bakir, e Florian Engels. 2018. "Industry-Integrator as retrofit solution for digital manufacturing methods in existing industrial plants". In Procedia Manufacturing, 17:1009-14. Elsevier B.V. https://doi.org/10.1016/j.promfg.2018.10.086.

Boyes, Hugh, Bil Hallaq, Joe Cunningham, e Tim Watson. 2018. "The industrial internet of things (IIoT): An analysis framework". Computers in Industry 101 (outubro): 1-12. https://doi.org/10.1016/j.compind.2018.04.015.

Cárdenas, Alvaro A., Saurabh Amin, e Shankar Sastry. 2008. "Secure control: Towards survivable cyber-physical systems". In Proceedings - International Conference on Distributed Computing Systems, 495-500.

https://doi.org/10.1109/ICDCS.Workshops.2008.40.

Cox, Michael, e David Ellsworth. 1997. “Application-controlled demand paging for out-of-core visualization". Proceedings of the IEEE Visualization Conference, $\mathrm{n}^{\mathrm{o}}$ November 1997: 235-44. https://doi.org/10.1109/visual.1997.663888.

Dalenogare, Lucas Santos, Guilherme Brittes Benitez, Néstor Fabián Ayala, e Alejandro Germán Frank. 2018. "The expected contribution of Industry 4.0 technologies for industrial performance". International Journal of Production Economics 204 (outubro): 383-94. https://doi.org/10.1016/j.ijpe.2018.08.019.

Davies, Ron. 2015. "Industry 4.0. Digitalisation for productivity and growth". European Parliamentary Research Service, $\mathrm{n}^{\circ}$ September: 10.

Del, Maria, Carmen Lucas-Estã, Theofanis P Raptis, Miguel Sepulcre, Andrea Passarella, Javier Gozalvez, e Marco Conti. 2019. "Communication and Data Management in Industry 4.0". The Digital Shopfloor: Industrial Automation in the Industry 4.0 Era. 
Demchenko, Yuri, Paola Grosso, Cees De Laat, e Peter Membrey. 2013. “Addressing big data issues in Scientific Data Infrastructure". In Proceedings of the 2013 International Conference on Collaboration Technologies and Systems, CTS 2013, 48-55. https://doi.org/10.1109/CTS.2013.6567203.

Drahoš, Peter, Erik Kučera, Oto Haffner, e Erich Stark. 2018. "Industrial Communication and Industry 4 . 0". Reseachgate.Net, $\mathrm{n}^{\circ}$ April: 40-44.

EcoStruxure Power Commission. Version 1.1: Schneider Electric Corporation, 2021.

Etz, Dieter, Hannes Brantner, e Wolfgang Kastner. 2020. "Smart manufacturing retrofit for brownfield systems". In Procedia Manufacturing.

https://doi.org/10.1016/j.promfg.2020.02.085.Gandomi, Amir, e Murtaza Haider. 2015. "Beyond the hype: Big data concepts, methods, and analytics". International Journal of Information Management 35 (2): 137-44. https://doi.org/10.1016/j.ijinfomgt.2014.10.007.

Ganzarain, Jaione, e Nekane Errasti. 2016. "Three stage maturity model in SME's towards industry 4.0". Journal of Industrial Engineering and Management 9 (5): 1119-28. https://doi.org/10.3926/jiem.2073.

Gao, Robert X., e Peng Wang. 2017. "Through Life Analysis for Machine Tools: From Design to Remanufacture". In Procedia CIRP, 59:2-7. Elsevier B.V. https://doi.org/10.1016/j.procir.2016.09.027.

Halenar, Igor, Martin Juhas, Bohuslava Juhasova, e Dmitrii Borkin. 2019. "Virtualization of production using digital twin technology". Proceedings of the 2019 20th International Carpathian Control Conference, ICCC 2019, 1-5. https://doi.org/10.1109/CarpathianCC.2019.8765940.

Hill, Richard, James Devitt, Ashiq Anjum, e Muhammad Ali. 2018. "Towards in-transit analytics for industry 4.0". In Proceedings - 2017 IEEE International Conference on Internet of Things, IEEE Green Computing and Communications, IEEE Cyber, Physical and Social Computing, IEEE Smart Data, iThings-GreenCom-CPSComSmartData 2017, 2018-Janua:810-17. Institute of Electrical and Electronics Engineers Inc. https://doi.org/10.1109/iThings-GreenCom-CPSComSmartData.2017.124.

Imtiaz, Jahanzaib, e Jurgen Jasperneite. 2013. "Scalability of OPC-UA down to the chip level enables 'internet of Things"'. In IEEE International Conference on Industrial Informatics (INDIN). https://doi.org/10.1109/INDIN.2013.6622935.

Jantunen, Erkki, Jaime Campos, Pankaj Sharma, e David Baglee. 2018. "Digitalisation of maintenance". 2017 2nd International Conference on System Reliability and Safety, ICSRS 2017 2018-Janua: 343-47. https://doi.org/10.1109/ICSRS.2017.8272846. 
Jazdi, N. 2014. "Cyber physical systems in the context of Industry 4.0". In Proceedings of 2014 IEEE International Conference on Automation, Quality and Testing, Robotics, AQTR 2014. IEEE Computer Society. https://doi.org/10.1109/AQTR.2014.6857843.

Jin, Xiaolong, Benjamin W. Wah, Xueqi Cheng, e Yuanzhuo Wang. 2015.

"Significance and Challenges of Big Data Research". Big Data Research 2 (2): 5964. https://doi.org/10.1016/j.bdr.2015.01.006.

Khan, M. Ali Ud Din, Muhammad Fahim Uddin, e Navarun Gupta. 2014. "Seven V's of Big Data understanding Big Data to extract value". In Proceedings of the 2014 Zone 1 Conference of the American Society for Engineering Education "Engineering Education: Industry Involvement and Interdisciplinary Trends", ASEE Zone 1 2014. IEEE Computer Society. https://doi.org/10.1109/ASEEZone1.2014.6820689.

Lee, Edward A. 2008. "Cyber physical systems: Design challenges". In Proceedings 11th IEEE Symposium on Object/Component/Service-Oriented Real-Time Distributed Computing, ISORC 2008, 363-69. https://doi.org/10.1109/ISORC.2008.25.

Lee, Jay, Behrad Bagheri, e Hung An Kao. 2015. "A Cyber-Physical Systems architecture for Industry 4.0-based manufacturing systems". Manufacturing Letters 3 (janeiro): 18-23. https://doi.org/10.1016/j.mfglet.2014.12.001.

Lee, Jay, Hung An Kao, e Shanhu Yang. 2014. "Service innovation and smart analytics for Industry 4.0 and big data environment". In Procedia CIRP, 16:3-8. Elsevier. https://doi.org/10.1016/j.procir.2014.02.001.

Leitão, Paulo, Stamatis Karnouskos, Luis Ribeiro, Jay Lee, Thomas Strasser, e Armando W. Colombo. 2016. "Smart Agents in Industrial Cyber-Physical Systems". Proceedings of the IEEE 104 (5): 1086-1101. https://doi.org/10.1109/JPROC.2016.2521931.

Lins, Romulo G., Bruno Guerreiro, Robert Schmitt, Jianing Sun, Marcio Corazzim, e Francis R. Silva. 2017. "A novel methodology for retrofitting CNC machines based on the context of industry 4.0". In 2017 IEEE International Symposium on Systems Engineering, ISSE 2017 - Proceedings. Institute of Electrical and Electronics Engineers Inc. https://doi.org/10.1109/SysEng.2017.8088293.

Lins, Theo, e Ricardo Augusto Rabelo Oliveira. 2020. "Cyber-physical production systems retrofitting in context of industry 4.0". Computers and Industrial Engineering. https://doi.org/10.1016/j.cie.2019.106193.

Lins, Theo, Ricardo Augusto Rabelo Oliveira, Luiz H.A. Correia, e Jorge Sá Silva. 2019. "Industry 4.0 retrofitting". In Brazilian Symposium on Computing System 
Engineering, SBESC, 2018-Novem:8-15. IEEE Computer Society. https://doi.org/10.1109/SBESC.2018.00011.

Liu, Yang, Yu Peng, Bailing Wang, Sirui Yao, e Zihe Liu. 2017. "Review on cyberphysical systems". IEEE/CAA Journal of Automatica Sinica 4 (1): 27-40. https://doi.org/10.1109/JAS.2017.7510349.

Mahnke, Wolfgang, Stefan Helmut Leitner, e Matthias Damm. 2009. OPC unified architecture. OPC Unified Architecture. https://doi.org/10.1007/978-3-540-688990 .

Mamo, Fesseha Tsegaye, Axel Sikora, e Christoph Rathfelder. 2017. "Legacy to Industry 4.0: A Profibus Sniffer”. In Journal of Physics: Conference Series. Vol. 870. Institute of Physics Publishing. https://doi.org/10.1088/17426596/870/1/012002.

Martins, André, Hugo Costelha, e Carlos Neves. 2019. "Shop Floor Virtualization and Industry 4.0". 19th IEEE International Conference on Autonomous Robot Systems and Competitions, ICARSC 2019, 1-6. https://doi.org/10.1109/ICARSC.2019.8733657.

MindSphere Siemens. 2021 Disponível em: < https://feidevlp.eu1.mindsphere.io/index.html\#/>. Acesso em: 2 fev. 2021.

Mitchell, Robert, e Ing Ray Chen. 2014. "A survey of intrusion detection techniques for cyber-physical systems". ACM Computing Surveys. https://doi.org/10.1145/2542049.

Moeuf, Alexandre, Robert Pellerin, Samir Lamouri, Simon Tamayo-Giraldo, e Rodolphe Barbaray. 2018. "The industrial management of SMEs in the era of Industry 4.0". International Journal of Production Research. https://doi.org/10.1080/00207543.2017.1372647.

Monostori, L., B. Kádár, T. Bauernhansl, S. Kondoh, S. Kumara, G. Reinhart, O. Sauer, G. Schuh, W. Sihn, e K. Ueda. 2016. "Cyber-physical systems in manufacturing". CIRP Annals 65 (2): 621-41. https://doi.org/10.1016/j.cirp.2016.06.005.

Node-red. 2021. Disponível em: < https://flows.nodered.org/node/@mindconnect/nodered-contrib-mindconnect>. Acesso em: 9 jan. 2021.

Nsiah, Kofi Atta, Manuel Schappacher, Christoph Rathfelder, Axel Sikora, e Voicu Groza. 2018. "An open-source toolkit for retrofit industry 4.0 sensing and monitoring applications”. In I2MTC 2018 - 2018 IEEE International Instrumentation and Measurement Technology Conference: Discovering New Horizons in Instrumentation and Measurement, Proceedings. https://doi.org/10.1109/I2MTC.2018.8409633. 
O’Donovan, Peter, Colm Gallagher, Ken Bruton, e Dominic T.J. O’Sullivan. 2018. “A fog computing industrial cyber-physical system for embedded low-latency machine learning Industry 4.0 applications". Manufacturing Letters 15 (janeiro): 139-42. https://doi.org/10.1016/j.mfglet.2018.01.005.

Pereira, A. C., e F. Romero. 2017. "A review of the meanings and the implications of the Industry 4.0 concept". Procedia Manufacturing 13: 1206-14. https://doi.org/10.1016/j.promfg.2017.09.032.

Qi, Qinglin, e Fei Tao. 2018. "Digital Twin and Big Data Towards Smart Manufacturing and Industry 4.0: 360 Degree Comparison”. IEEE Access 6 (janeiro): 3585-93. https://doi.org/10.1109/ACCESS.2018.2793265.

Rajkumar, Ragunathan, Insup Lee, Lui Sha, e John Stankovic. 2010. "Cyber-physical systems: The next computing revolution”. In Proceedings - Design Automation Conference, 731-36. https://doi.org/10.1145/1837274.1837461.

Rauch, Erwin, Dominik T. Matt, Christopher A. Brown, Walter Towner, Andrew Vickery, e Salinee Santiteerakul. 2018. "Transfer of industry 4.0 to small and medium sized enterprises". Advances in Transdisciplinary Engineering 7: 63-71. https://doi.org/10.3233/978-1-61499-898-3-63.

Ray, P. P. 2018. "A survey on Internet of Things architectures". Journal of King Saud University - Computer and Information Sciences. King Saud bin Abdulaziz University. https://doi.org/10.1016/j.jksuci.2016.10.003.

Rüßmann, Michael, Markus Lorenz, Philipp Gerbert, Manuela Waldner, Jan Justus, Pascal Engel, e Michael Harnisch. 2015. "Industry 4.0: The Future of Productivity and Growth in Manufacturing Industries".

Schneider Electric. 2016. “Acti 9 Smartlink SI B User Manual”, 215.

Schröder, Christian. 2016. "The Challenges of Industry 4.0 for Small and Medium-sized Enterprises". www.fes-2017plus.de.

Shi, Jianhua, Jiafu Wan, Hehua Yan, e Hui Suo. 2011. "A survey of Cyber-Physical Systems". In 2011 International Conference on Wireless Communications and Signal Processing, WCSP 2011. https://doi.org/10.1109/WCSP.2011.6096958.

Shi, Junyang, Mo Sha, e Zhicheng Yang. 2018. "DiGS: Distributed graph routing and scheduling for industrial wireless sensor-actuator networks". In Proceedings International Conference on Distributed Computing Systems, 2018-July:354-64. Institute of Electrical and Electronics Engineers Inc. https://doi.org/10.1109/ICDCS.2018.00043. 
Siemens. 2018a. "MindSphere: Enabling the world's industries to drive their digital transformations".

Https://Www.Plm.Automation.Siemens.Com/Global/En/Products/Mindsphere/Inter net-of-Things-Iot.Html, 24. www.siemens.com/mindsphere.

. 2018b. "MindSphere security model", $\mathrm{n}^{\circ}$ December: 1-10.

Sisinni, Emiliano, Abusayeed Saifullah, Song Han, Ulf Jennehag, e Mikael Gidlund. 2018. "Industrial internet of things: Challenges, opportunities, and directions". IEEE Transactions on Industrial Informatics 14 (11): 4724-34. https://doi.org/10.1109/TII.2018.2852491.

Sommer, Lutz. 2015. "Industrial revolution - Industry 4.0: Are German manufacturing SMEs the first victims of this revolution?" Journal of Industrial Engineering and Management 8 (5): 1512-32. https://doi.org/10.3926/jiem.1470.

Sousa Jabbour, Ana Beatriz Lopes de, Charbel Jose Chiappetta Jabbour, Cyril Foropon, e Moacir Godinho Filho. 2018. "When titans meet - Can industry 4.0 revolutionise the environmentally-sustainable manufacturing wave? The role of critical success factors". Technological Forecasting and Social Change 132 (October 2017): 1825. https://doi.org/10.1016/j.techfore.2018.01.017.

Stock, T., e G. Seliger. 2016. "Opportunities of Sustainable Manufacturing in Industry 4.0”. In Procedia CIRP. https://doi.org/10.1016/j.procir.2016.01.129.

Strange, Roger, e Antonella Zucchella. 2017. "Industry 4.0, global value chains and international business". Multinational Business Review 25 (3): 174-84. https://doi.org/10.1108/MBR-05-2017-0028.

Thoben, Klaus Dieter, Stefan Alexander Wiesner, e Thorsten Wuest. 2017. “"Industrie 4.0' and smart manufacturing-a review of research issues and application examples". International Journal of Automation Technology. Fuji Technology Press. https://doi.org/10.20965/ijat.2017.p0004.

Tuptuk, Nilufer, e Stephen Hailes. 2018. "Security of smart manufacturing systems". Journal of Manufacturing Systems 47 (abril): 93-106. https://doi.org/10.1016/j.jmsy.2018.04.007.

Urquhart, Lachlan, e Derek McAuley. 2018. "Avoiding the internet of insecure industrial things". Computer Law and Security Review 34 (3): 450-66. https://doi.org/10.1016/j.clsr.2017.12.004.

Verba, Nandor, Kuo Ming Chao, Anne James, Daniel Goldsmith, Xiang Fei, e Sergiu Dan Stan. 2017. "Platform as a service gateway for the Fog of Things". Advanced Engineering Informatics 33: 243-57. https://doi.org/10.1016/j.aei.2016.11.003. 
Wan, Jiafu, Shenglong Tang, Di Li, Shiyong Wang, Chengliang Liu, Haider Abbas, e Athanasios V. Vasilakos. 2017. "A Manufacturing Big Data Solution for Active Preventive Maintenance". IEEE Transactions on Industrial Informatics 13 (4): 2039-47. https://doi.org/10.1109/TII.2017.2670505.

Wang, Yichuan, Lee Ann Kung, e Terry Anthony Byrd. 2018. "Big data analytics: Understanding its capabilities and potential benefits for healthcare organizations". Technological Forecasting and Social Change 126 (janeiro): 3-13. https://doi.org/10.1016/j.techfore.2015.12.019.

Witkowski, Krzysztof. 2017. "Internet of Things, Big Data, Industry 4.0 - Innovative Solutions in Logistics and Supply Chains Management". In Procedia Engineering, 182:763-69. Elsevier Ltd. https://doi.org/10.1016/j.proeng.2017.03.197.

Wollschlaeger, Martin, Thilo Sauter, e Juergen Jasperneite. 2017a. "The future of industrial communication: Automation networks in the era of the internet of things and industry 4.0". IEEE Industrial Electronics Magazine. https://doi.org/10.1109/MIE.2017.2649104.

2017b. "The future of industrial communication: Automation networks in the era of the internet of things and industry 4.0". IEEE Industrial Electronics Magazine 11 (1): 17-27. https://doi.org/10.1109/MIE.2017.2649104.

$\mathrm{Xu}, \mathrm{Li} \mathrm{Da}$, Eric L. Xu, e Ling Li. 2018. "Industry 4.0: State of the art and future trends". International Journal of Production Research 56 (8): 2941-62. https://doi.org/10.1080/00207543.2018.1444806.

Yang, Shanshan, Aravind M. R., Jacek Kaminski, e Helene Pepin. 2018. "Opportunities for Industry 4.0 to Support Remanufacturing”. Applied Sciences 8 (7): 1177. https://doi.org/10.3390/app8071177.

Yin, Shen, e Okyay Kaynak. 2015. "Big Data for Modern Industry: Challenges and Trends". Proceedings of the IEEE. Institute of Electrical and Electronics Engineers Inc. https://doi.org/10.1109/JPROC.2015.2388958.

Zezulka, F., P. Marcon, Z. Bradac, J. Arm, T. Benesl, e I. Vesely. 2018. "Communication Systems for Industry 4.0 and the IIoT". IFAC-PapersOnLine 51 (6): 150-55. https://doi.org/10.1016/j.ifacol.2018.07.145.

Zhong, Ray Y., Xun Xu, Eberhard Klotz, e Stephen T. Newman. 2017. "Intelligent Manufacturing in the Context of Industry 4.0: A Review". Engineering 3 (5): 61630. https://doi.org/10.1016/J.ENG.2017.05.015.

Zhou, Keliang, Taigang Liu, e Lifeng Zhou. 2016. "Industry 4.0: Towards future industrial opportunities and challenges". In 2015 12th International Conference on Fuzzy Systems and Knowledge Discovery, FSKD 2015, 2147-52. Institute of 
Electrical and Electronics Engineers Inc.

https://doi.org/10.1109/FSKD.2015.7382284. 